\title{
\#USGS
}

science for a changing world

\section{Yellowstone Volcano Observatory 2019 Annual Report}

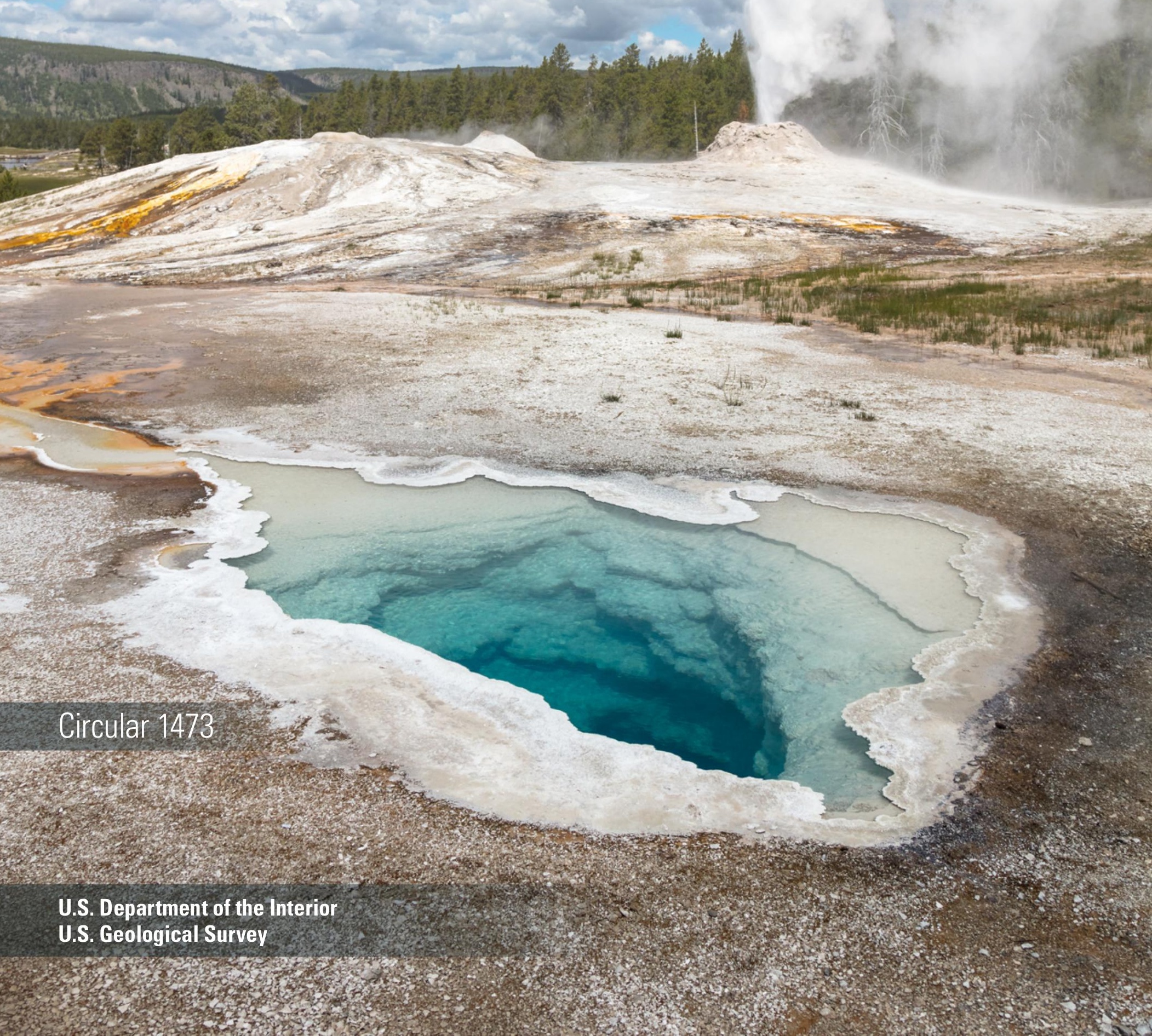

U.S. Department of the linterior

U.S. Geological Survey 


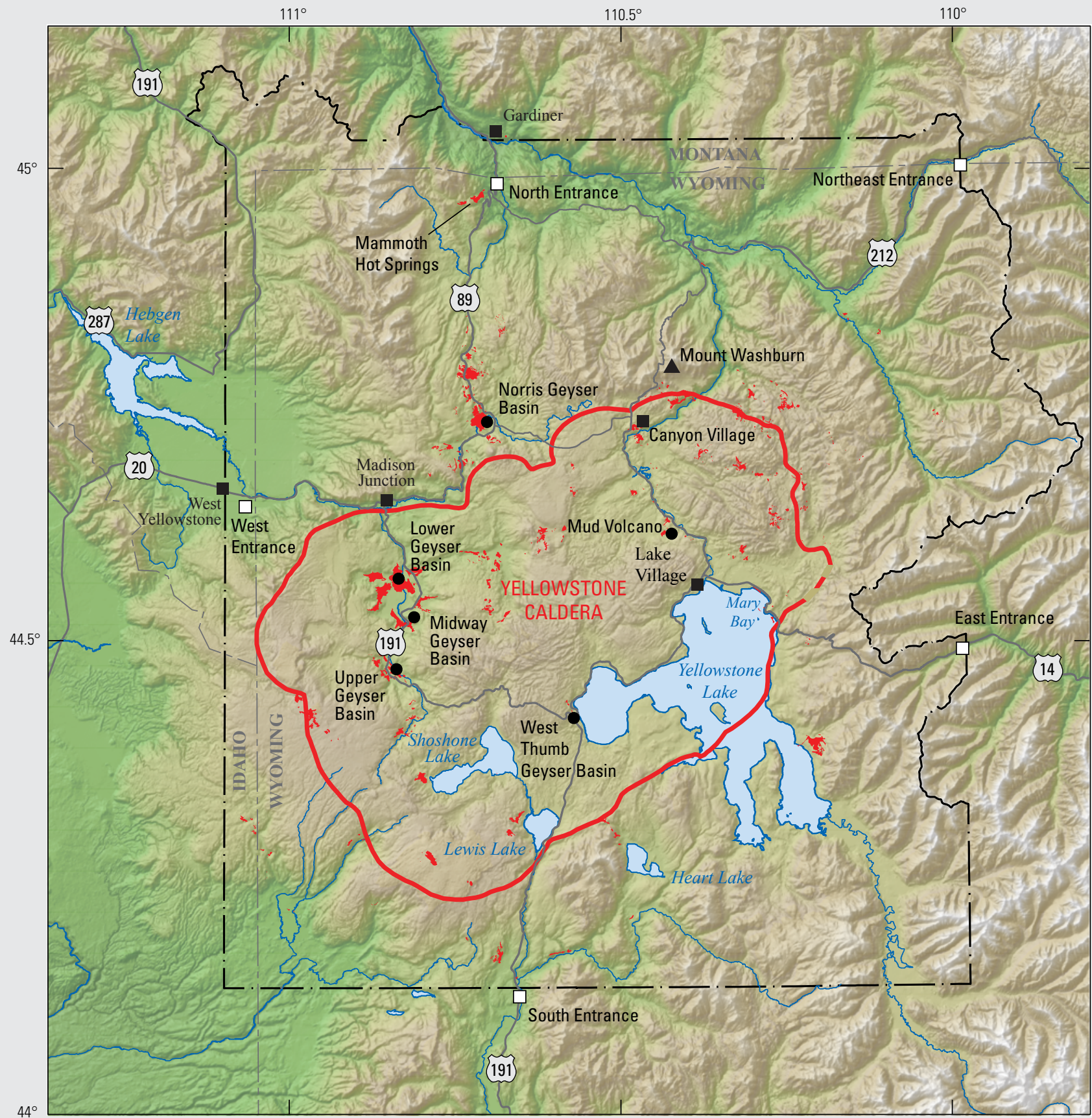

Base from 30-meter National Elevation Dataset

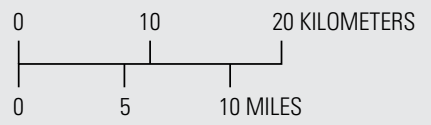

Location map showing thermal areas (in red) and noteworthy geographic features in the Yellowstone National Park region. The red line marks Yellowstone Caldera.

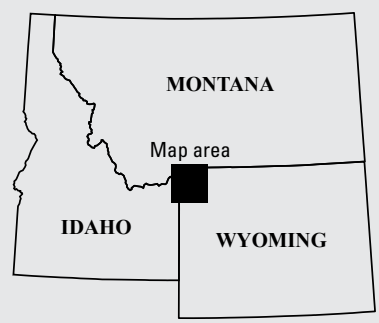

Cover. National Park Service photograph of Lion Geyser and Heart spring by Jacob W. Frank.

Back cover. U.S. Geological Survey photograph of sample collection in Yellowstone Lake by Jake Lowenstern (top left); National Park Service photographs of Ear Spring by Annie Carlson (top right) and Castle Geyser by Stan Mordensky (bottom).

Facing page. National Park Service photograph of Cliff Geyser at Black Sand Geyser Basin by Diane Renkin. 


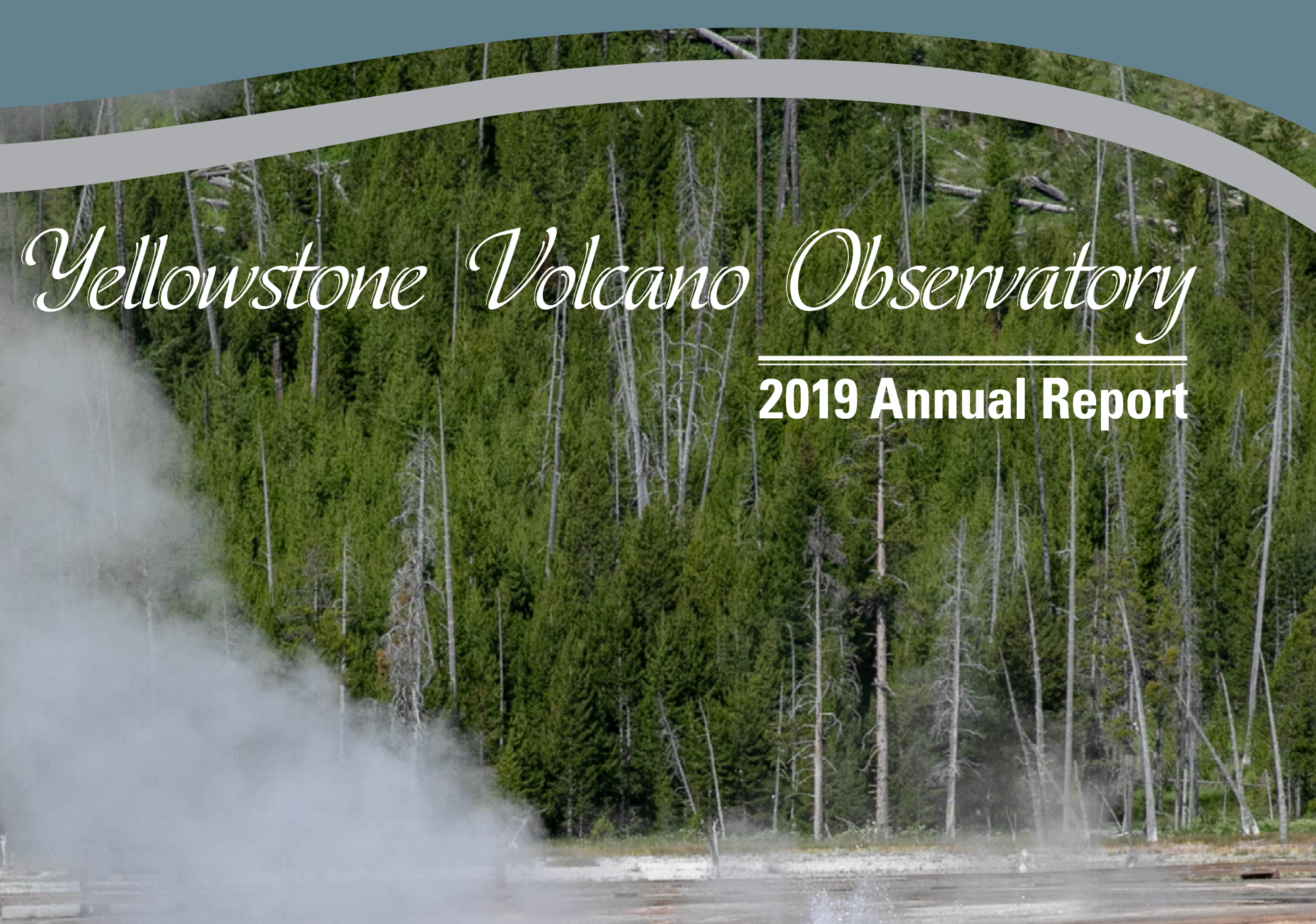

Circular 1473

8 


\section{U.S. Geological Survey, Reston, Virginia: 2021}

For more information on the USGS - the Federal source for science about the Earth, its natural and living resources, natural hazards, and the environment-visit https://www.usgs.gov or call 1-888-ASK-USGS.

For an overview of USGS information products, including maps, imagery, and publications,

visit https://store.usgs.gov.

Any use of trade, firm, or product names is for descriptive purposes only and does not imply endorsement by the U.S. Government.

Although this information product, for the most part, is in the public domain, it also may contain copyrighted materials as noted in the text. Permission to reproduce copyrighted items must be secured from the copyright owner.

\section{Suggested citation:}

Yellowstone Volcano Observatory, 2021, Yellowstone Volcano Observatory 2019 annual report: U.S. Geological Survey Circular 1473, 35 p., https://doi.org/10.3133/cir1473.

ISSN 1067-084X (print)

ISSN 2330-5703 (online) 


\section{Contents}

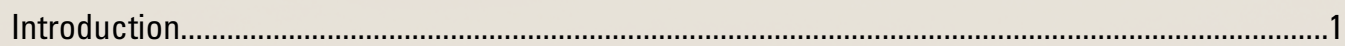

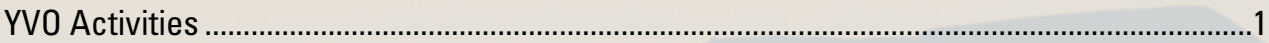

Seismology

Summary of Seismicity during 2019

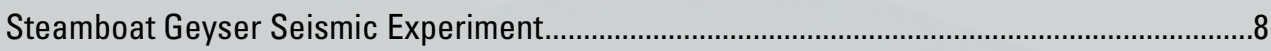

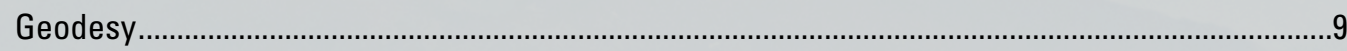

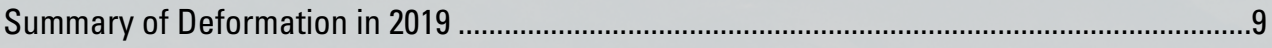

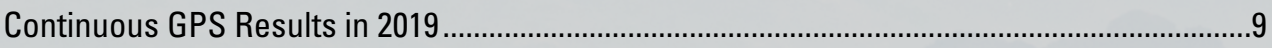

Semipermanent GPS Results ...........................................................................................

Interferometric Synthetic Aperture Radar (InSAR) Results ..................................................11

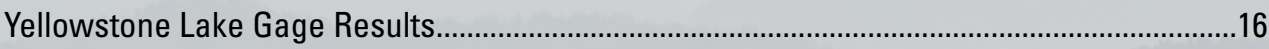

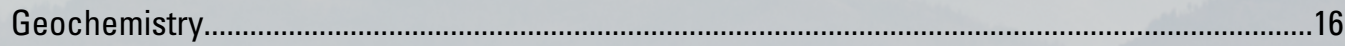

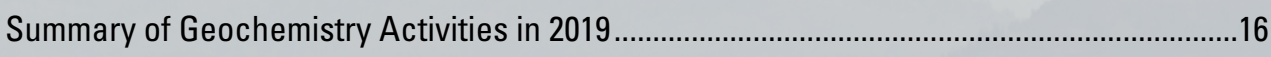

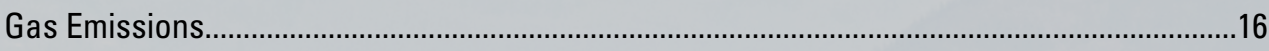

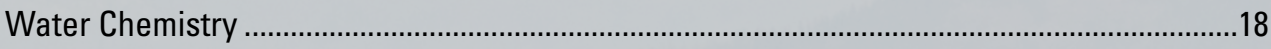

Shoshone Geyser Basin and Shoshone and Lewis Lakes................................................18

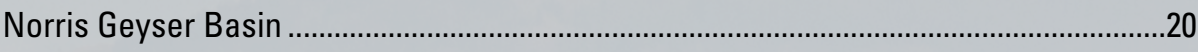

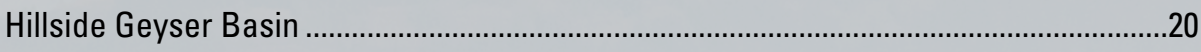

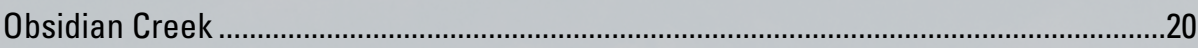

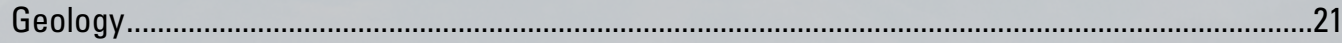

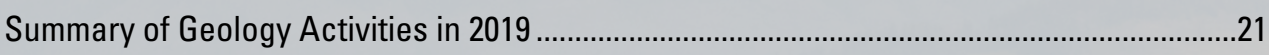

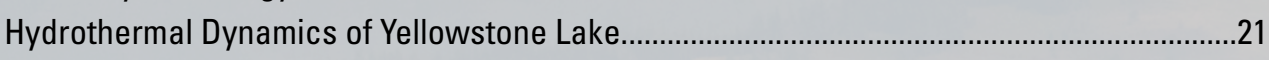

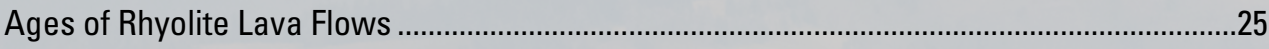

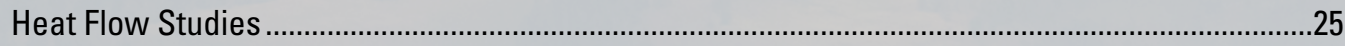

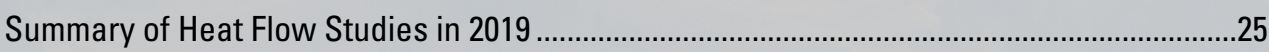

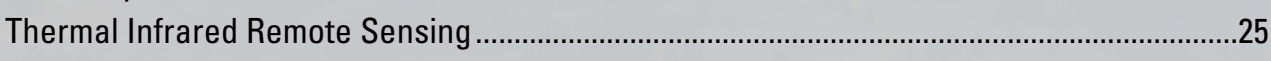

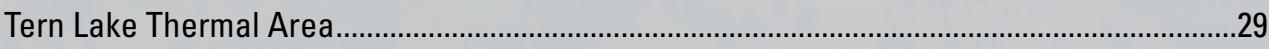

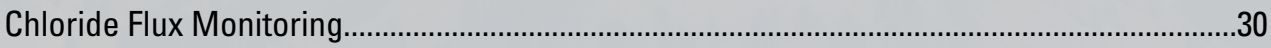

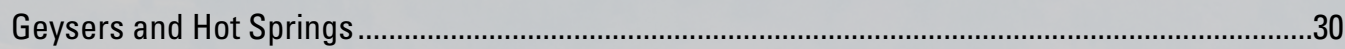

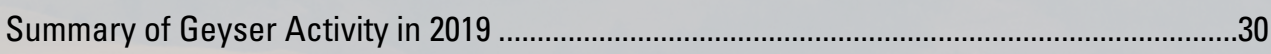

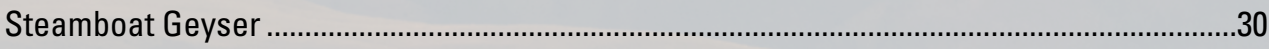

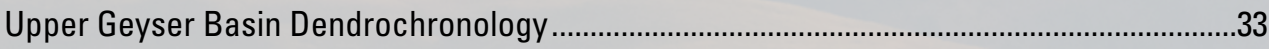

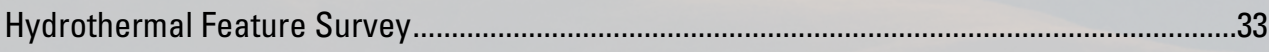

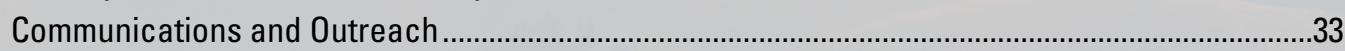

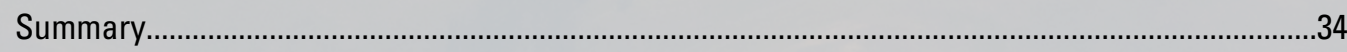

2019 Publications

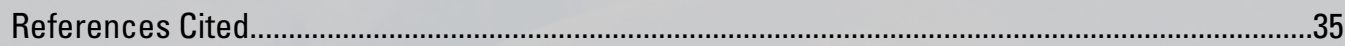




\section{Table}

1. Water eruptions of Steamboat Geyser in 2019

\section{Sidebars}

Hazards in the Yellowstone Region .2

What is the Yellowstone Volcano Observatory?

Seismicity in Yellowstone Plateau . .3

Monitoring Geodetic Change in Yellowstone.

Geochemical Monitoring in Yellowstone Caldera.

Geology of Yellowstone Plateau

Monitoring Thermal Changes at Yellowstone Caldera

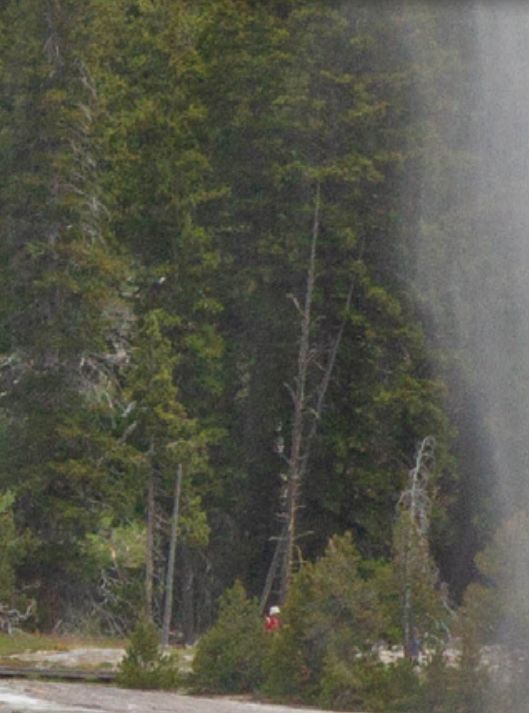

National Park Service photograph showing Beehive Geyser and bison by Diane Renkin. 


\section{Yellowstone}

By the Yellowstone Volcano Observatory ${ }^{1}$

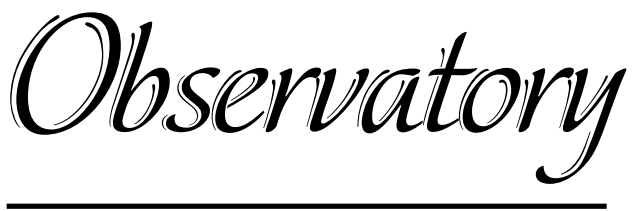

2019 Annual Report

\section{Introduction}

The Yellowstone Volcano Observatory (YVO) monitors volcanic and hydrothermal activity associated with the Yellowstone magmatic system, conducts research into magmatic processes occurring beneath Yellowstone Caldera, and issues timely warnings and guidance related to potential future geologic hazards (see sidebar on volcanic hazards on p. 2). The observatory is a collaborative consortium made up of the U.S. Geological Survey (USGS), Yellowstone National Park, University of Utah, University of Wyoming, UNAVCO, Wyoming State Geological Survey, Montana Bureau of Mines and Geology, and Idaho Geological Survey (see sidebar on YVO on p. 3). The USGS arm of YVO also has the operational responsibility for monitoring volcanic activity in the Intermountain West, including Arizona, New Mexico, Utah, and Colorado.

This report summarizes the activities and findings of YVO during the year 2019, focusing on the Yellowstone volcanic system. Highlights of YVO research and related activities during 2019 included

- Deploying a portable seismic array near Steamboat Geyser in Norris Geyser Basin that recorded signals from seven major water eruptions,

- Deploying a semipermanent Global Positioning System (GPS) array from May to October,

- Surveying soil carbon dioxide $\left(\mathrm{CO}_{2}\right)$ flux and temperature and operating an eddy covariance system to make continuous measurements of $\mathrm{CO}_{2}$, steam, and heat fluxes just north of Norris Geyser Basin,

- Collecting and analyzing water samples from Shoshone Geyser Basin, the outlets of Shoshone and Lewis Lakes, Cinder Pool in Norris Geyser Basin, and several locations along Obsidian Creek,

- Exploring and documenting a new thermal area near Tern Lake that was discovered in 2018,

- Measuring specific conductance along major rivers to determine the chloride flux and total heat output of the Yellowstone hydrothermal system,
- Conducting an inventory of hydrothermal features in Norris Geyser Basin and Upper Geyser Basin as part of a park-wide project that began in 2018, and

- Sampling of tree rings and silica sinter deposits in the Upper Geyser Basin to better understand hydrothermal activity over time.

Continuing the pattern that started in 2018, Steamboat Geyser, in Norris Geyser Basin, erupted 48 times in 2019-a new record for a calendar year! Overall, however, noteworthy geyser activity in Yellowstone National Park was much reduced relative to the previous year. Thermal features on Geyser Hill in the Upper Geyser Basin had returned to their normal activity styles after Ear Spring's September 2018 eruption and did not show any significant changes in 2019. Giant Geyser, also in the Upper Geyser Basin, did not experience any eruptions after March 2019. Seismicity was reduced relative to previous years, and deformation of Norris Geyser Basin, which started as uplift in 2015 and paused in late 2018, shifted to subsidence in late 2019. Overall subsidence of the caldera floor, ongoing since late 2015 or early 2016 , continued at rates of a few centimeters (1-2 inches) per year.

Throughout 2019, the aviation color code for Yellowstone Caldera remained at "green" and the volcano alert level remained at "normal." Total seismicity-1,218 located earthquakes - was low relative to previous years.

\section{YVO Activities}

In April 2019, YVO scientists and collaborators gathered at Montana State University in Bozeman for a 2-day workshop on monitoring Yellowstone's hydrothermal system. Thanks to more than a decade of intensive efforts, many of the goals of YVO's volcano and earthquake monitoring plan (YVO, 2006) have been achieved. A network of 46 permanent seismographs of the Yellowstone Seismic Network (operated in large part by the University of Utah) ensures that all earthquakes greater than magnitude 1.5 are reliably located, and several dozen GPS stations, along with four borehole strainmeters and five borehole tiltmeters (all operated by UNAVCO), track ground deformation with exceptional precision. Now that the region is well monitored in this respect, YVO is turning its attention to the thermal areas 


\section{Hazards in the Yellowstone Region}

The Yellowstone Plateau in the northern Rocky Mountains of Wyoming, Montana, and Idaho is centered on a youthful, active volcanic system with subterranean magma (molten rock), boiling and pressurized waters, and a variety of active faults. This combination creates a diversity of hazards, but the most catastrophic events - large volcanic explosions - are also the least likely to occur.

Over the past 2.1 million years, Yellowstone Caldera has had three immense explosive volcanic eruptions that blanketed large parts of the North American continent with ash and debris and created sizable calderas. Yellowstone Caldera, which comprises nearly one third of the land area in Yellowstone National Park, formed 631,000 years ago during the most recent of these large explosive phases. Its formation was followed by dozens of less explosive but massive lava flows, the latest of which erupted 70,000 years ago.
Tectonic extension of the western United States is responsible for large earthquakes in the Yellowstone region along faults such as the Teton and Hebgen Faults. Most recently, a devastating magnitude 7.3 earthquake in 1959 killed 28 people, and a strong magnitude 6.1 earthquake near Norris Geyser Basin in 1975 was widely felt.

Yellowstone National Park's famous geothermal waters create fabulous hot springs and geysers but occasionally explode catastrophically to create craters found throughout the park. At least 25 explosions that left craters greater than 100 meters (328 feet) wide have occurred since the last ice age ended in the Yellowstone area 16,000-14,000 years ago. Much smaller explosions, which leave craters only a few meters (yards) across, happen every few years in the

Yellowstone area.

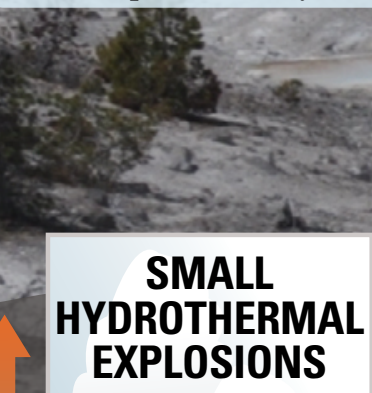

(Several to many per century)

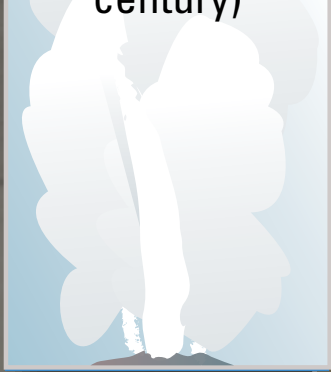

Yellowstone area. 
and deploying equipment to better track changes in hydrothermal activity - for example, geyser eruptions. Most monitoring stations in Yellowstone, including seismic and deformation equipment, are located away from thermal areas because those areas create noise related to geyser eruptions and groundwater flow that can interfere with locating earthquakes or ground deformation across the region. Currently, only one seismic station (YNM) is located in a thermal area-Norris Geyser Basin. There are no GPS stations in thermal areas. The group discussion at the Bozeman workshop focused on what new methods and types of equipment might be needed in addition to seismic and deformation monitoring. For example, infrasound - which is noise that is inaudible to humans but accompanies many surface processes, including geyser eruptions - might be monitored to track changes in hydrothermal activity across a broad region. In the years to come, YVO will work with collaborators on a plan to better monitor Yellowstone's hydrothermal areas that also respects the fragility and spectacle of these incredible natural resources.

YVO scientists were also active in the communities around Yellowstone, presenting public lectures and community events designed to inform local residents about recent research results from, and current activity at, Yellowstone. Events in Gardiner and West Yellowstone, Montana, and Cody, Wyoming, attracted several dozen people each. USGS and Idaho Geological Survey scientists also participated in a regional emergency management meeting in Rexburg, Idaho, providing information about Yellowstone activity and regional geologic hazards. YVO continued to publish "Yellowstone Caldera Chronicles," a series of weekly articles authored by YVO and collaborating scientists about science, history, current research, and recent activity in Yellowstone. The Yellowstone Caldera Chronicles were widely viewed online, on social media, and in some local newspapers, which reprinted the articles.
In December, a number of YVO scientists participated in a special session at the Fall Meeting of the American Geophysical Union in San Francisco, California, entitled "Magmatic and Hydrothermal Activity of the Yellowstone Plateau, or, How I Learned to Stop Worrying and Love the Volcano." The session was organized to bring together scientists from different disciplines to highlight new research into how Yellowstone works, from subsurface magmatic processes to surface hydrothermal activity. The session included nearly 40 presentations spanning an array of topics, including petrology, field volcanology, geophysics, and geochemistry. Ideally, the session will lead to new collaborations that will feed the next decade of research.

\section{Seismology}

Earthquakes have been monitored in the Yellowstone area since the 1970s (see sidebar on seismicity on p. 6-7). The Yellowstone Seismic Network is maintained and operated by the University of Utah Seismograph Stations, which records data from 46 stations in the Yellowstone region. On average, about 1,500-2,500 earthquakes are located in and around Yellowstone National Park every year (most of which are too small to be felt by humans), making the Yellowstone region one of the most seismically active areas in the United States.

\section{Summary of Seismicity during 2019}

During 2019, the University of Utah Seismograph Stations located 1,218 earthquakes in the Yellowstone region (fig. 1), including three that were felt (meaning that people reported some shaking). The largest of the year was a magnitude 3.5 event on August 15, 2019, at 1:46 p.m. local time located along the southern boundary of Yellowstone National Park. 


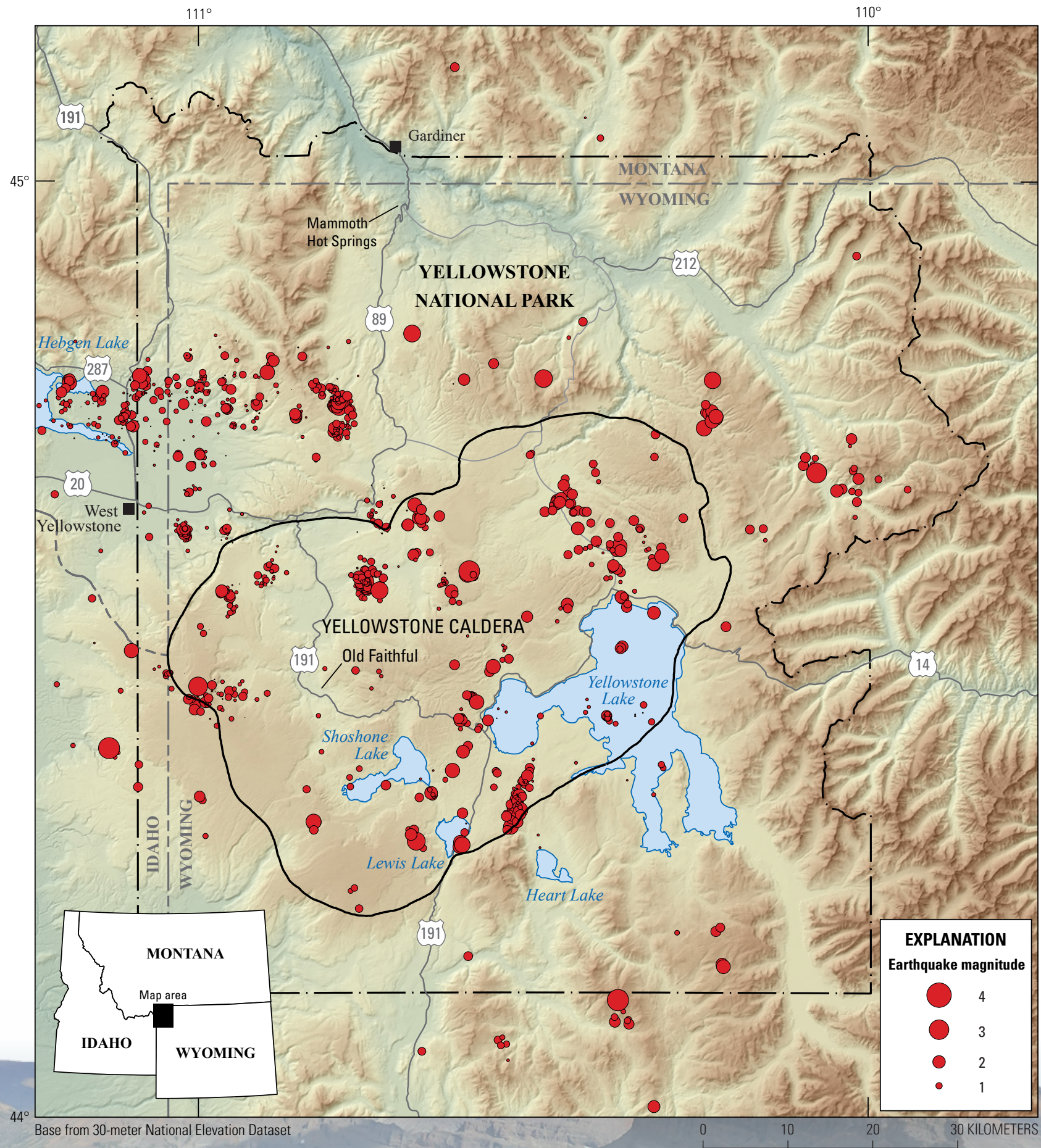

Base from 30-meter National Elevation Dataset

15 MILES

Figure 1. Map of earthquakes (red circles) that occurred during 2019 in the Yellowstone National Park region.

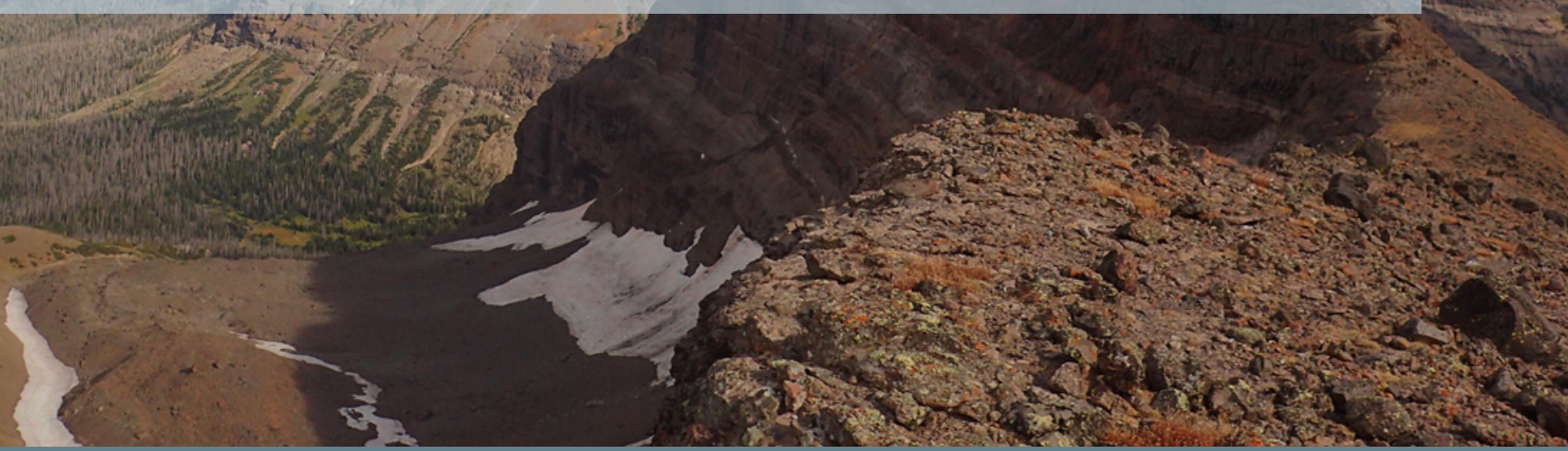




\section{Seismicity in Yellowstone Plateau}

Seismicity in the Yellowstone

Plateau is monitored by the University of Utah Seismograph Stations. The earthquake monitoring network, known as the Yellowstone Seismic Network, consists of about 46 seismometers installed in the seismically active Yellowstone National Park and surrounding area. It is designed for the purpose of monitoring earthquake activity associated with tectonic faulting as well as volcanic and hydrothermal activity. Data are also used to study the subsurface processes of Yellowstone Caldera.
Seismic monitoring in the Yellowstone area began in earnest during the early 1970s, when a seismic network was installed by the U.S. Geological Survey. This network operated until the early 1980s when it was discontinued for budgetary reasons. The network was re-established and expanded by the University of Utah in 1984 and has been in operation ever since. Over the years, the Yellowstone Seismic Network has been updated with modern digital seismic recording equipment, making it one of the most modern volcano-monitoring networks in the world.

Presently, data are transmitted from seismic stations in the Yellowstone area to the University of Utah in real-time using a sophisticated radio and satellite telemetry system. Given that Yellowstone Plateau is a high-elevation region that experiences heavy snowfall and frigid temperatures much of the year, and that many of the data transmission sites are located on tall peaks, it is a challenge to keep the data flowing during the harsh winter months. It is not uncommon

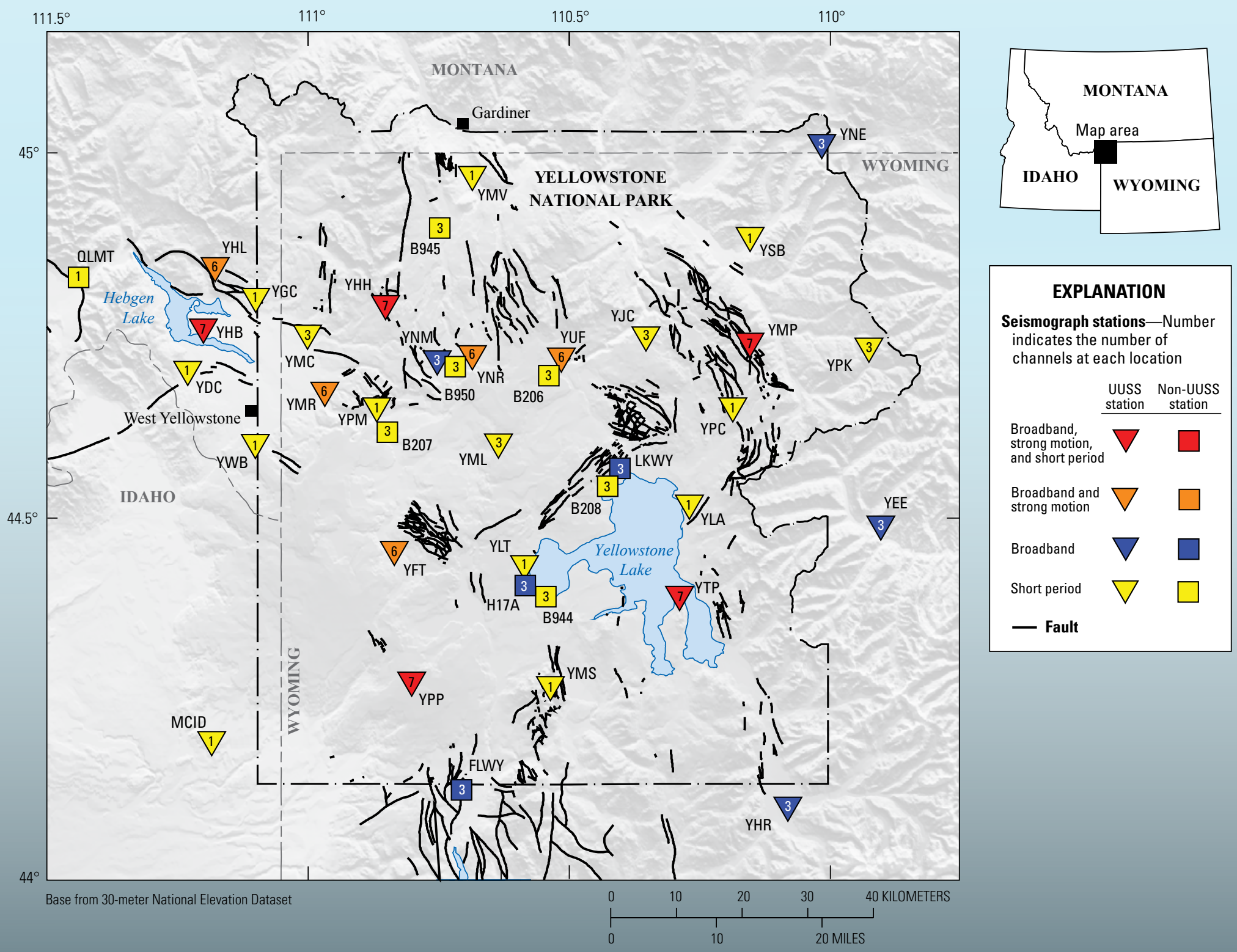


for seismometers to go offline for short periods because the solar panels or antennas get covered in snow and ice. Sometimes seismometers that go offline during the winter cannot be accessed until the following spring.

Since 1973, there have been more than 50,000 earthquakes located in the Yellowstone region. More than 99 percent of those earthquakes are magnitude 2 or below and are not felt by anyone. Since 1973, there has been one magnitude 6 event - the 1975 magnitude 6.1 Norris earthquake located near Norris Geyser Basin (the largest earthquake ever recorded in Yellowstone National Park). There have also been two earthquakes in the magnitude 5 range, 29 earthquakes in the magnitude 4 range, and 391 earthquakes in the magnitude 3 range. The largest earthquake ever recorded in the Yellowstone area was the 1959 magnitude 7.3 Hebgen Lake earthquake, which was located just west of the national park boundary and north-northwest of West Yellowstone, Montana. That earthquake was responsible for 28 deaths and had a major impact on the hydrothermal systems of nearby Yellowstone National Park, including Old Faithful Geyser.

Earthquake swarms (earthquakes that cluster in time and space) account for about 50 percent of the total seismicity in the Yellowstone region. They are most common in the east-west band of seismicity between Hebgen Lake and Norris Geyser Basin. Most swarms are small and short, containing 10-20 earthquakes and lasting for 1-2 days, although large swarms of thousands of earthquakes lasting for months do occur on occasion (for example, in 1985-86 and in 2017).

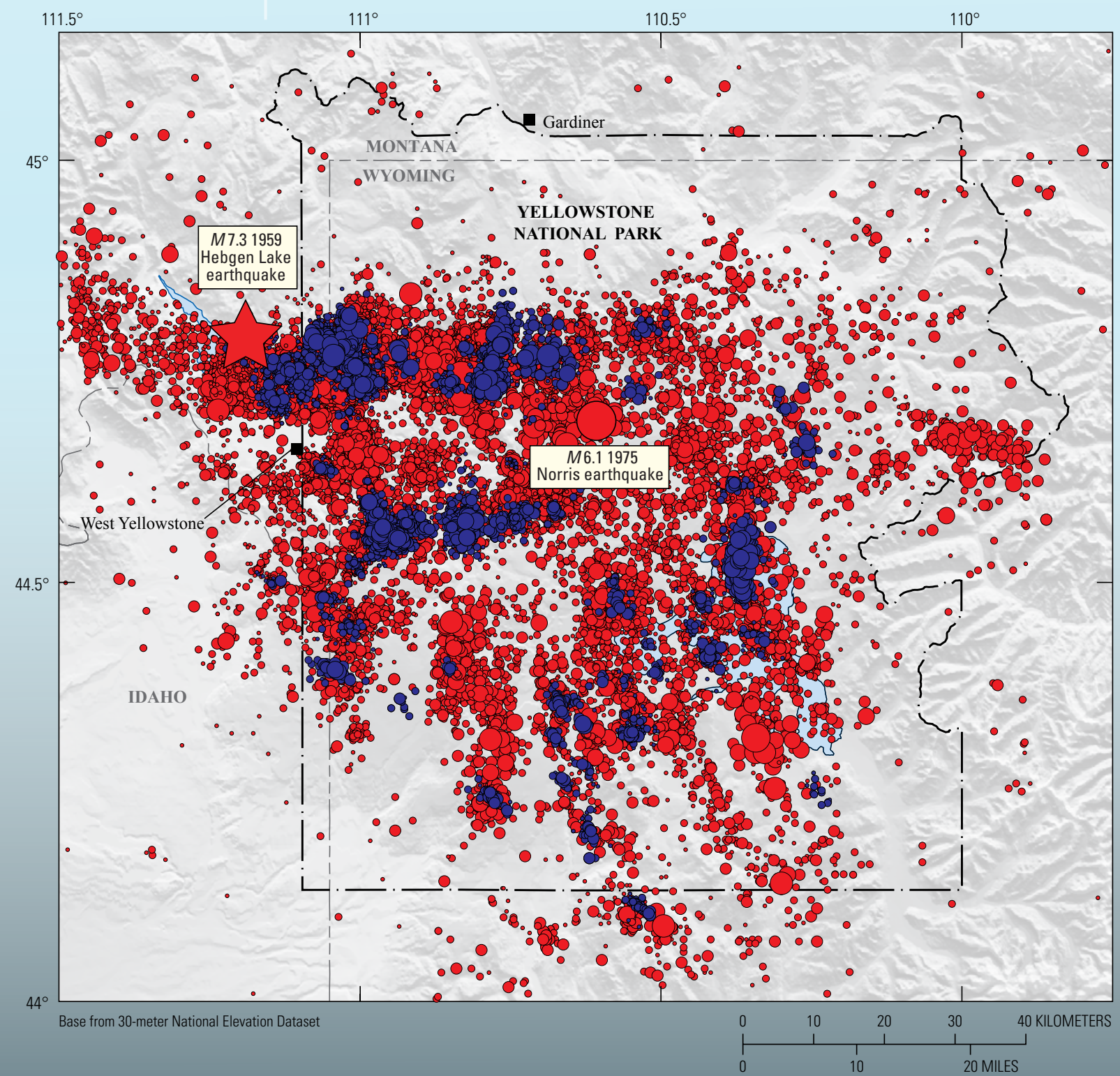

\section{EXPLANATION}

Earthquake magnitude $(\boldsymbol{M})$

6

$\bigcirc 5$

○ 4

$\bigcirc 3$

$\circ 2$ 
Of the total number of earthquakes, 420 (about 35 percent of all the earthquakes that were located in 2019) occurred as part of 17 swarms, which are defined as the occurrence of many earthquakes in the same small area over a relatively short period of time. Swarm activity is common in Yellowstone and typically includes nearly half of all earthquakes that occur in the region. The largest swarm in 2019 included 86 events during October 26-28 about 9 kilometers (5.5 miles) northwest of Norris Geyser Basin, of which the largest was a magnitude 2.6 event on October 26. A 60-event swarm occurred in late July about 13 kilometers (8 miles) north-northeast of Old Faithful Geyser. All other swarms in 2019 consisted of less than 30 earthquakes each.

\section{Steamboat Geyser Seismic Experiment}

In response to the continued activity of Steamboat Geyser in Norris Geyser Basin, the University of Utah, in cooperation with Yellowstone National Park, temporarily deployed 51 nodal seismometers around Steamboat Geyser, the tallest active geyser in the world. The instruments were deployed on June 13 and removed on July 22. The goal was to record seismic signals associated with water eruptions of Steamboat Geyser. The deployment spanned seven major eruptions: June 15, June 19, June 23, June 28, July 4, July 10, and July 18 (fig. 2).

Along with the four major eruptions recorded in the 2018 experiment (see the 2018 YVO annual report [YVO, 2021]), these 11 eruptions are the only Steamboat Geyser eruptions to be recorded by a dense seismic array. The data will be used to image the subsurface structure of Steamboat Geyser and to look for anomalous signals that could be indicative of the cause of the increased eruptive activity since March 2018. In addition, the data will be used to investigate the subsurface connections between hydrothermal features, namely between Steamboat Geyser and Cistern Spring. The spring is known to empty completely after major eruptions of Steamboat Geyser (see Geysers and Hot Springs section).

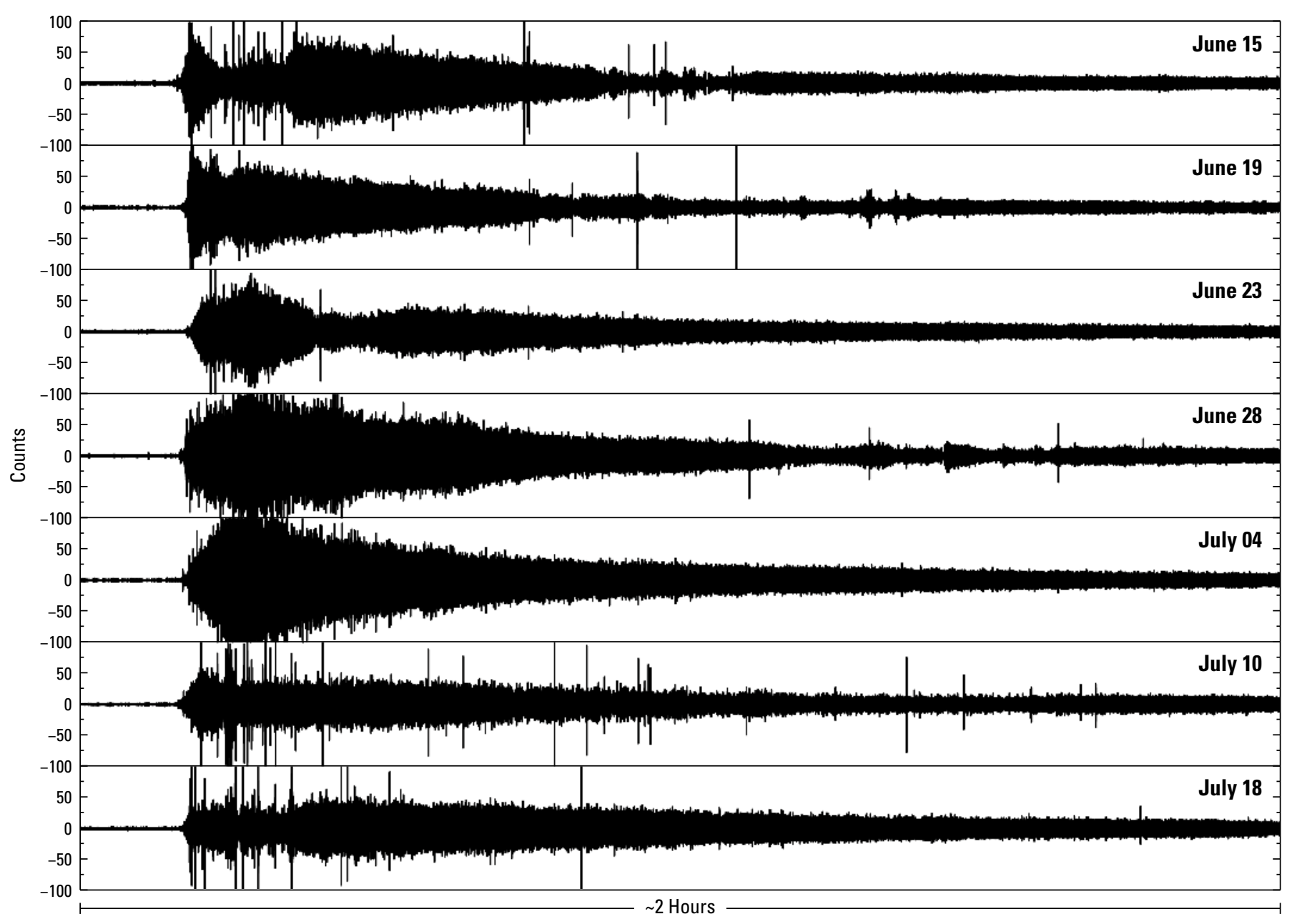

Figure 2. Plot showing eruptions of Steamboat Geyser recorded at a nodal seismic station located about 11 meters ( 36 feet) from the geyser vent. In total, 51 stations were deployed for about a month during June-July 2019. Recording seismic signals related to Steamboat Geyser eruptions from such short distances can highlight subtle differences between eruptions, such as differing seismic amplitudes. 


\section{Geodesy}

Geodesy is the scientific discipline focused on changes in the shape (warping) of Earth's surface, called deformation, such as uplift, subsidence, and faulting. At Yellowstone, these changes are caused by a combination of magmatic, tectonic, and hydrothermal processes. Deformation is measured using networks of GPS ${ }^{2}$ stations, borehole tiltmeters and strainmeters, and a remote-sensing technique called interferometric synthetic aperture radar (InSAR) (see sidebar on monitoring geodetic change on p. 12-14). Geodesy also includes changes in Earth's gravity field, which can indicate variations in mass beneath the surface caused by movement of magma or groundwater, for example. Together, geodetic data are used to develop models of subsurface sources of deformation and gravity change, which in turn provide insights into the physical processes responsible for activity observed at the surface.

\section{Summary of Deformation in 2019}

Ground deformation in 2019 included continued subsidence of the floor of Yellowstone Caldera and little deformation around Norris Geyser Basin. In 2019, five borehole tiltmeters and four borehole strainmeters operated within Yellowstone National Park. These exceptionally sensitive instruments are most useful for detecting short-term changes in deformation (for example, caused by earthquakes or sudden fluid movements) because their signals can drift over periods of weeks to months and show trends not related to deformation. The tiltmeter and strainmeter networks did not detect any meaningful changes related to Yellowstone's tectonic or magmatic systems during 2019 although, as in past years, the strainmeter network did detect the effects of seiches in Yellowstone Lake (see section on Yellowstone Lake Gage Results).

A high-precision gravity survey was performed at selected benchmarks throughout the park in 2019. The results cannot be compared directly to those from similar surveys in 2017 and 2018 because a new type of gravity meter was used in 2019. Calibration of the new meters, pending additional field work, will enable direct comparison and assessment of any changes that might have occurred over time. Such changes can be caused by various processes, including uplift or subsidence of the ground surface and subsurface movements of magma or groundwater.

\section{Continuous GPS Results in 2019}

Throughout 2019, surface deformation measured by 15 continuous GPS stations in Yellowstone National Park mostly followed trends established during previous years (fig. 3). Stations inside Yellowstone Caldera subsided at rates of about 2 centimeters (1 inch) per year (see stations OFW2, WLWY, and HVWY in fig. 3) - a continuation of the trend that, except for a brief period of uplift in 2014-2015, has persisted since 2010. The subsidence appears to have stalled and may have even switched to slight uplift during the summer months (May-August), but subsidence resumed after that time. It is not clear if the pause in subsidence at some stations was a seasonal effect or a subtle caldera-wide change, but it was too small to affect the overall deformation pattern.

At Norris Geyser Basin, only minor subsidence was noted toward the end of 2019 (station NRWY in fig. 3). Uplift that began in late 2015 or early 2016 paused in late 2018 (see the 2018 YVO annual report).

Station coordinates and daily time series plots for Yellowstone continuous GPS stations are available at https:// earthquake.usgs.gov/monitoring/gps/YellowstoneContin.

\section{Semipermanent GPS Results}

In 2019, the Yellowstone semipermanent GPS network comprised 14 stations in the park and one in the adjacent Hebgen Lake Ranger District of Gallatin National Forest (fig. 4). All 15 stations were deployed in May and removed in October to take advantage of generally benign summertime conditions and to avoid the more rigorous operating requirements imposed by harsh Rocky Mountain winters. The 2019 deployment included the first full-season installation of three sites that were established at the end of the 2018 season: SOLF, H191, and CNYN. Twelve of the 15 stations recorded data successfully for the entire time they were deployed. Of those, three (CNYN, HRSB, and LEWC) showed short-term offsets in the data probably caused by weather or other extraneous effects, and not real ground movement. The offsets make it difficult to assess year-to-year changes at those stations pending more detailed analysis. Three other stations (H191, HADN, and LAK1) experienced temporary outages caused by equipment failures or animal disturbance; each was repaired before the end of its deployment. As was the case in 2017 and 2018, three stations close to the shore of Yellowstone Lake (SEDG, LAK1, and LAK2) recorded seasonal elevation changes on the order of 2-3 centimeters (about 1 inch) that are caused by changing water level. During spring runoff, the lake level rises, and the increased weight of water in the lake causes the lakeshore to subside. As the lake level falls later in summer, the lakeshore rebounds upward. At other stations, the rates of subsidence inside the caldera and near Norris Geyser Basin were too low to be apparent in the 2019 data alone. Short-term trends in those data reflect mostly seasonal or weather-related effects.

Year-to-year changes from summer 2018 to summer 2019 are more revealing of ground deformation, although interpretation of the data is complicated by the fact that the stations are not deployed for a full year. For example, stations BRYL and FTNF show net upward movement from 2018 to 2019. From past experience, those stations respond to deformation at Norris Geyser Basin more so than the caldera. Their upward movement might seem surprising, given that Norris Geyser Basin stopped uplifting in late 2018. But the data in figure 4 are for May-October 2018 and May-October 2019; the stations were removed in October each year. So, stations BRYL and FTNF show the effects of net Norris Geyser Basin uplift that occurred between October 2018 and May 2019hence the net upward trends.

${ }^{2}$ In this report, we use GPS as a general and more familiar term for Global Navigation Satellite Systems (GNSS), even though GPS specifically refers to the Global Positioning System operated by the United States. 


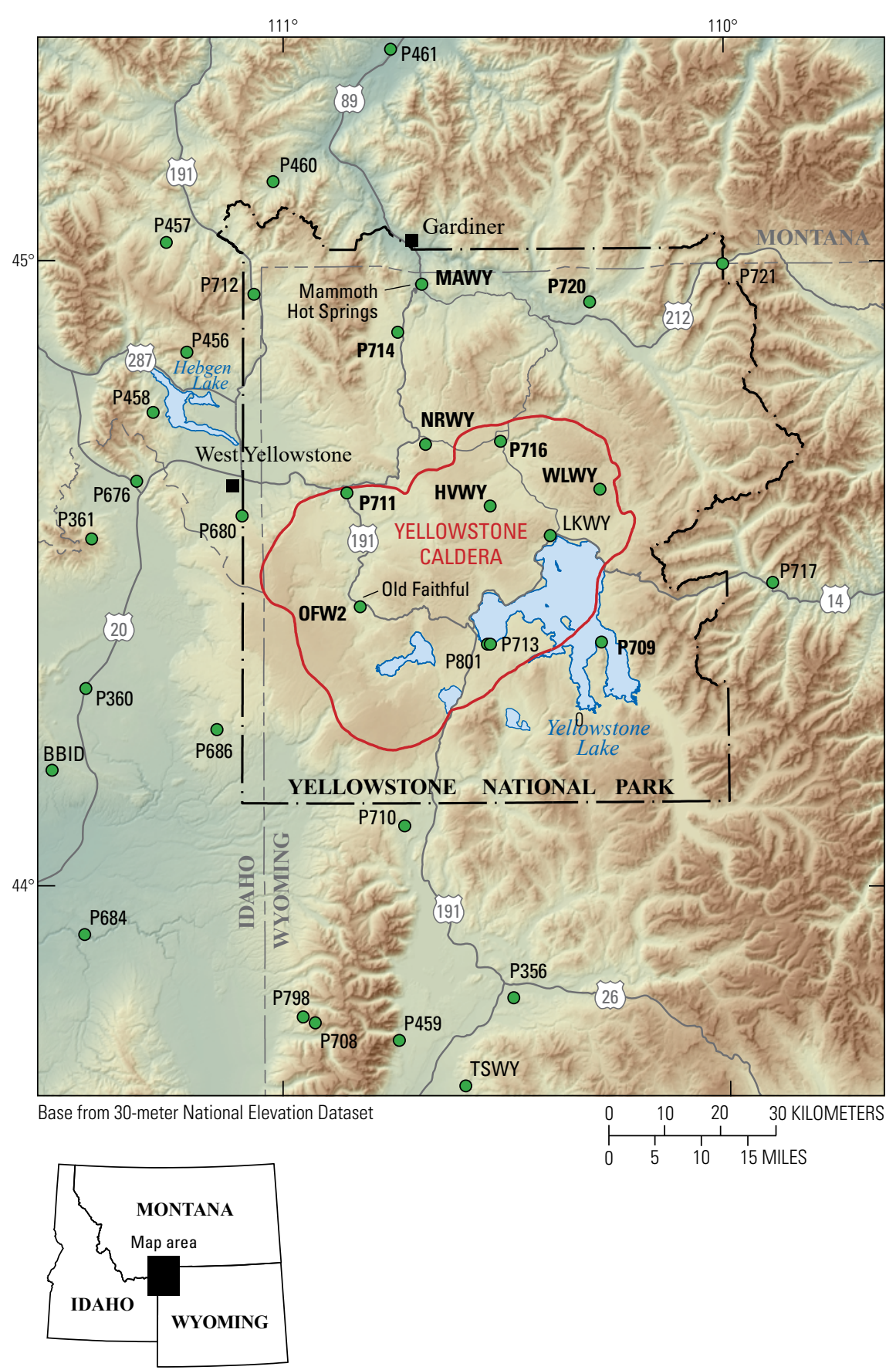

Figure 3. Map of continuous Global Positioning System (GPS) stations showing the deformation observed in Yellowstone National Park in 2019. Vertical displacement (up or down movement of the ground) throughout the year is plotted for 10 selected GPS stations (green dots) located around the park. The vertical axis of all plots is in centimeters, where downward trends indicate subsidence and upward trends indicate uplift. Each dot is the average position for a single day. Overall trends during 2019, neglecting short-term seasonal and other variations, are subsidence within Yellowstone Caldera (exemplified by stations HVWY, WLWY, and OFW2), very little deformation transitioning to slow subsidence late in the year near Norris Geyser Basin (at station NRWY), and no significant vertical motion elsewhere. Gaps during time series indicate periods when GPS stations were not operational.

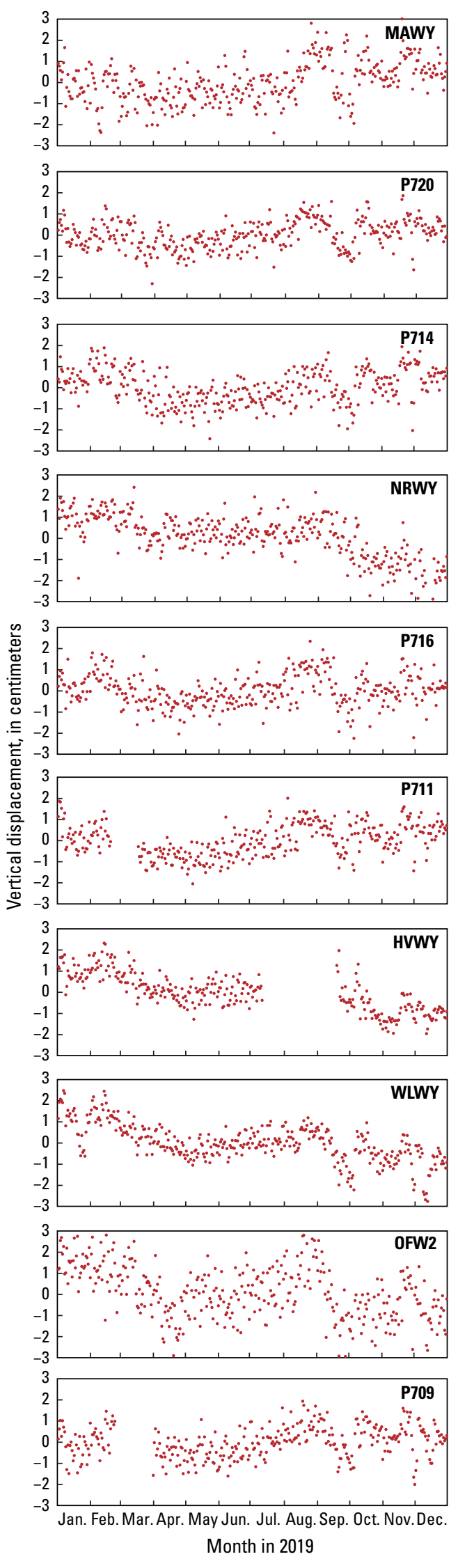



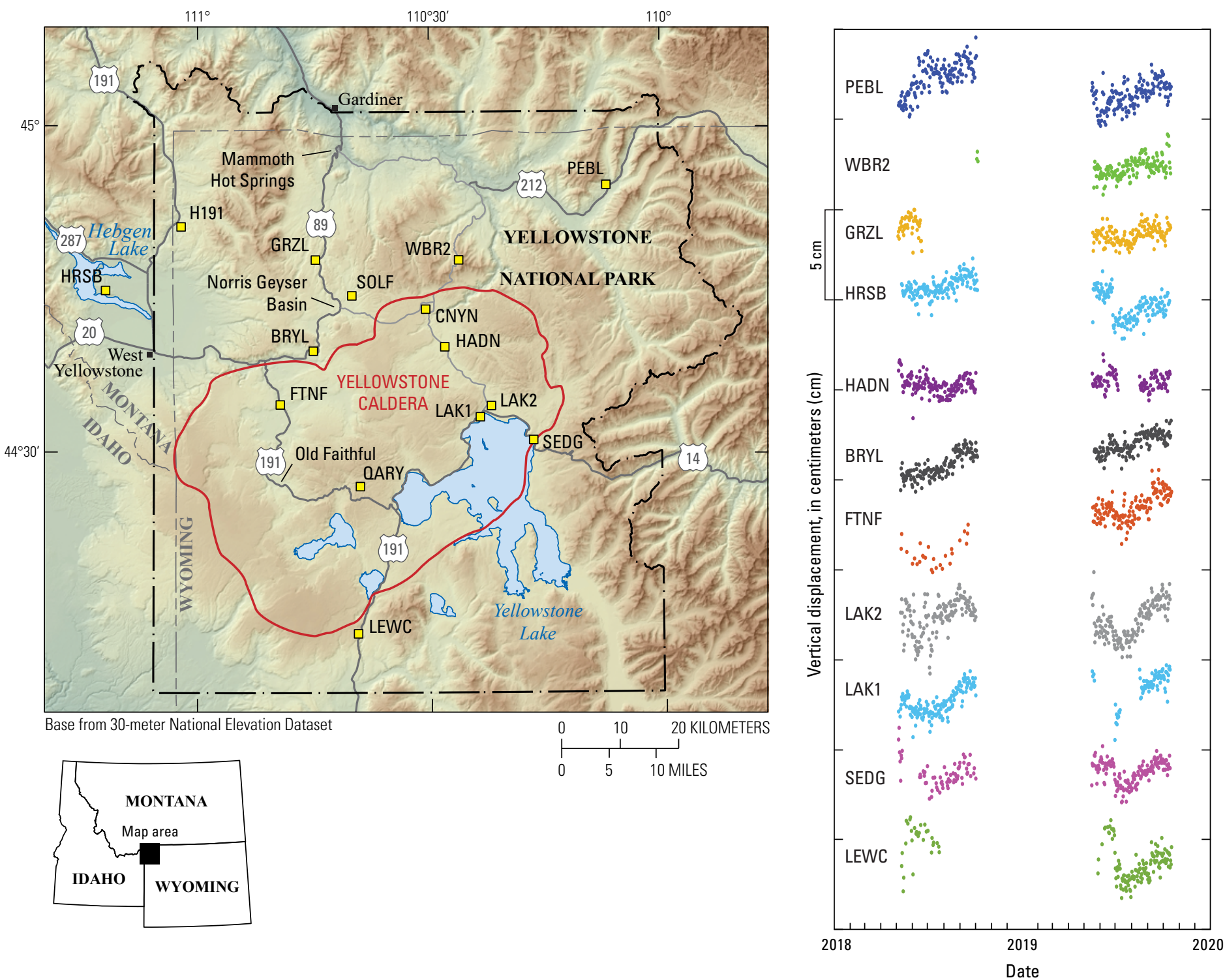

Figure 4. Map of semipermanent Global Positioning System (GPS) stations showing the deformation observed in and around Yellowstone National Park in 2018 and 2019. Vertical displacement (up or down movement of the ground) throughout the year is plotted for 11 selected semipermanent GPS stations (yellow squares on map) located around the park. The distance between tick marks is 5 centimeters. Downward trends indicate subsidence and upward trends indicate uplift. See text for discussion of trends.

The semipermanent GPS technique has both advantages and disadvantages compared to continuous GPS. Semipermanent GPS stations are less expensive, less intrusive on the landscape, and portable enough to be deployed in areas that might be off limits to a continuous GPS installation. When the semipermanent GPS station is not deployed, all that remains is a small steel pin attached to rock that serves as an enduring benchmark. A clear disadvantage of semipermanent GPS compared to continuous GPS is that semipermanent GPS data are intermittent whereas continuous GPS data are collected year round. Also, semipermanent GPS data are not telemetered, so they are available only after the stations have been retrieved in the fall and the data have been processed. Used together, though, the two approaches complement one another by providing precise ground deformation data from dozens of sites in and around Yellowstone National Park. This large number of stations is necessary to adequately characterize complex deformation patterns at Yellowstone, which can change rapidly.

Station coordinates and daily time-series plots for Yellowstone semipermanent GPS stations are available at https:// earthquake.usgs.gov/monitoring/gps/Yellowstone_SPGPS.

\section{Interferometric Synthetic Aperture Radar (InSAR) Results}

Satellite InSAR uses data from orbiting satellites to map ground deformation by comparing satellite-to-ground distances at different times. Resulting images are called interferograms and they show how much the surface moved during the time between satellite observations, along with uncertainty introduced by 


\section{Monitoring Geodetic Change in Yellowstone}

Subtle changes to the shape of a volcano's surface, called deformation, can manifest as swelling, sinking, or cracking. This deformation can be caused by the accumulation, withdrawal, or migration of magma, gas, or other fluids (typically water) beneath the ground, or by movements in Earth's crust owing to motion along faults. Typically, this deformation is very small in magnitude - a few centimeters (inches) or less - and so can only be detected and monitored using very sensitive instruments. Changes in the amount of material beneath the ground also result in variations in gravity at the surface. Combining measurements of gravity change with deformation can help to reveal the type of fluid that is accumulating or withdrawing-for instance, magma versus gas.

By measuring the pattern and style of surface deformation, it is possible to determine the location of subsurface fluid storage areas. For example, as magma or water accumulates in a reservoir below ground, the surface above will swell. The pattern of this surface inflation can be used to identify the depth of fluid accumulation, and the scale of the deformation can provide information on how much and what type of fluid is accumulating. By monitoring changes in deformation over time, it is possible to assess how magma, water, and gas are moving in the subsurface. The technique is an important tool for forecasting potential future eruptions. In the days, months, and years before a volcanic eruption, many volcanoes inflate as magma accumulates underground. Rapid changes in deformation may be a sign that magma is ascending towards the surface. Yellowstone Caldera presents a complicated situation because deformation may be caused by magma, water, or gas.

A variety of instruments help to monitor ground deformation in the Yellowstone region. UNAVCO, a non-profit consortium funded by the National Science Foundation, operates and maintains a network of Global Positioning System (GPS) instrumentation, as well as borehole strainmeters and tiltmeters. Borehole strainmeters and tiltmeters are designed to detect very small changes in deformation style especially over short time intervals (even down to minutes), but they tend to drift over days to weeks so cannot track longterm ground deformation. This is where GPS, the backbone of the Yellowstone Caldera deformation monitoring network, comes into play. There are 15 continuously recording GPS stations within Yellowstone National Park and many more in the surrounding region. Data from these sites, as well as temporary deployments of GPS stations ("semipermanent GPS"), are employed to precisely record the horizontal and vertical positions of fixed points at the surface. Variation in the positions over time, relative to the rest of the North American continent, gives an indication of how the ground in the Yellowstone region deforms owing to local processes, such as subsurface fluid accumulation and withdrawal, and faulting caused by earthquakes. Data from continuous GPS stations in the Yellowstone region are transmitted via radio and satellite links to UNAVCO's archives, where they are made publicly available at https://www.unavco.org/ data/dai.

YVO scientists use satellite measurements, called interferometric synthetic aperture radar (InSAR), to take a broad snapshot of deformation. Two radar images of the same area that were collected at different times from similar vantage points in space are compared against each other. Any movement of the ground surface toward or away from the satellite is measured and portrayed as a "picture"- not of the surface itself but of how much the surface moved during the time between images. Unlike visible or infrared light, radar waves penetrate most weather
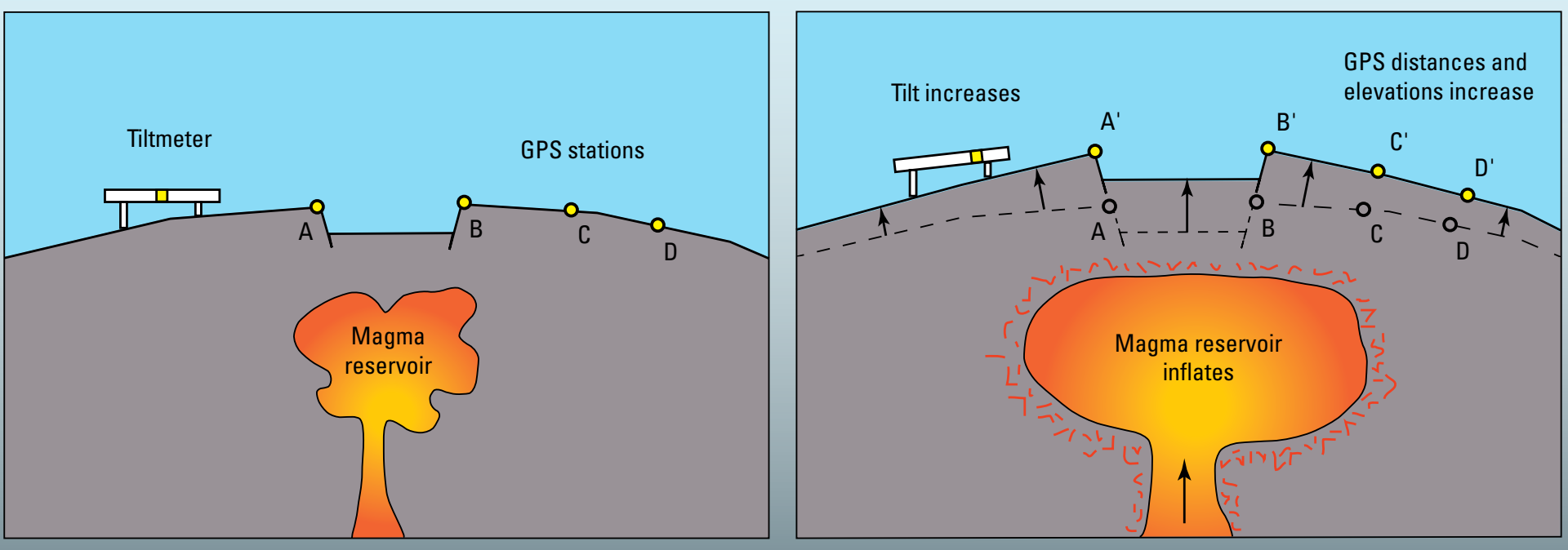
clouds and are equally effective in darkness, so, using InSAR, it is possible to track ground deformation even in bad weather and at night.

InSAR greatly extends scientists' ability to monitor volcanoes because, unlike other techniques that rely on measurements at a few points, InSAR produces a map of ground deformation that covers a very large area with centimeter-scale accuracy. This technique is especially useful at remote, difficult-toaccess volcanoes and at locations where hazardous conditions prevent or limit ground-based volcano monitoring. However, unlike continuous GPS, which provides data all the time, InSAR data are only available once every few days or weeks, when one of several radar satellites is overhead.

Measurements of changes in Earth's gravity field are another means to study processes that occur underground, hidden from sight. When magma accumulates beneath the surface or a large amount of water

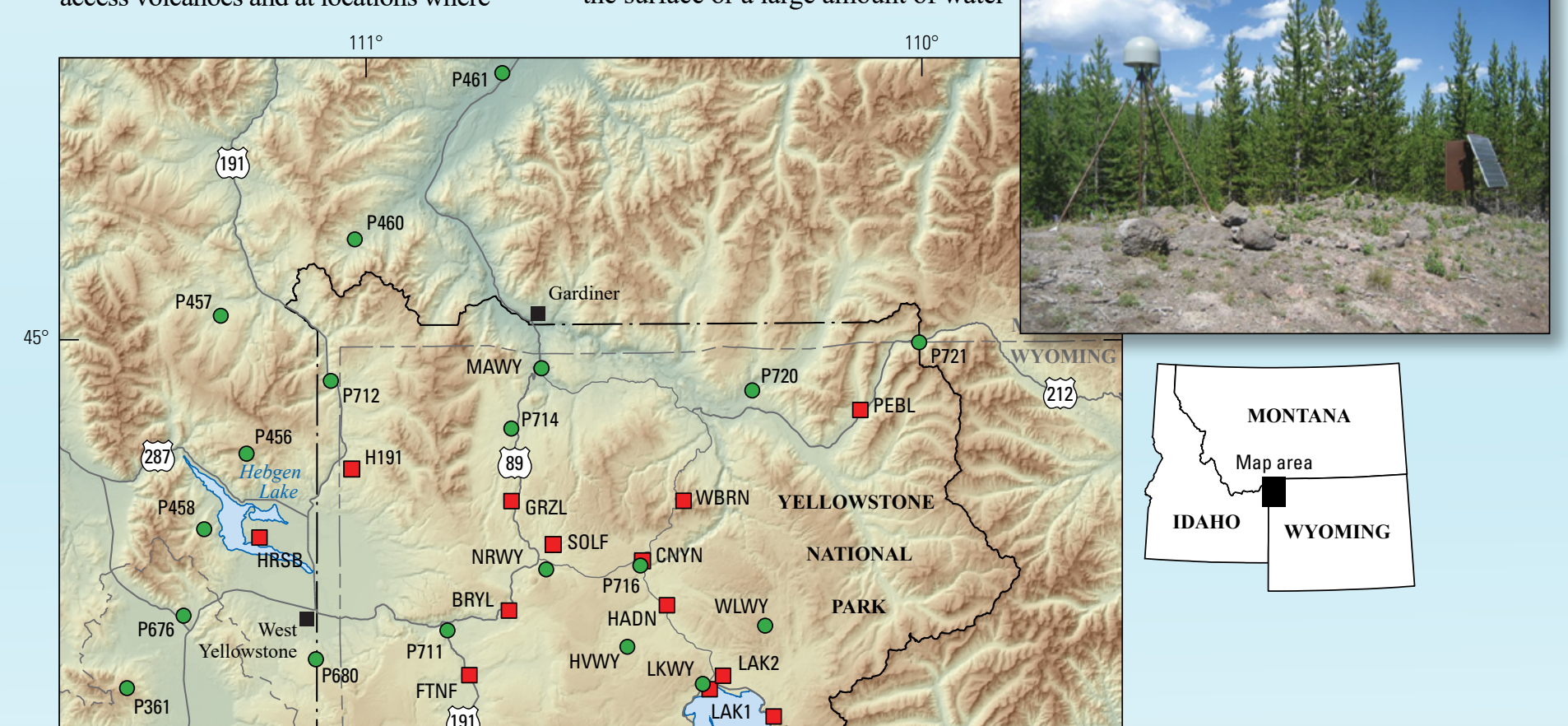

is expelled from a geyser, for example, the redistribution of material causes subtle changes in the gravity field. The difference is miniscule, but gravity is stronger at the surface above areas of high mass than it is above less massive material. In a dynamic environment like Yellowstone, the distribution of mass can change over time. For example, gravity will increase if more magma

Map showing locations of continuous (green dots) and semipermanent (red squares) Global Positioning System (GPS) sites in the Yellowstone area. Photograph shows continuous GPS station P711 in Yellowstone National Park. 


\section{Monitoring Geodetic Change in Yellowstone}

accumulates in a shallow reservoir, or if porous rock fills with groundwater. Combining gravity measurements, which can record changes in subsurface mass, with deformation, which can indicate changes in subsurface volume, it is possible to calculate the density of the fluids that are driving the changes seen at the surface. High-density fluids are likely to be magma, whereas lowdensity fluids reflect the presence of water or gas.

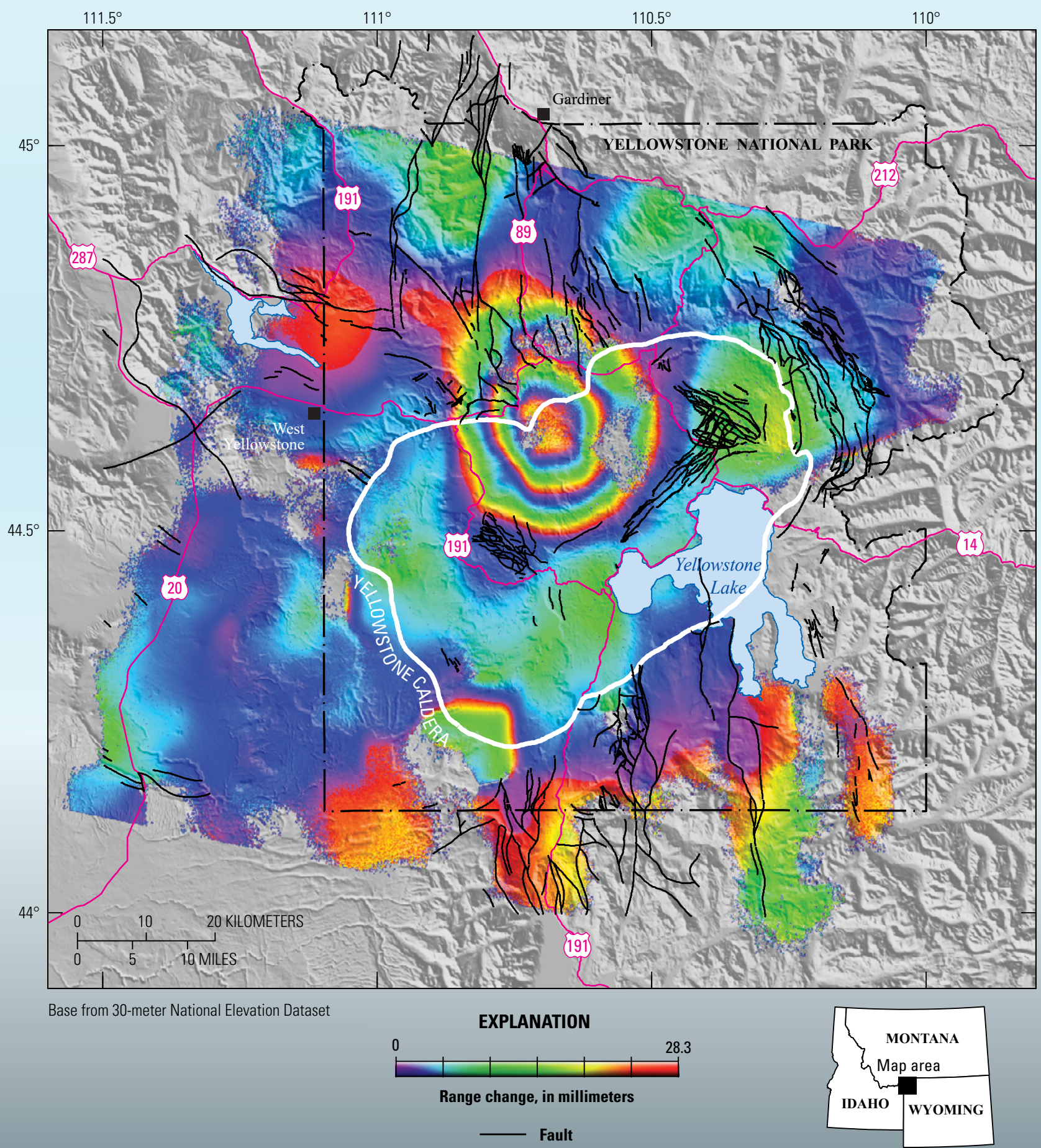

Map of past ground deformation in the Yellowstone region. This image was created using data from satellite passes in 1996 and 2000. The image shows 125 millimeters (about 5 inches) of uplift centered near the north rim of Yellowstone Caldera, about 10 kilometers ( 6.2 miles) south of Norris Junction. Each full cycle of color (from red through green to purple) represents about 28 millimeters (1 inch) of surface movement toward or away from the satellite (mostly uplift or subsidence). Here, the bullseye centered along the north caldera rim near Norris Geyser Basin shows an area of uplift approximately $35 \times 40$ kilometers (22×25 miles) in size. Modified from U.S. Geological Survey Professional Paper 1788 (Dzurisin and others, 2012). 
atmospheric variations. Surface movements from InSAR are less precise than those from GPS, but InSAR has two big advantages. First, whereas GPS measures changes at specific locations, InSAR shows the entire pattern of surface deformation as a spatially continuous image - essentially a map of ground movements in the satellite-to-ground direction. Second, InSAR does not require access to or permitted installations in the study area. Observations are made remotely with no impact on the landscape or environment. When deformation is rapid, a disadvantage is that current InSAR satellites have repeat times measured in days, whereas GPS data are continuous. Other disadvantages are that, in the Yellowstone region, InSAR data are not usable during winter months because most of the surface is covered with snow. In addition, InSAR only shows deformation in one direction (line-of-sight of the satellite) compared to the three-dimensional deformation given by GPS. The best InSAR images typically span one or more years, with observations in summer or fall when the surface is mostly snow free. By combining GPS and InSAR data, YVO scientists can track ground deformation continuously with very high precision at more than two dozen sites in the park, as well as map year-to-year deformation (more often when deformation rates are high) at somewhat lower precision across the entire park.

A radar interferogram for the period from September 2018 to September 2019 revealed a deformation pattern consistent with that indicated by GPS observations - subsidence of the caldera by about 2 centimeters (less than 1 inch) and little net deformation (only slight subsidence) in the area around Norris Geyser Basin (fig. 5).

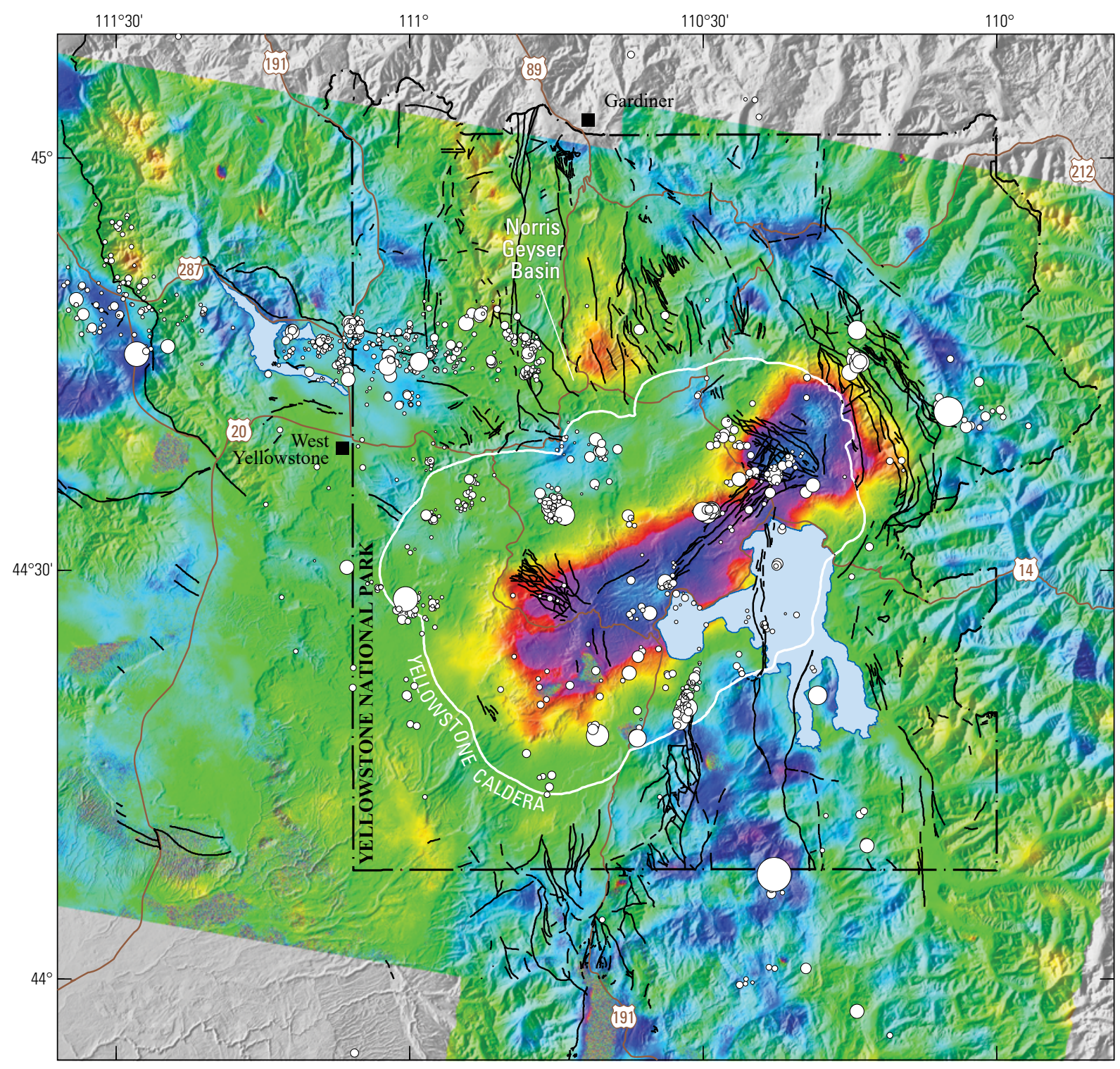

EXPLANATION

Earthquake magnitude

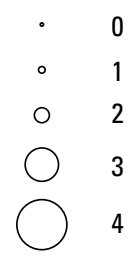

Range change, in millimeters

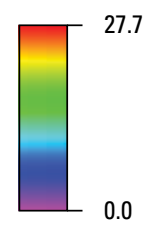

Fault

Base from 30-meter National Elevation Dataset

Figure 5. Interferogram created from data collected on September 21, 2018, and September 16, 2019, by the Sentinel-1 satellite system. Colored fringes indicate a change in distance (called range change) between the satellite and ground surface that is caused by surface deformation. In this interferogram, the fringes indicate subsidence (an increase in the range between the ground and the satellite) of as much as 2 centimeters (less than 1 inch) in the central part of Yellowstone Caldera and less subsidence of a small area near Norris Geyser Basin during the time period spanned by the images. What look like blue "stripes" in the south part of the park and elsewhere in the image are atmospheric artifacts. White circles show earthquakes that occurred from September 2018 to September 2019. Circle size scales with magnitude; the largest is about magnitude 3. 


\section{Yellowstone Lake Gage Results}

Prior to 2017, the water level in Yellowstone Lake was determined by occasional measurements at Bridge Bay marina or inferred from a streamgage on the Yellowstone River at the lake outlet near Fishing Bridge. A pressure-depth gage was installed in 2017 at the Grant Village dock (see the 2017 YVO annual report [YVO, 2019]), enabling lake-level measurements to be made at 1-minute intervals. These measurements in 2019 showed normal spring and early summer lake level increases owing to snowmelt influx, and then late summer to early fall decreases owing to outflow (fig. 6). The maximum variation in lake level over the course of the year was about 1.3 meters ( 4.25 feet).

As observed previously, a seiche was measured more or less continuously over the year (fig. 6 inset). Seiches are waves that cause short-term variations in the surface level of Yellowstone Lake, thus far observed to range from a few centimeters to 15 centimeters (peak-to-peak) during storms or atmospheric events. Although they are too subtle and slow to be noticed by the human eye, they can change the distribution of water in the lake over time - generally over periods of about an hour. Deformation patterns recorded by borehole strainmeters throughout Yellowstone National Park reveal the presence of these seiches and have been used to provide insights into the structure of the subsurface - for example, the depth and viscosity of the magma reservoir beneath Yellowstone Caldera. the interface between its hydrothermal and magmatic systems, with the ultimate goal of investigating processes that are hidden from direct observation (see sidebar on geochemical monitoring on $\mathrm{p}$. 17). Thermal features provide a window into Yellowstone's depths, and geochemistry is a powerful tool for illuminating those depths.

\section{Summary of Geochemistry Activities in 2019}

In 2019, YVO scientists continued gas and heat emission measurements, and also sampled water in various areas for laboratory analysis. Soil carbon dioxide $\left(\mathrm{CO}_{2}\right)$ flux and temperature surveys were conducted in an area just north of Norris Geyser Basin (about 200 meters [about 650 feet] southwest of the bridge over the Gibbon River north of Norris Geyser Basin), and an eddy covariance system, installed in 2018, made continuous measurements of $\mathrm{CO}_{2}$, steam $\left(\mathrm{H}_{2} \mathrm{O}\right)$, and heat fluxes. Water samples were collected from Shoshone Geyser Basin and at the outlets of Shoshone and Lewis Lakes to better understand the geological and geochemical processes that influence water chemistry. In addition, water samples were collected from Cinder Pool (in Norris Geyser Basin) and from several locations along Obsidian Creek. Data from previous water and gas samples, especially in the southwest part of Yellowstone National Park, were published in online databases (Bergfeld and others, 2019; McCleskey and others, 2019).

\section{Geochemistry}

\section{Gas Emissions}

In 2019, the multi-year study of temporal variations in gas and heat emissions continued at a location just north dynamic thermal features are aimed at better understanding

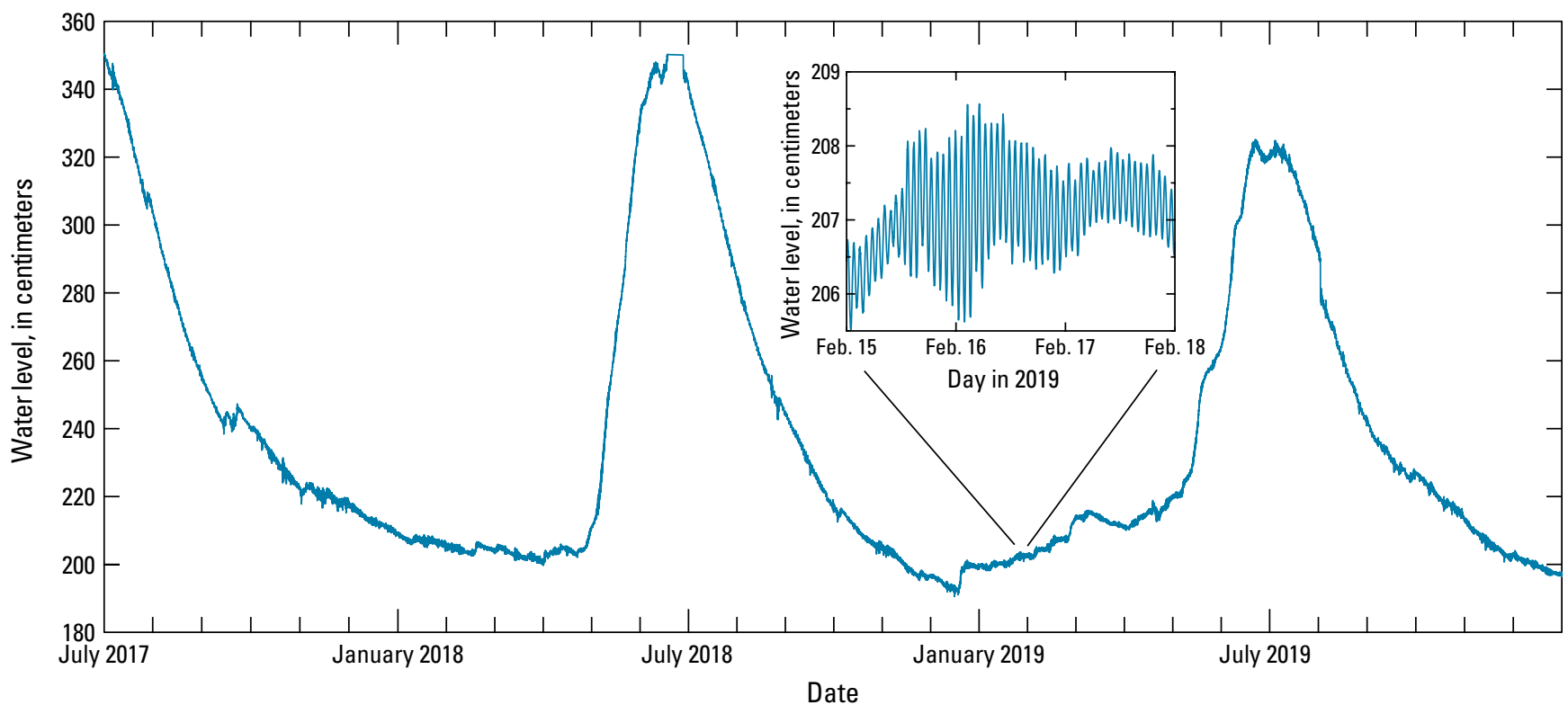

Figure 6. Plot of Yellowstone Lake level from July 2017 to January 2020 recorded by a gage located at the Grant Village boat dock. Rapid increases are caused by ice thaw and snowmelt influx (spring) whereas slower decreases are caused by water outflux (summer to fall). Minor variations (inset) show seiche waves of a few centimeters in height that occurred throughout the period. These seiche waves occur even during periods when the lake is covered by ice, as shown by the example, which is from February 2019. 


\section{Geochemical Monitoring in Yellowstone Caldera}

Deep beneath the surface, gasses are dissolved in magma, but as magma rises toward the surface the pressure decreases and gases separate from the liquid to form bubbles. Because gas is less dense than magma, the bubbles can rise more quickly and be detected at the surface of the Earth.

Similarly, water can also transport material up to the surface where it can be studied by scientists. Groundwater circulates deep within the Earth's crust in volcanic regions, where it can be heated by magma to over $200^{\circ} \mathrm{C}$ (around $400{ }^{\circ} \mathrm{F}$ ). This causes it to rise along fractures, bringing dissolved material up toward the surface. By studying the chemical makeup of this thermal water, scientists can gain a better picture of the conditions deep within a volcano.

In Yellowstone Caldera, volcanic gas emissions are usually sampled by hand directly from fumaroles (gas vents), although some temporary automated measurements of certain types of gases have been employed. Likewise, measurements of water chemistry are typically done by collecting samples and analyzing the chemical makeup of the water in the laboratory.

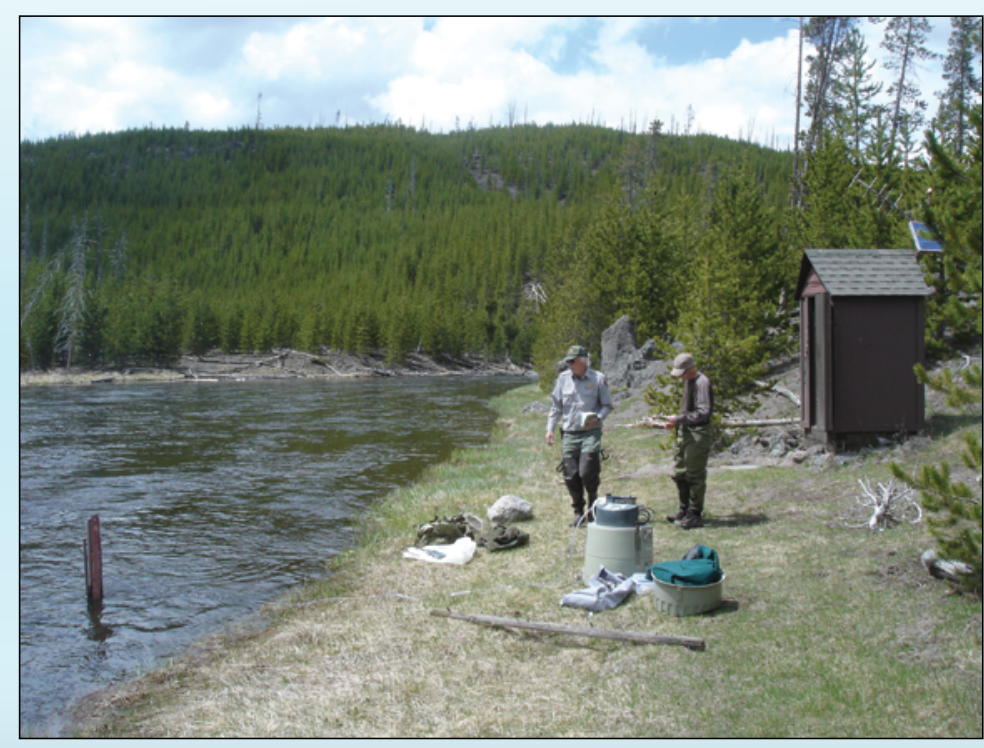

Scientists collect water samples from the Firehole River in Yellowstone National Park. U.S. Geological Survey photograph by Jim Ball, 2014. of Norris Geyser Basin. The project commenced in July 2018 (see the 2018 YVO annual report) after an exploratory summer-only investigation in 2016 and involved discrete measurements of soil $\mathrm{CO}_{2}$ flux and operation of an eddy covariance system. Eddy covariance is a micrometeorological technique that measures the turbulent flux of $\mathrm{CO}_{2}, \mathrm{H}_{2} \mathrm{O}$, and heat emitted from ground areas upwind of the sensors; at Yellowstone, these areas are on the order of tens of hectares (thousands of acres) in size.

Figure 7 shows a simulated map of soil $\mathrm{CO}_{2}$ flux based on accumulation chamber measurements made at the locations shown by the black dots on June 25, 2019. Integrating soil $\mathrm{CO}_{2}$ flux over the study area ( 0.04 square kilometers) yielded a total $\mathrm{CO}_{2}$ emission rate of 2.9 metric tons per day. This emission rate was similar to that determined for the same area in July 2018 (2.4 metric tons per day), but substantially lower than in October 2016 (9.8 metric tons per day), as determined by Lewicki and others (2017).

The eddy covariance system measured $\mathrm{CO}_{2}$, sensible heat, and latent heat fluxes on a half-hourly basis. Eddy covariance $\mathrm{CO}_{2}$ flux measurements are plotted versus wind direction in figure $8 \mathrm{~A}$ and were relatively high when wind was from the southwest, such that the eddy covariance system was downwind from several steam vents. Whereas eddy covariance $\mathrm{CO}_{2}$ fluxes were highly variable on a half-hourly basis, the seasonally smoothed data, constructed using a 90-day window, was

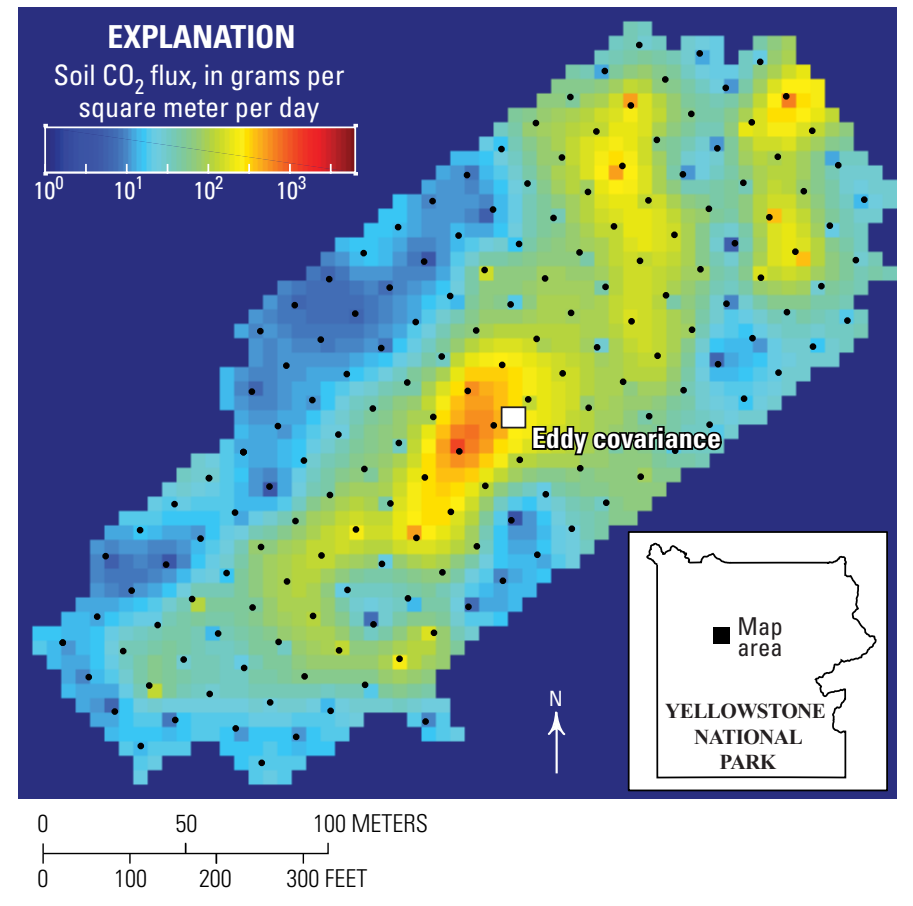

Figure 7. Map of $\log$ soil $\mathrm{CO}_{2}$ flux at an area just north of Norris Geyser Basin, simulated based on accumulation chamber measurements made at locations shown by the black dots on June 25 , 2019. White square shows the location of an eddy covariance station. 

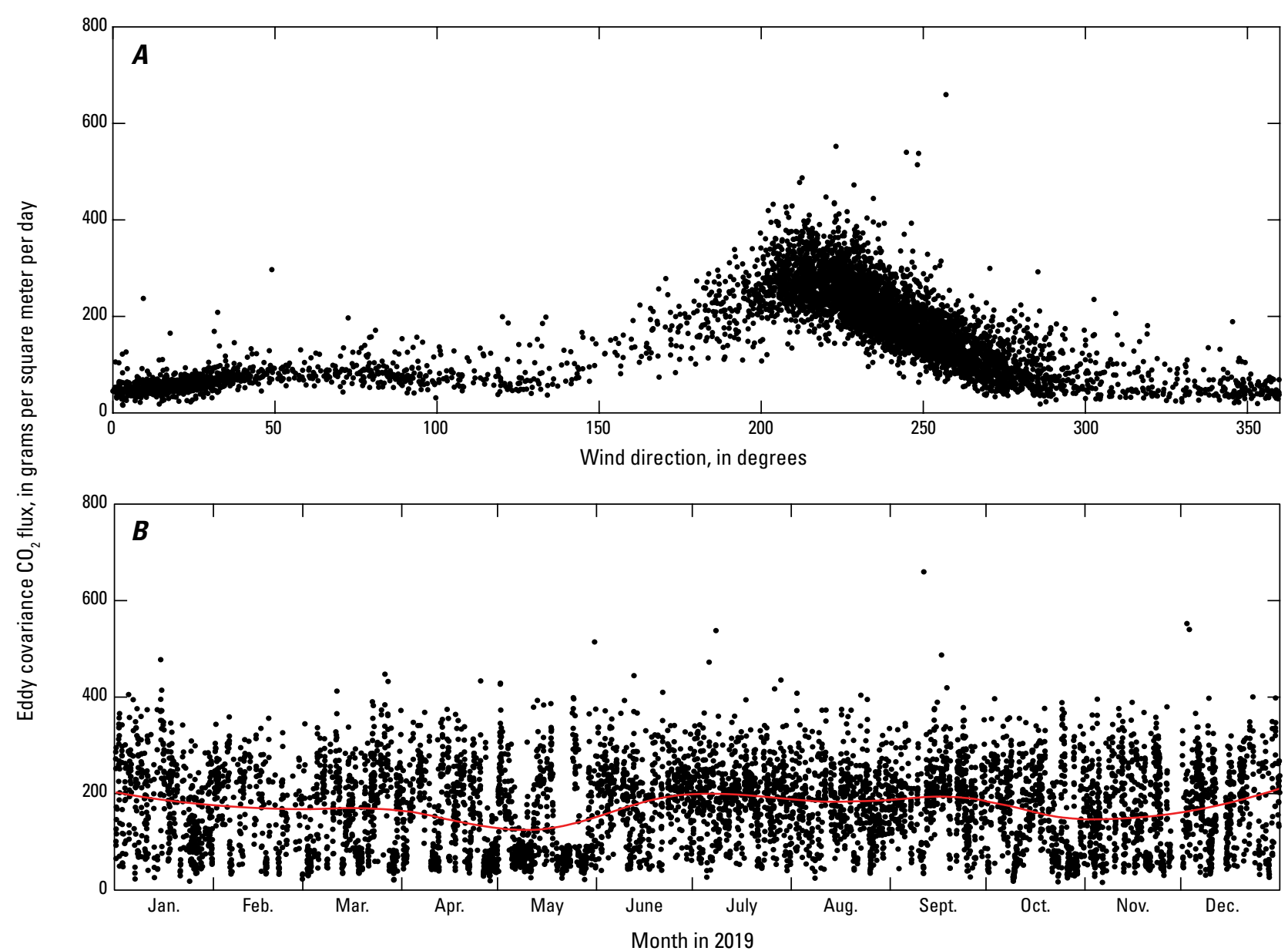

Figure 8. Plots of eddy covariance $\mathrm{CO}_{2}$ flux versus wind direction $(A)$ and time $(B)$. Red line shows data smoothed using a 90-day (seasonal) window.

stable at around 175 grams per square meter per day (fig. $8 B$ ), consistent with observations in 2018 (see the 2018 YVO annual report). Time-series data of half-hourly eddy covariance sensible, latent, and sensible plus latent heat fluxes are shown in figure 9. Since we are interested in quantifying the hydrothermal component of this heat, we only consider fluxes measured during the nighttime, when solar effects are minimized (red dots on fig. 9). The average values of nighttime sensible, latent, and sensible plus latent heat fluxes during the study timeframe were 85,128 , and 212 watts per square meter, respectively, and demonstrate that the latent (evaporative) heat flux was the dominant of the two components measured. Nighttime sensible plus latent heat flux is plotted against nighttime eddy covariance $\mathrm{CO}_{2}$ flux in figure 10. The good correlation between these parameters supports the idea that nighttime measurements of heat flux are representative of hydrothermal, rather than solarrelated, heat fluxes. These records of eddy covariance $\mathrm{CO}_{2}$ and heat flux will provide a baseline against which future changes can be assessed in the context of hydrothermal activity in Norris Geyser Basin, as well as caldera unrest.

\section{Water Chemistry}

\section{Shoshone Geyser Basin and Shoshone and Lewis Lakes}

In September 2019, scientists from the USGS and Yellowstone National Park sampled thermal waters at Shoshone Geyser Basin, an area of diverse thermal features near the west shore of Shoshone Lake in the southwest part of the park (fig. 11). Measured $\mathrm{pH}$ ranged from 1.7 to 9.4, temperatures from 30 to 93 degrees Celsius $\left({ }^{\circ} \mathrm{C}\right)$, and specific conductance from 1,200 to 6,900 microsiemens per centimeter. Samples were analyzed for major ions, trace elements, and sulfur, arsenic, and mercury redox species. In addition, water samples and stream discharge were measured at the outlets of Shoshone and Lewis Lakes to determine the geothermal contributions from the thermal areas surrounding the lakes. The goals of this study are to identify the geological and chemical processes affecting the water chemistry. Shoshone Geyser Basin is an ideal study site because of the diversity of its thermal features. 

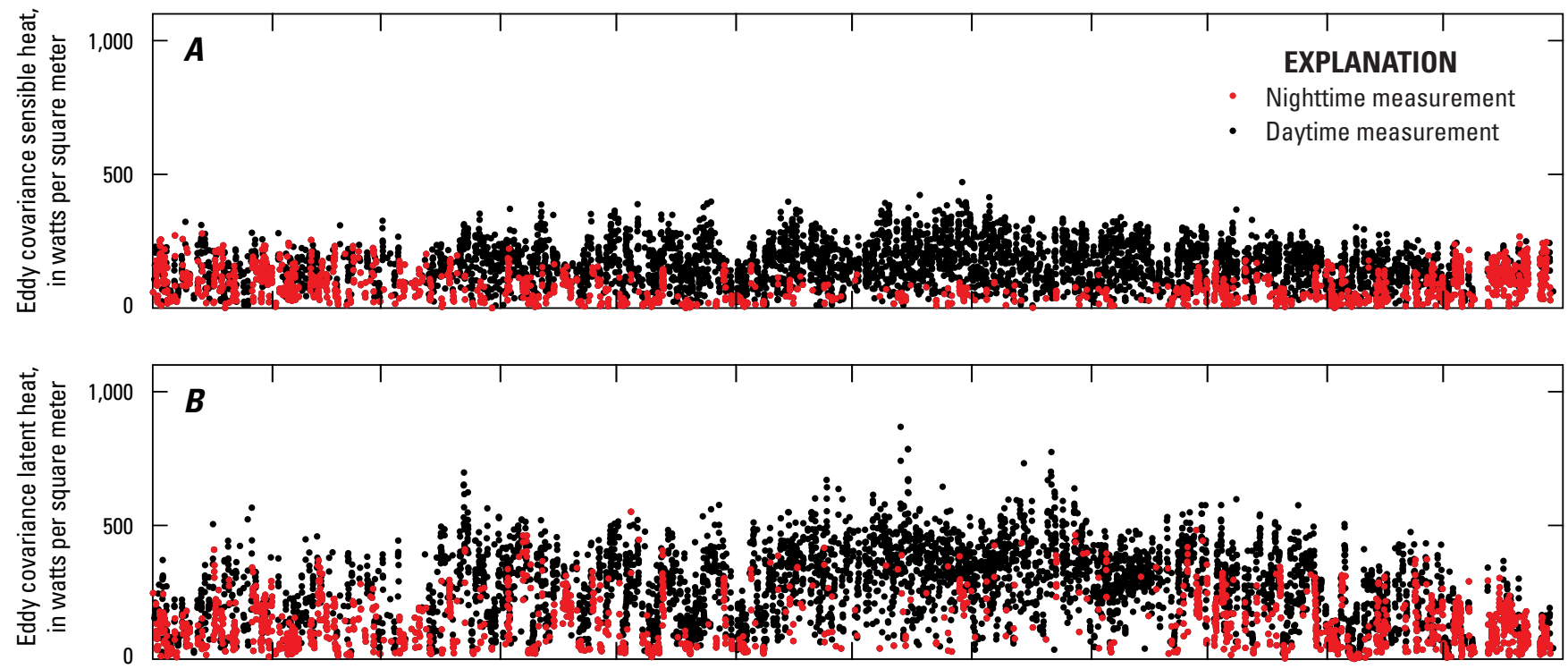

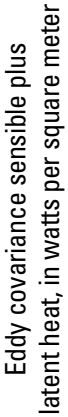

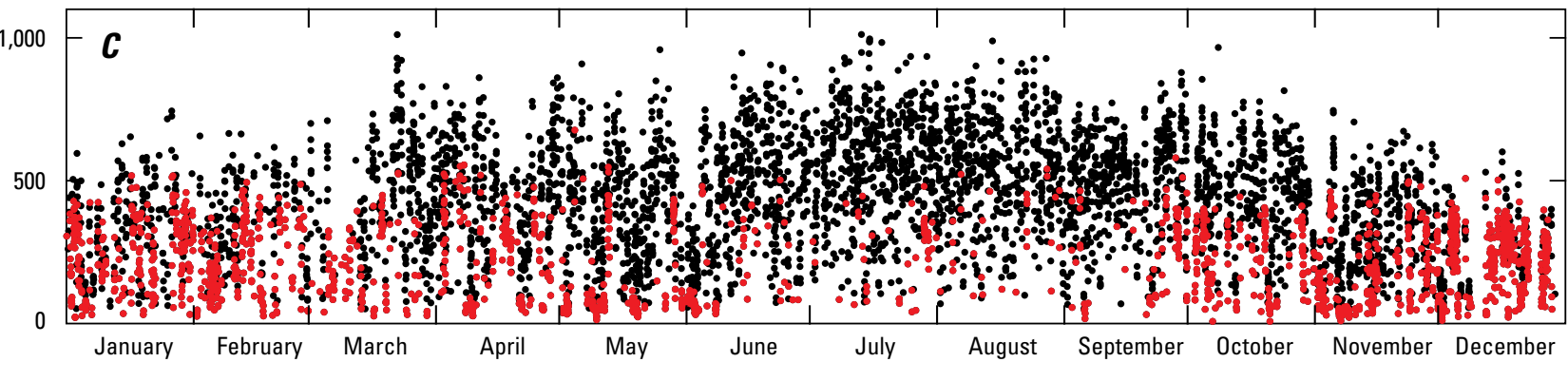

Figure 9. Time-series plots of eddy covariance sensible $(A)$, latent $(B)$, and sensible plus latent $(C)$ heat fluxes.
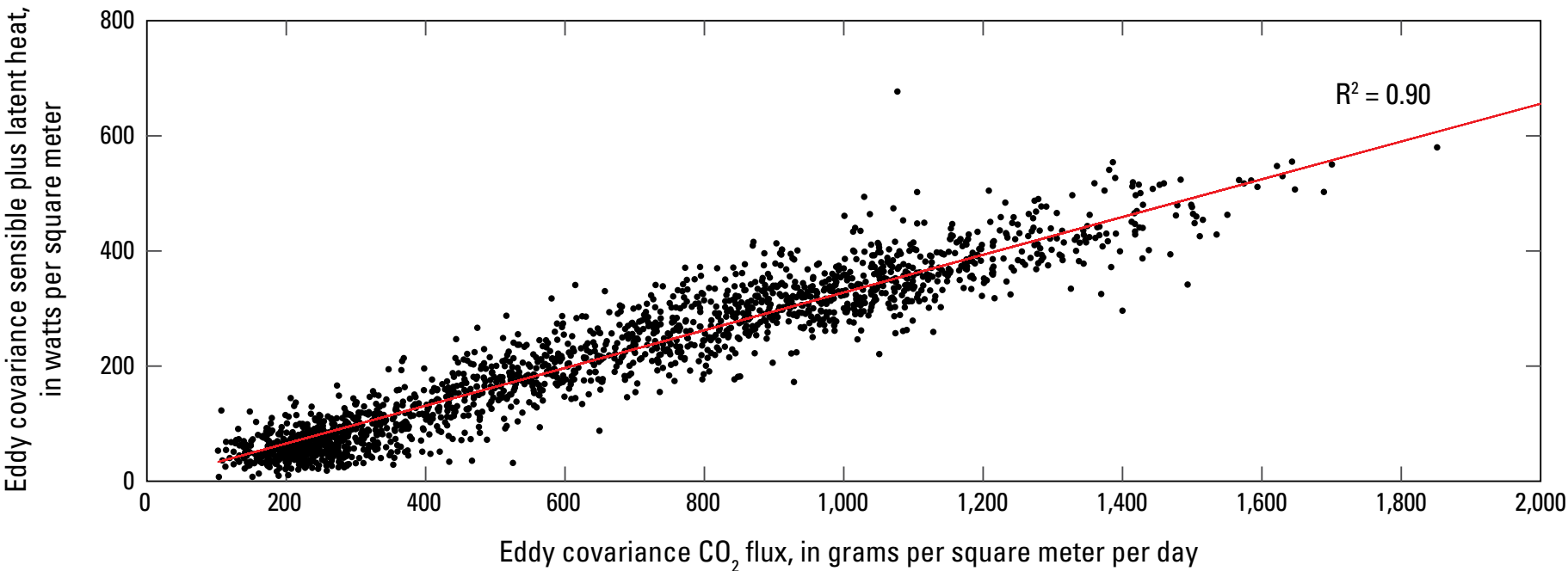

Figure 10. Plot of nighttime eddy covariance sensible plus latent heat flux versus nighttime $\mathrm{CO}_{2}$ flux. 

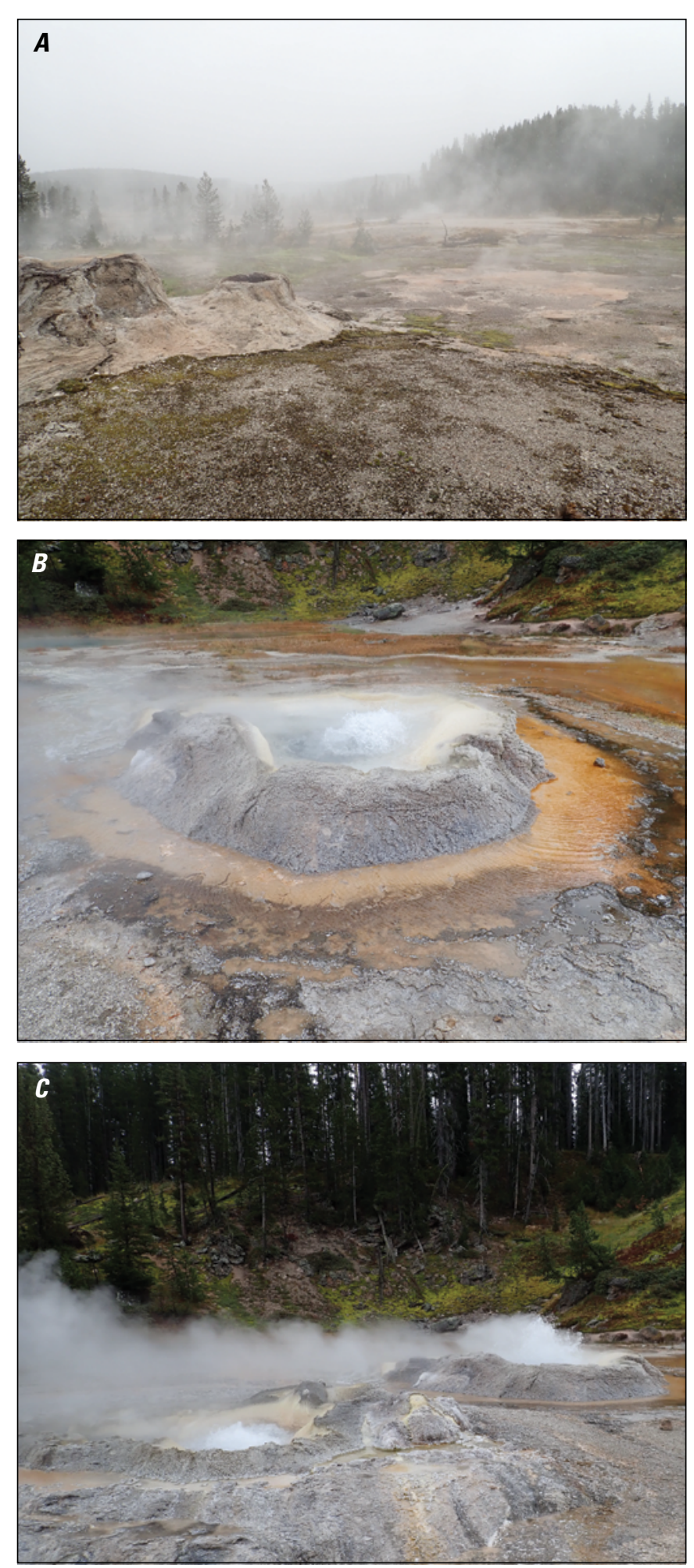

Figure 11. Photographs showing examples of thermal features in Shoshone Geyser Basin. U.S. Geological Survey photographs by Blaine McCleskey taken on September 17, 2019.

\section{Norris Geyser Basin}

Water samples were collected from four features in Norris Geyser Basin and analyzed for major and trace elements, anions, and arsenic and sulfur redox species. Of particular interest was Cinder Pool, whose chemistry and appearance drastically changed in 2018. Numerous water samples have been collected from Cinder Pool over the past 20 years, but recent measurements have indicated a drop in $\mathrm{pH}$ from 4.2 to 3.7 along with lower concentrations of reduced sulfur species. This might explain the cessation of formation of cinders (millimeter-size, black, hollow sulfur spherules) in 2019 compared to previous years, and therefore the lack of black cinders floating on the pool (which gave the feature its name).

\section{Hillside Geyser Basin}

In September 2019, USGS and University of California at Berkeley scientists began investigations of the Hillside group of springs near the Upper Geyser Basin. Discharge from some of the more prominent springs in the Hillside group (Asta and Hillside Springs) is visible at the base of the cliff to the west of the road between Black Sand Geyser Basin and Biscuit Basin. The goal of the campaign was to sample travertine deposits that crop out in the area. These deposits might hold important information on Yellowstone's postglacial climate and hydrothermal activity. A total of ten samples were collected, and chemical and isotopic analyses of these samples has begun.

\section{Obsidian Creek}

Obsidian Creek, which flows along the corridor between Norris Geyser Basin and Mammoth Hot Springs, receives water from several thermal areas and features, including Roaring Mountain, Semi-Centennial Geyser, Clearwater Springs, and Lemonade Creek. To determine the source and fate of solutes, water sampling in conjunction with water discharge measurements was performed at sites along Obsidian Creek and its inflows in September 2019. Arsenic (As), which is found in high concentrations in many geothermal waters, typically remains in rivers and creeks in Yellowstone because it is not commonly consumed in chemical reactions. Obsidian Creek, however, is a sink for arsenic because water flowing from Roaring Mountain, which has a low $\mathrm{pH}$ and is rich in reduced iron, mixes with alkaline waters from Obsidian Creek. Iron is then oxidized and forms precipitates that bond with arsenic. Arsenic concentrations in Obsidian Creek downstream of Roaring Mountain decrease with distance (fig. 12), testifying to this effect. These chemical processes are important to understanding and quantifying river transport of arsenic throughout Yellowstone. 


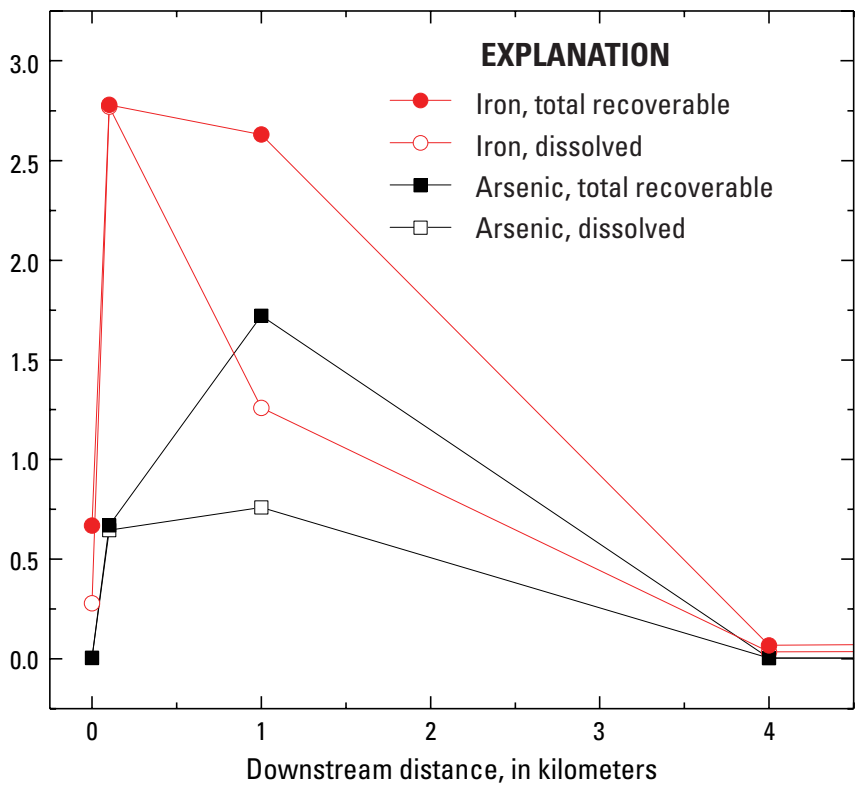

Figure 12. Plot of iron and arsenic concentrations in Obsidian Creek at various distances downstream from Roaring Mountain.

\section{Geology}

Geologic research in Yellowstone National Park is focused on interpreting the rock record as a means of better understanding conditions that preceded and accompanied past eruptions. The primary tools for this work include mapping rock compositions and structures and determining the ages of specific rock units. This work established the foundation for understanding eruptions in the Yellowstone area (see sidebar on the geology of Yellowstone Plateau on p. 22-23) and continues to be refined as new analytical tools become available.

\section{Summary of Geology Activities in 2019}

Geologic research in 2019 included precise dating of lava flows erupted since the most recent caldera-forming eruption about 631,000 years ago as well as continuation of the Hydrothermal Dynamics of Yellowstone Lake (HD-YLAKE) project to explore the geology and hydrothermal features of Yellowstone Lake. The focus of HD-YLAKE activities shifted from the area known as "Deep Hole" in 2016 and 2017 to the West Thumb basin area in 2018. Analysis of the large volume of data and samples collected so far continued in 2019. Preliminary results from the age-determination project indicate the postcaldera lava-flow eruptions were clustered in time during five discrete episodes - a finding similar to flows and domes erupted after the previous caldera-forming eruption 1.3 million years ago (see the 2017 YVO annual report).

\section{Hydrothermal Dynamics of Yellowstone Lake}

The Hydrothermal Dynamics of Yellowstone Lake (HD-YLAKE) project began in late 2015, funded by the National Science Foundation with support from the USGS and the National Park Service (Yellowstone National Park). The project involves scientists from numerous institutions around the world and seeks to understand how Yellowstone Lake hydrothermal systems respond to geological and environmental changes by observing temporal changes in temperature and compositions of hydrothermal fluids, the heat flow of the system, seismicity, water-column processes, and the microbial communities inhabiting the vent fields. The field strategy uses a two-pronged approach: (1) geophysical and geochemical monitoring of the active hydrothermal system over a continuous 2-year period (with instruments deployed annually), and (2) analyses of sediment cores to study the postglacial $(\sim 15,000$-year) history of sedimentary, tectonic, and hydrothermal activity beneath the lake.

In 2019, the final funding year for the project, HD-YLAKE scientists continued to assemble and interpret the myriad data collected over the past 3 years (2016-2018) of active field work and deployment of a full-scale network of instruments on the floor of Yellowstone Lake and around the perimeter of the lake. These data included results from a lake-wide network of pressure-temperature gauges, heat-flow equipment, ten lake-bottom seismometers, and two chemical sensors in active hydrothermal vents (fig. 13). Most samples and data were collected from an area in the northern part of Yellowstone Lake known as "Deep Hole" (2016-2017) and from three distinct thermal sites in the West Thumb basin (2018). Fluids, temperatures, and solids have been collected from the Deep Hole site at water depths of about 110 meters (360 feet), where hydrothermal fluids discharge at temperatures as high as $174^{\circ} \mathrm{C}$. These temperatures are the hottest hydrothermal vent fluids yet measured in Yellowstone National Park.

The eight piston cores (as long as 11.7 meters [38.4 feet]) collected in 2016 from six different geologic environments in the northern part of Yellowstone Lake were compared with four piston cores collected in 1992 in the southern part of Yellowstone Lake and West Thumb basin. Additionally, sediments from two piston cores collected in 2017 in Cub Creek pond, about 4 kilometers (2.5 miles) due east of Yellowstone Lake, and samples from six gravity cores collected in the northern part of the lake were included in this comparison. One of two tephras (from eruptions of the Cascade Range volcanoes Mount Mazama at 7,700 years ago and Glacier Peak at 13,700 years ago) were identified in all but one of the 14 piston cores under analysis, and at least five separate hydrothermal explosion events were identified in the piston cores. Additionally, 6 of the 27 gravity cores collected between 2016 and 2018 were analyzed stratigraphically; three of these cores (all less than 1 meter [3 feet] in length) contain material from what may have been small hydrothermal explosion events, indicating recent hydrothermal activity. Analyses of the cores include continuous measurements 


\section{Geology of Yellowstone Plateau}

The Yellowstone Plateau volcanic field developed through three volcanic cycles that span more than 2 million years and include two of the world's largest known eruptions. About 2.1 million years ago, eruption of the Huckleberry Ridge Tuff produced more than 2,450 cubic kilometers ( 588 cubic miles) of volcanic deposits - enough material to cover the entire state of Wyoming in a layer 10 meters ( 30 feet) thick - and created the large, approximately 75 kilometer (47 mile) wide, Huckleberry Ridge Caldera. A second cycle concluded with the eruption of the much smaller Mesa Falls Tuff around 1.3 million years ago and resulted in formation of the Henrys Fork Caldera. Activity subsequently shifted to the present Yellowstone Plateau and culminated 631,000 years ago with the eruption of the $>1,000$ cubic kilometer ( 240 cubic mile) Lava Creek Tuff and consequent formation of the $45 \times 85$ kilometer $(28 \times 53$ mile $)$ Yellowstone Caldera.
The three extraordinarily large explosive eruptions in the past 2.1 million years each created a giant caldera and spread enormous volumes of hot, fragmented volcanic rocks as pyroclastic flows over vast areas. The accumulated hot ash, pumice, and other rock fragments welded together from their heat and the weight of overlying material to form extensive sheets of hard lava-like rock. In some sections, these welded ash-flow tuffs are more than 400 meters $(1,300$ feet $)$ thick. The ash-flow

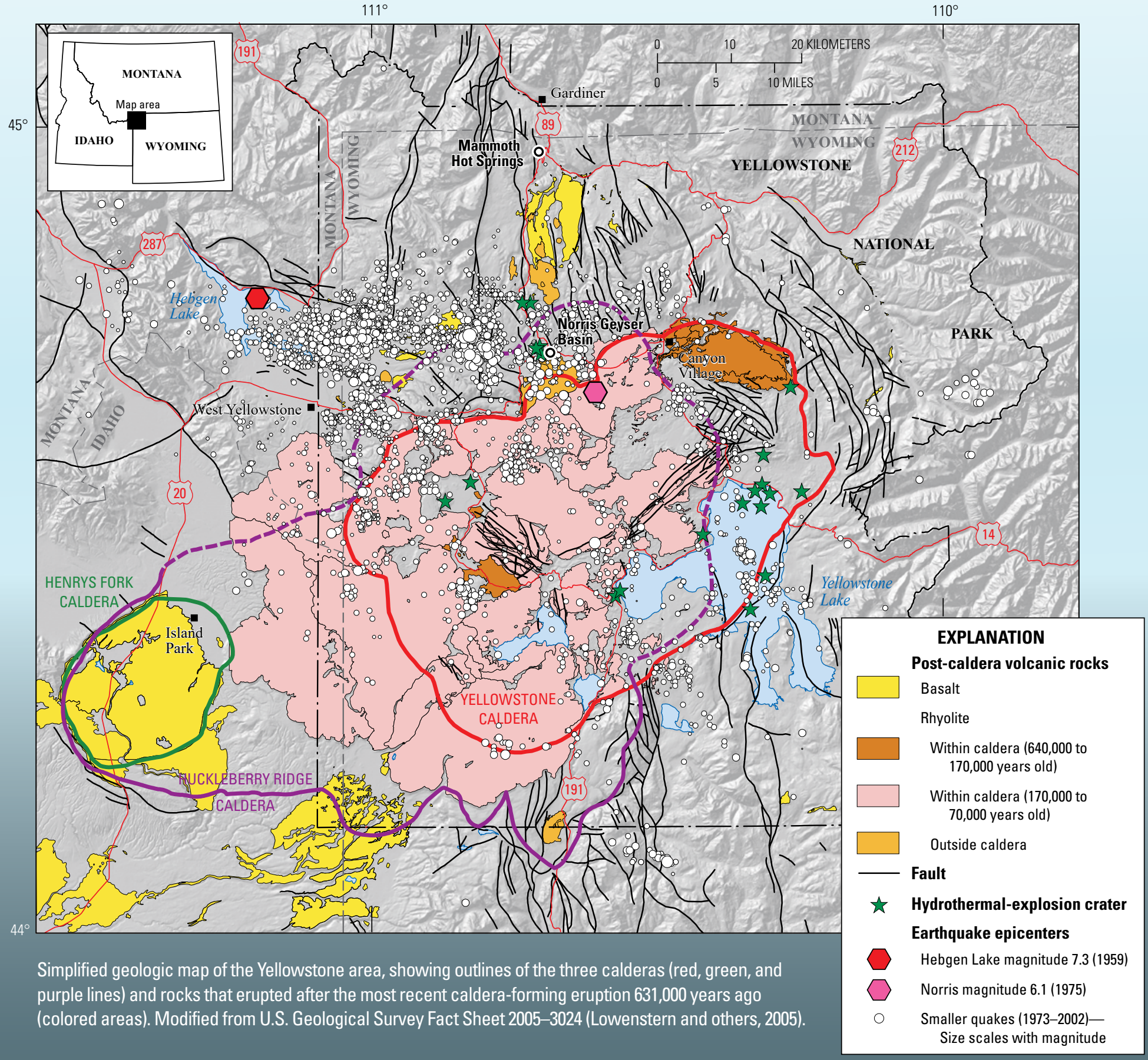


sheets account for more than half the material erupted from Yellowstone Caldera.

Before and after these caldera-forming events, eruptions in the Yellowstone area produced rhyolitic and basaltic rockslarge rhyolite lava flows (pink and orange colors on simplified geologic map on previous page), some smaller rhyolite pyroclastic flows in and near where the calderas collapsed, and basalt lava flows (yellow color on simplified geologic map) around the margins of the calderas.
Large volumes of rhyolitic lava flows (approximately 600 cubic kilometers, or 144 cubic miles) were erupted in the most recent caldera between 170,000 and 70,000 years ago. No magmatic eruptions have occurred since then, but large hydrothermal explosions have taken place since the end of the last ice age in the Yellowstone region, 16,000-14,000 years ago.

Yellowstone Caldera's volcanism is only the most recent in a 17-million-year history of volcanic activity that has occurred progressively from near the common border of southeastern Oregon, northern Nevada, and southwestern Idaho to Yellowstone National Park as the North American Plate has drifted over a hot spot - a stationary area of melting within Earth's interior. At least six other large volcanic centers along this path generated caldera-forming eruptions; the calderas are no longer visible because they are buried beneath younger basaltic lava flows and sediments that blanket the Snake River Plain.

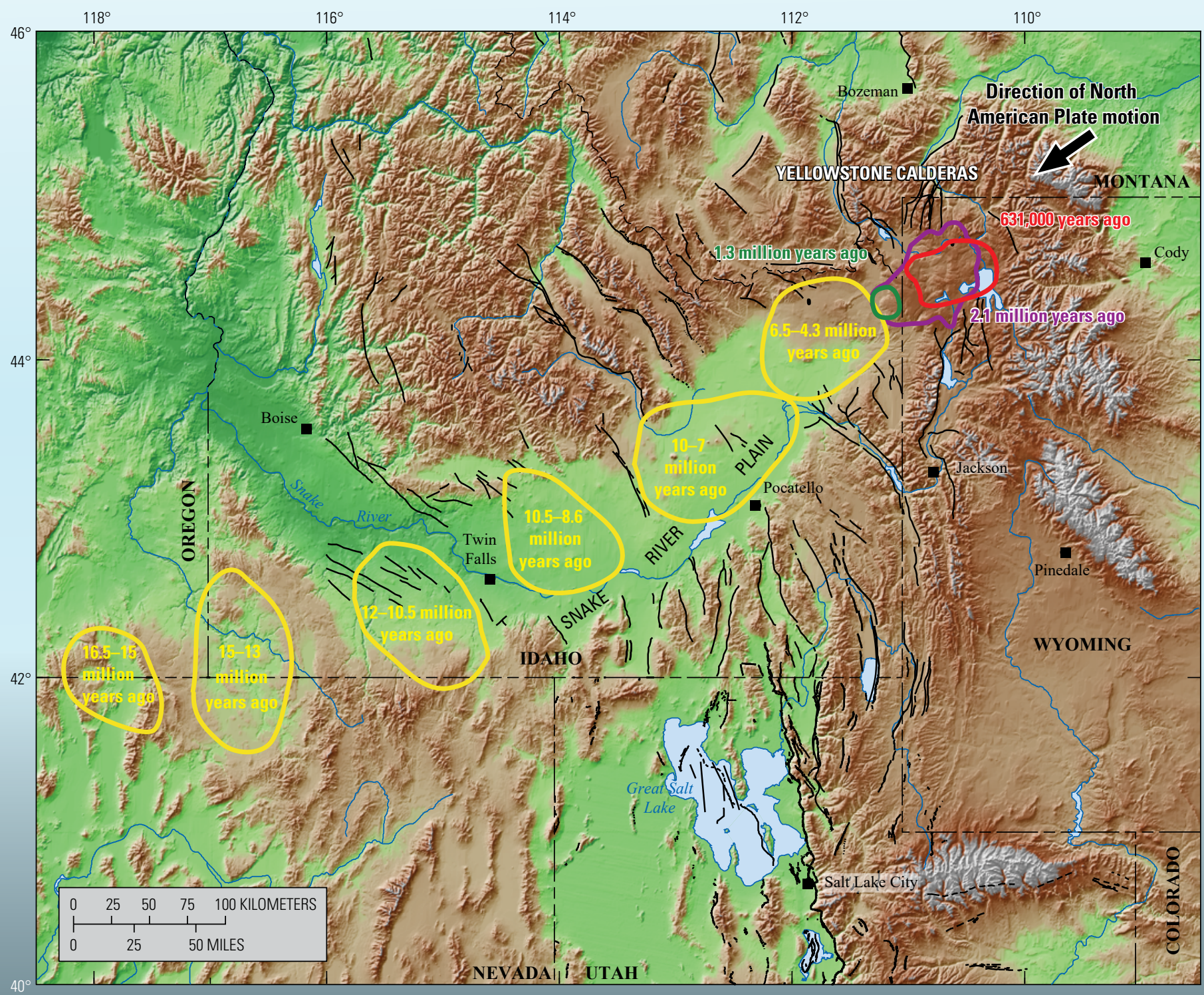

Volcanic centers are outlined where the Yellowstone Hot Spot produced one or more caldera eruptions—essentially "ancient Yellowstones" — during the time periods indicated. As the North American Plate drifted southwest over the hot spot, the volcanism progressed northeast, from the common border of southeastern Oregon, northern Nevada, and southwestern Idaho 16.5 million years ago and reaching Yellowstone National Park about 2 million years ago. Mountains (whites, browns, and tans) surround the low elevations (greens) of the seismically quiet Snake River Plain. The low elevations of the Snake River Plain mark the alignment of past calderas that have since been filled in by lava flows and sediments. Black lines show faults within the region. Modified from Smith and Siegel (2000) with permission. 


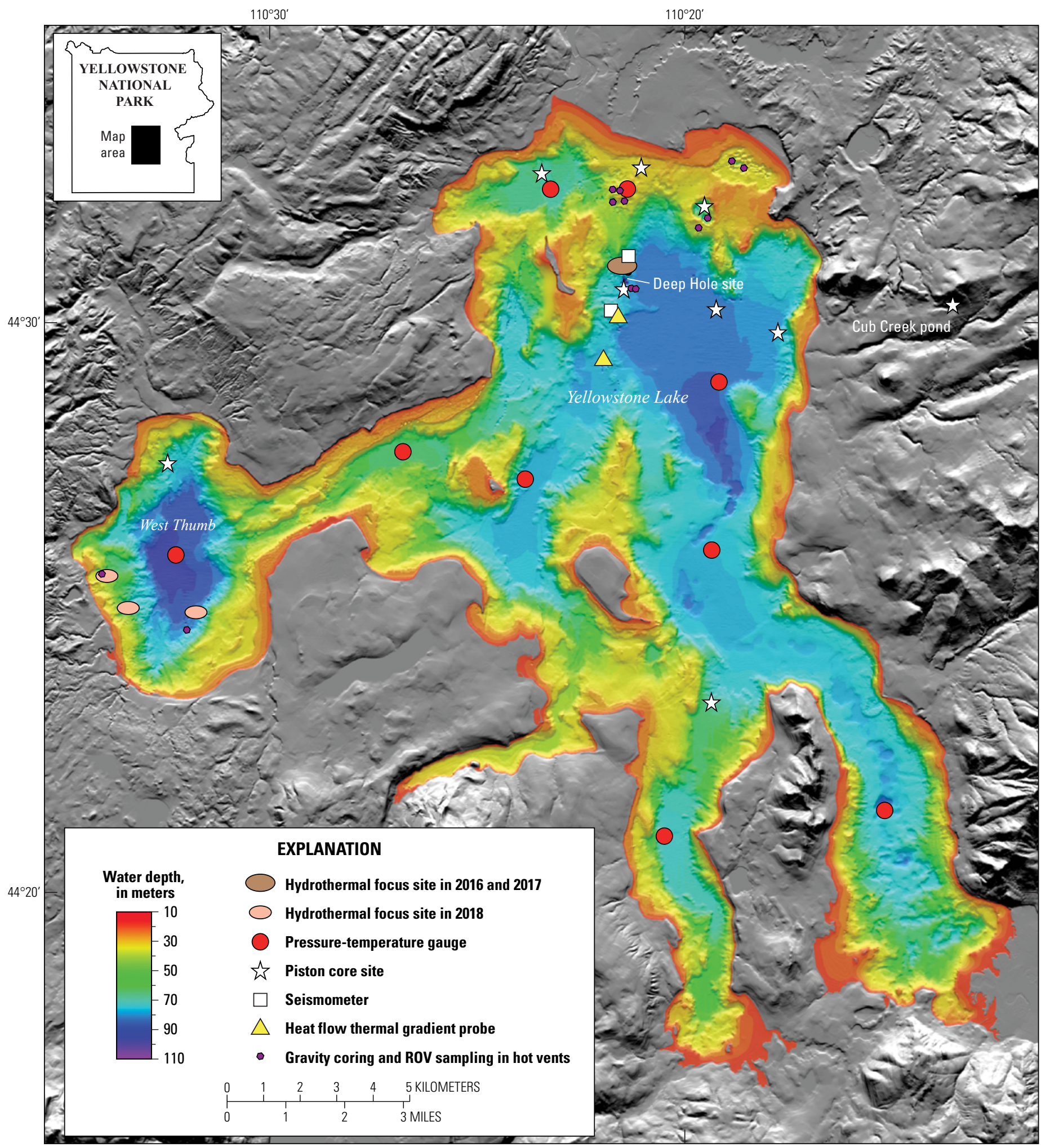

Base from U.S. Geological Survey Scientific Investigations

Map 2973 by Morgan and others (2007)

Figure 13. Bathymetric map of Yellowstone Lake showing locations of instruments deployed in 2016-2018. All instruments have been recovered from the lake floor. Locations of the sediment piston cores collected in 1992, 2016, and 2017 also are shown. 
for density, magnetic susceptibility, selected geothermal elements using scanning X-ray fluorescence, geochemical analyses of solids and pore water, smear slides, and granulometric and component analyses.

\section{Ages of Rhyolite Lava Flows}

Work on constraining the timing of volcanism within the Yellowstone Plateau volcanic field continued during 2019. The goals of this work are to better constrain the timing and periodicity of (1) the most recent episode of rhyolite volcanism within the Yellowstone Plateau volcanic field, which occurred from $\sim 170,000$ to 70,000 years ago and produced the Central Plateau Member rhyolites, and (2) basaltic volcanism throughout the Yellowstone Plateau volcanic field over the past 2 million years. Previous work on dating the Central Plateau Member rhyolites constrains the general timing of eruptions during this episode but lacks the precision to determine any periodicity of volcanism. For example, the large uncertainties on eruption ages estimated in prior studies hamper our ability to assess whether eruptions during this volcanic episode were clustered in time, such that multiple eruptions occurred over a short time interval, as is observed in older intracaldera volcanic episodes at Yellowstone. Age constraints on basalts of the Yellowstone Plateau volcanic field are sparse, and, as a result, little is known about the temporal or spatial relation between basaltic and rhyolitic volcanism at Yellowstone. To improve our understanding of the timing and periodicity of volcanism at Yellowstone, we have applied modern, high-precision ${ }^{40} \mathrm{Ar} /{ }^{39} \mathrm{Ar}$ dating to the Central Plateau Member rhyolites and Yellowstone basalts to better constrain their eruption ages.

The USGS Argon geochronology laboratory in Menlo Park, Calif., made progress on dating the Central Plateau Member rhyolites. In total, eight samples were dated via single-crystal incremental heating of sanidine, and 15 to 20 sanidine grains were analyzed per sample. These results compare with results from 2018 and suggest that the Central Plateau Member rhyolites erupted in five pulses, at approximately 161,000, 151,000,111,000,104,000, and 72,000 years ago. During each of these eruptive pulses, as many as seven rhyolites may have erupted over a span of 1,000 years or less. No Yellowstone basalts were dated in 2019, but 16 samples were prepared for ${ }^{40} \mathrm{Ar} /{ }^{39} \mathrm{Ar}$ analysis to take place in 2020. Additionally, basalt samples for future dating experiments were retrieved from the USGS sample warehouse. Work will continue in 2020 to complete dating the Central Plateau Member rhyolites and Yellowstone basalts.

\section{Heat Flow Studies}

The 10,000+ on-land thermal features of the Yellowstone region range in temperature from just a few degrees Celsius above the normal background temperature to well above boiling (as hot as $138^{\circ} \mathrm{C}$ ). Studies of thermal features are accomplished by ground-based monitoring (including both intermittent observations and continuous temperature monitoring), thermal infrared remote sensing observations from satellite and aircraft, and proxy measurements of chloride in Yellowstone National Park's rivers (see sidebar on monitoring thermal changes on p. 26-27).

\section{Summary of Heat Flow Studies in 2019}

The total radiative heat output from Yellowstone's thermal areas in 2019, as measured by satellite thermal infrared observations, was slightly lower than measured in previous years, whereas heat output based on chloride flux in Yellowstone's rivers was comparable to previous years. Together, the thermal infrared and chloride flux measurements indicate that the total thermal discharge remained relatively steady. The system remains dynamic, however, as evidenced by the 2018 discovery of a new thermal area near Tern Lake (see the 2018 YVO annual report). Scientists visited this thermal area on foot for the first time in 2019 to collect detailed observations of the characteristics of the region.

\section{Thermal Infrared Remote Sensing}

Analysis and interpretation of thermal infrared remote sensing data for characterizing Yellowstone's thermal areas has been ongoing for years. Satellite-based thermal infrared data with moderate spatial resolution (90 to 100 meters per pixel) are useful for mapping, measuring, and monitoring the characteristics of most of Yellowstone's thermal areas on a regional to park-wide scale, although there are challenges. Hot springs and fumarole fields are relatively subtle thermal features compared to extremely hot features like active lavas or fires. This is because they exhibit sub-boiling to boiling temperatures at the surface in areas that are generally small with respect to the pixel size of moderateresolution thermal infrared image data. Even in thermal areas, the majority of the surface heating comes from the sun. The thermal infrared emittance from some thermal areas can be masked, or even exceeded, by rocky sun-facing slopes during the day. Nighttime thermal infrared data are therefore preferred for analysis because this minimizes the effects of solar radiance on surface thermal emission and maximizes thermal contrast between thermal areas and background areas. At night, water bodies are generally warmer and more radiant than the surrounding land surface and are thus another source of surface radiance that can mask thermal areas adjacent to lakes. In Yellowstone, lakes that do not receive thermal input from nearby hot springs or underwater vents are frozen from late winter through early spring. Therefore, nighttime thermal infrared data from January through May are preferred. During these times, cloud-free thermal infrared data can differentiate most thermal areas from ambient background areas, again because of greater thermal contrast, and these data can be used to evaluate surface thermal metrics, such as geothermal radiant heat flux and geothermal radiative power output. Another 


\section{SIDEBAR}

\section{Monitoring Thermal Changes at Yellowstone Caldera}

A lot of heat is released from

Earth's surface in the Yellowstone area. The evidence of this heat flow includes thermal features like hot springs, geysers, mud pots, and fumaroles. Tracking the temperatures and sizes of thermal areas is critical for monitoring Yellowstone Caldera's hydrothermal activity and also for understanding and preserving these spectacular features. The task is challenging, however, given that there are more than 10,000 individual thermal features spread out over a large and mostly inaccessible area within Yellowstone National Park.

Some specific thermal features are continuously monitored with temperature sensors, such as at Norris Geyser Basin. There, thermal probes are connected via radio links so that data within the thermal-monitoring network can be viewed at all times. These thermal probes have proven useful for detecting geyser eruptions when visual observations are impossible (owing to weather or time of day).

Temperature probes can only be used to measure the output of a few specific features. To look at overall thermal output of Yellowstone, other techniques are employedfor instance, tracking the chemistry of the

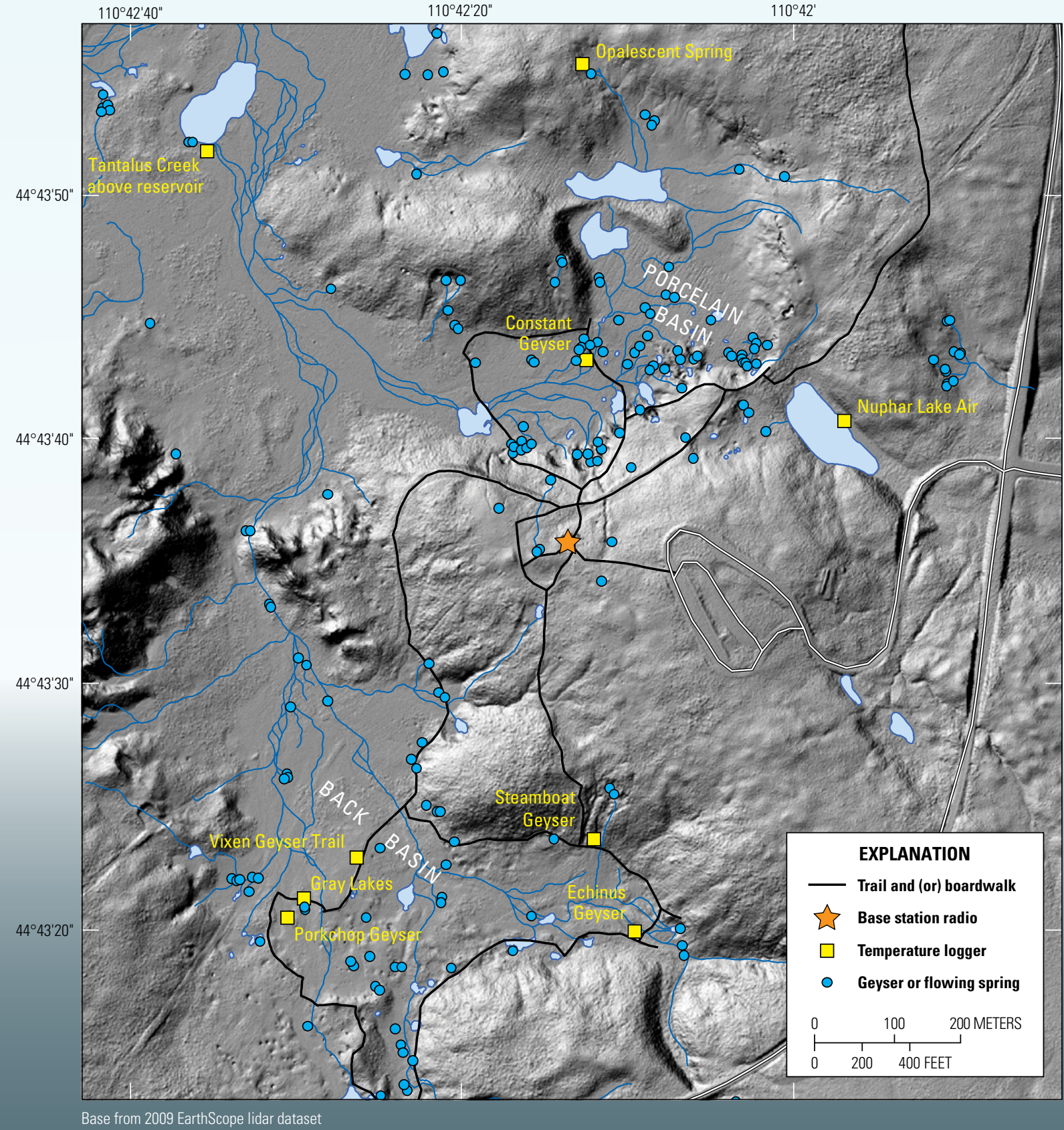

Map of temperature measurement sites in Norris Geyser Basin. 
Yellowstone area's major rivers. Since the hot water from thermal features ultimately ends up in rivers, changes in river chemistry are used to track overall hydrothermal activity. The most useful chemical indicator is the chloride composition of the river water, because hydrothermal water has a high concentration of chloride. In fact, nearly all (95 percent) of the chloride in Yellowstone rivers comes from thermal features. Thus, monitoring the chloride flux in the major rivers in Yellowstone National Park provides an overview of hydrothermal activity. River water samples were once collected periodically and manually to measure chloride, but now measurements of specific conductance (a proxy for chloride) are collected continuously by automated monitoring stations on all the park's major rivers.

Another method for obtaining broad views of Yellowstone Caldera's thermal output is to use satellites, which measure surface temperature and detect changes over time. One of the advantages of satellite-based thermal infrared remote sensing is that researchers can view nearly all of the thermal areas in the park at once. Unfortunately, this broad view comes at a cost - thermal infrared satellite images tend to have low spatial resolution, with pixels that are 90 meters (about 300 feet) on a side. Nevertheless, thermal infrared images of Yellowstone National Park have enough detail to make maps of temperature anomalies, which are especially useful in areas that are not easily accessible.

Satellite thermal infrared temperature anomaly map of Yellowstone National Park's thermal areas based on a Landsat-8 image from April 20, 2017. The warmest areas (yellow) are $20-30^{\circ} \mathrm{C}$ (68-86 ${ }^{\circ} \mathrm{F}$ ) above background; the cooler areas (purple) are $2-3^{\circ} \mathrm{C}\left(36-37^{\circ} \mathrm{F}\right)$ above background. By comparing maps like this for different times, scientists assess changes in thermal areas over time and estimate the total heat output from the Yellowstone region.

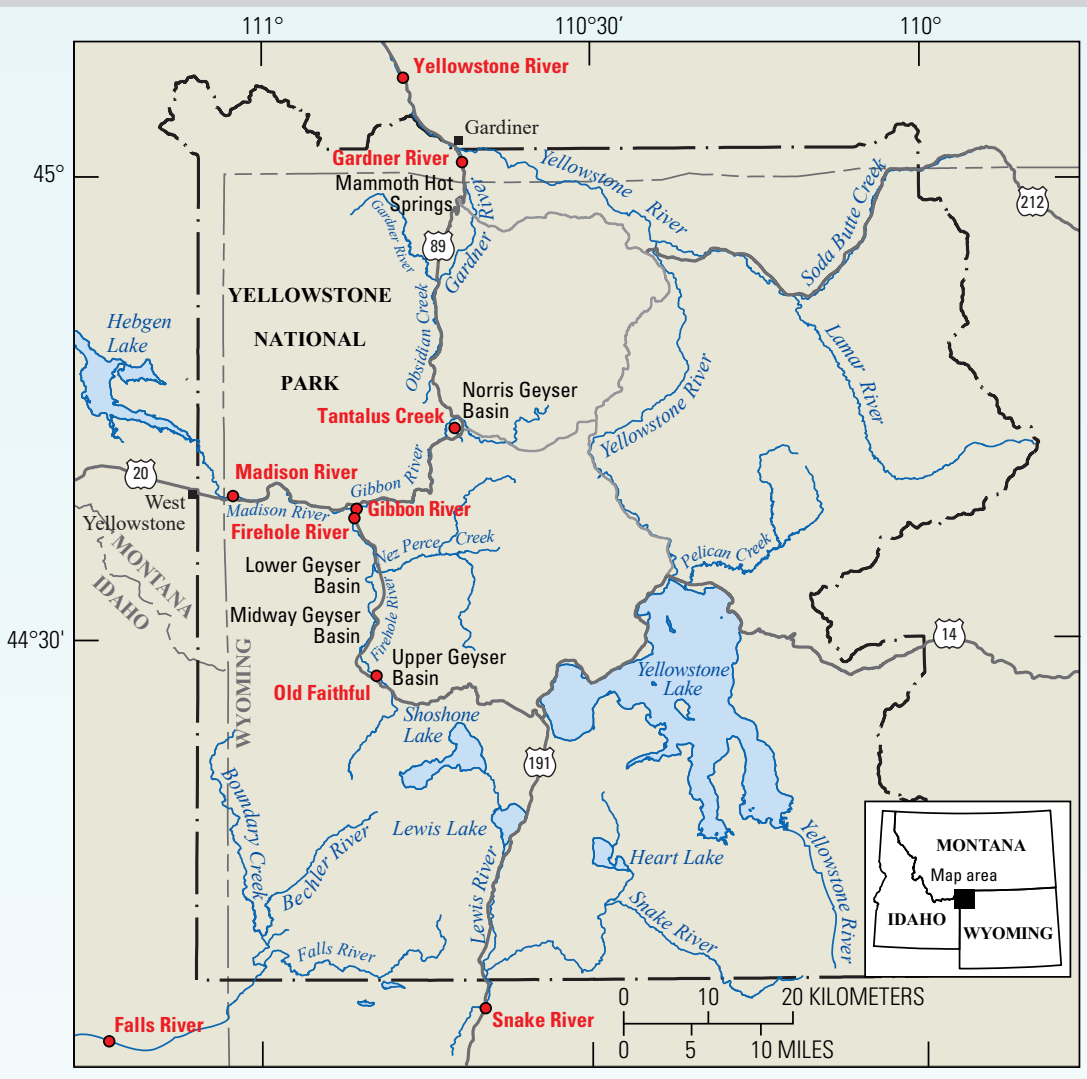

Map showing river chemistry monitoring sites (red dots) in Yellowstone National Park.

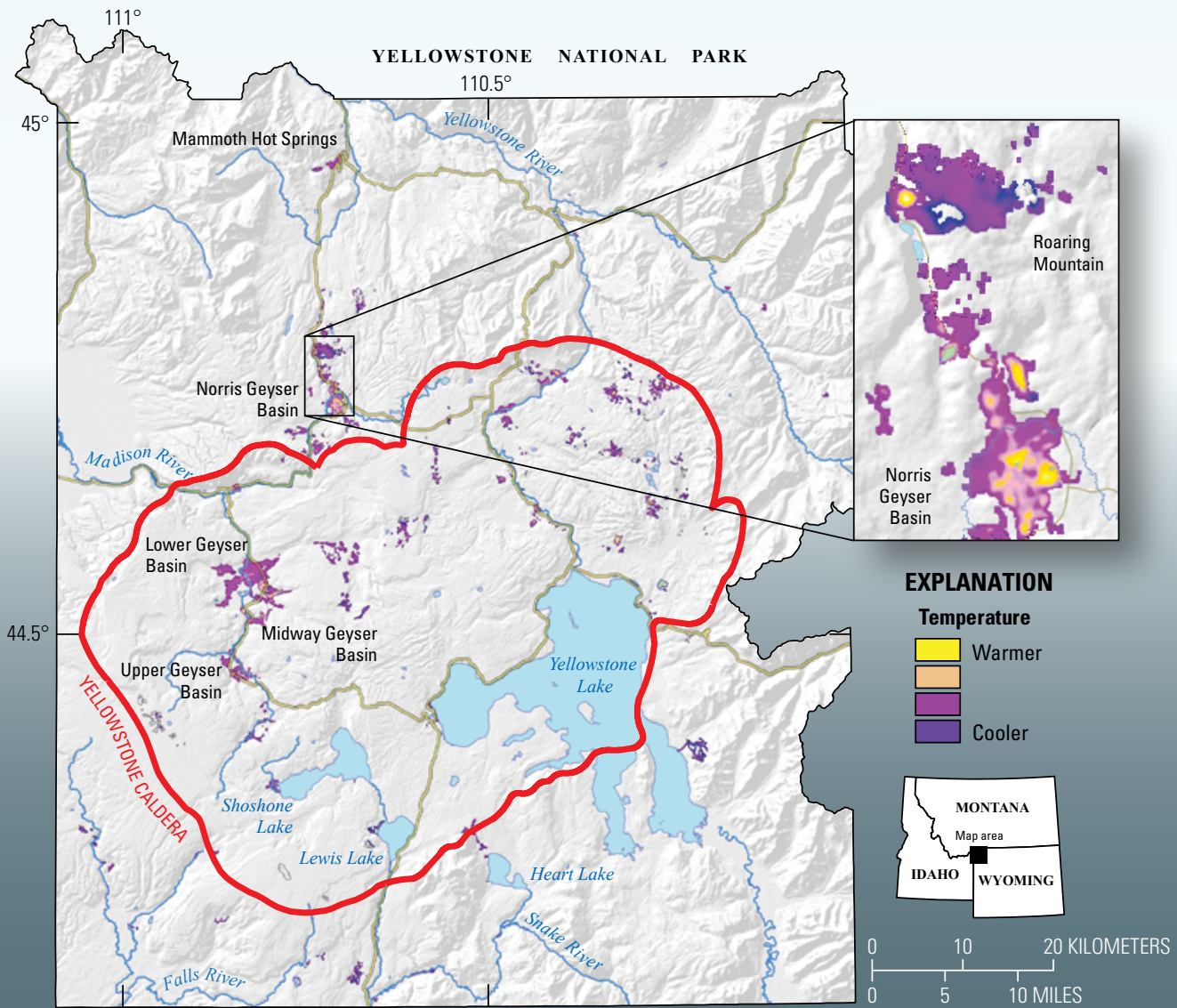

Base from 30-meter National Elevation Dataset 
advantage of wintertime data is their utility for characterizing thermal input to lakes. Thermal infrared images acquired in April and May commonly reveal lakes that have thermal input, either from underwater vents or from nearby hot springs. These data have revealed the presence of warm vents and springs not previously cataloged in the thermal vent inventory database.

Data from the Advanced Spaceborne Thermal Emission and Reflection Radiometer (ASTER) instrument aboard the National Aeronautics and Space Administration's Terra satellite have been acquired intermittently over parts of Yellowstone since the year 2000. In 2019, there were 14 dates with ASTER scenes (seven

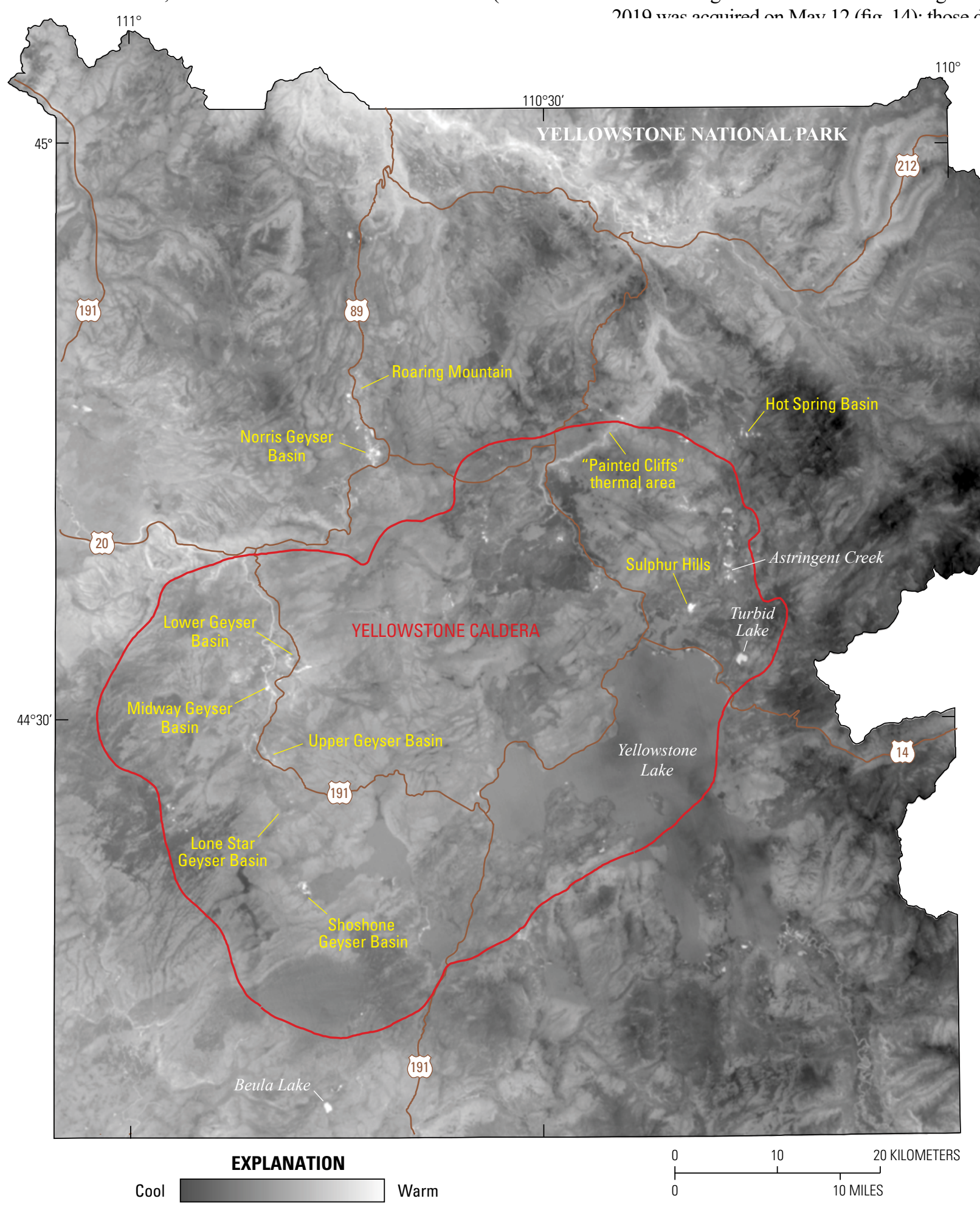

nighttime and seven daytime) that covered parts of Yellowstone, of which four were mostly cloud free, including one nighttime scene in January and one in April. Landsat-8 thermal infrared data cover the entire park in a single scene and have been regularly acquired since 2013, nominally every 16 days. In a given year, Landsat-8 will acquire at most 44 scenes over Yellowstone (half during the day and half at night), although nighttime scenes are not always acquired owing to on-orbit calibration events or data capacity limitations. In 2019, 20 Landsat-8 nighttime scenes were acquired, five of which were clear to mostly cloud free. The earliest clear Landsat- 8 nighttime thermal infrared image over Yellowstone in

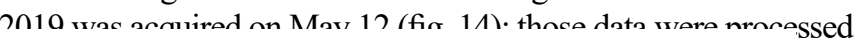


The results of analyses of the May 12, 2019, Landsat-8 thermal infrared data were similar to analyses from previous years. The thermal areas with the highest pixel temperatures above background were Sulphur Hills, Midway Geyser Basin, and Lower Geyser Basin. The thermal areas with the highest geothermal radiant emittance (in watts per square meter) were Sulphur Hills, Shoshone and Lone Star Geyser Basins, and two large lakes with significant thermal input, Beula Lake and Turbid Lake. The thermal areas with the highest total geothermal radiative power output (in megawatts) include Norris, Lower, Midway, Upper, and Hot Spring geyser basins, Astringent Creek, Roaring Mountain, and the area known as "Painted Cliffs." Summation of the geothermal radiative power output for all of Yellowstone's thermal areas measured from the May 12, 2019, Landsat- 8 thermal infrared data is about 1.1 gigawatts. This is lower than the 1.3 gigawatts determined during the previous 2 years (see the 2017 and 2018 YVO annual reports). The reason for this lower value is unclear at this time. It may reflect seasonal, climate, or weather effects, or it might just be the natural variation of the system. Future work will seek to address this question.

\section{Tern Lake Thermal Area}

In August 2019, a field visit was made to the thermal area that was discovered in 2018 near Tern Lake, on the east side of Yellowstone National Park (fig. 15; see the 2018 YVO annual report). The visit included both on-the-ground measurements and a helicopter overflight with a thermal infrared camera. The overview provided by the aerial imagery showed that the warmest zone was an arch-shaped region in the central part of the tree-kill area, although some young trees, which clearly started growing after the initial formation of the thermal area more than a decade ago, were in close proximity to the hot areas (fig. 16). Surface temperatures in the hottest zone were $70-80{ }^{\circ} \mathrm{C}$ and had boiling temperatures $\left(92{ }^{\circ} \mathrm{C}\right.$ at that elevation) just beneath the surface. There were several areas of steaming fumaroles that had boiling temperatures at the surface and sulfur crystals forming around the fumarole edifices. Trees that had fallen in the warmest zone were blackened and partly decomposed (oxidized) into carbon on the sides facing or in contact with the warm ground.

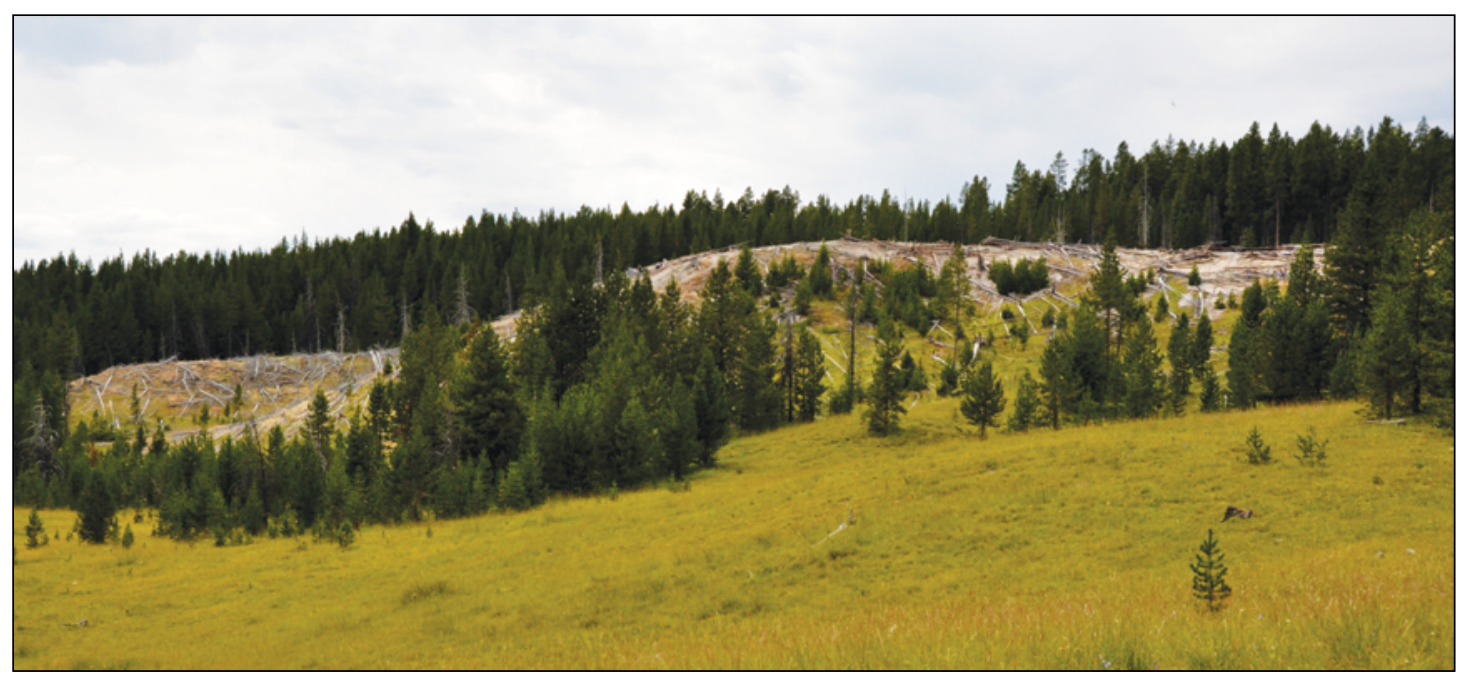

Figure 15. Photograph of the newly discovered thermal area near Tern Lake. U.S. Geological Survey photograph by Mike Poland on August 20, 2019.
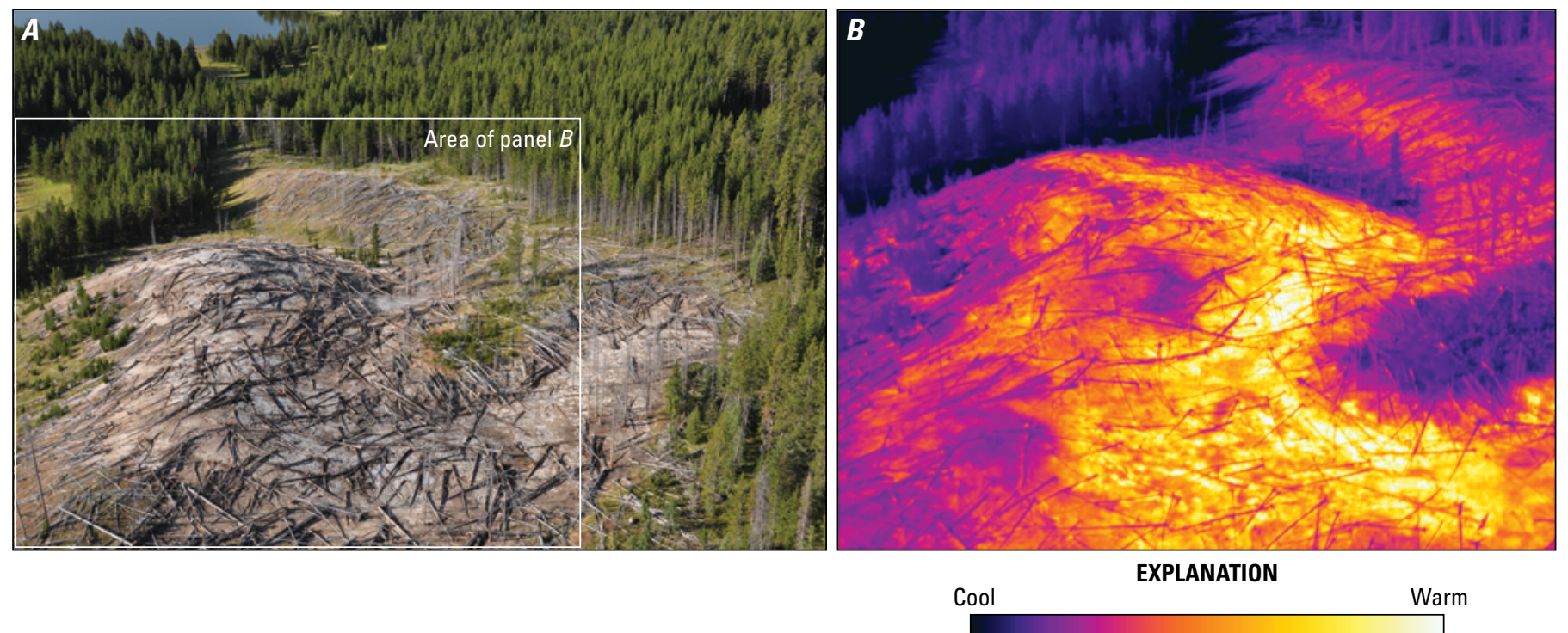

Figure 16. Aerial visible (left) and corresponding thermal (right) images of the newly discovered thermal area near Tern Lake. U.S. Geological Survey photographs by Mike Poland (visible) and R. Greg Vaughan (thermal) on August 19, 2019. 
These observations confirm that the feature is a steam-heated acid-sulfate thermal area with no liquid water discharging at the surface. The presence of young trees suggests the possibility that this new thermal area has stabilized and is no longer growing, allowing zones of new trees to return to cooler areas of the initial tree-kill area. In the coming years, continued monitoring of this new site will answer the question of whether it is expanding or shrinking, heating or cooling, or maintaining its current configuration and temperature.

\section{Chloride Flux Monitoring}

Tracking changes in river chemistry is important to identify overall changes in Yellowstone's hydrothermal system. There are more than 10,000 hydrothermal features scattered throughout Yellowstone National Park, and their discharges ultimately reach a major river, which acts as a collection and delivery system for thermal water. Nearly all of the chloride in the rivers that drain Yellowstone comes from emerging hot spring water heated underground by underlying magma. Monitoring chloride flux in major rivers is thus an effective way to estimate total heat output from Yellowstone's hydrothermal system. By tracking temporal variations in chloride flux, changes in heat flux from Yellowstone can be estimated.

The USGS and Yellowstone National Park have collaborated on chloride flux monitoring in the park since the 1970s, mostly by collecting water samples, measuring chloride concentrations in the samples, and combining that information with river discharge measurements to calculate chloride flux. Beginning in 2010, the USGS installed stations along major rivers to automatically measure specific conductance (an indication of how well water conducts an electrical current), which can be used as a proxy for chloride concentration and other solutes. The use of specific conductance also allows for continuous measurements every 15 minutes. In 2019, many of the specific conductance probes were fitted with a telemetry system so real-time measurements could be captured. Specific conductance measurements were made at monitoring sites along the Madison, Firehole, Gibbon, Snake, Gardner, Yellowstone, and Fall Rivers (see sidebar on monitoring thermal changes on p. 26-27).

In 2019, the total chloride flux leaving Yellowstone was 52.4 kilotons, which was determined by adding the fluxes measured from the Madison, Yellowstone, Snake, and Fall Rivers. The 2019 chloride flux was consistent with historical measurements of 52.6 \pm 4.1 kilotons (from 1983-2003 and 2013-2018). Furthermore, the percentages of the total flux from the Madison (44 percent), Yellowstone (34 percent), Snake (11 percent), and Fall (11 percent) Rivers for 2019 were similar to previous determinations (see the 2018 YVO annual report). The total heat output for 2019 was estimated using the chloride inventory method to be 5,990 megawatts, if all the chloride discharged by the rivers that drain Yellowstone is derived from a single deep fluid with a chloride concentration of 400 milligrams per liter and a temperature of $340^{\circ} \mathrm{C}$. The heat output for 2019 was consistent with previous estimates ranging from 4,000 to 8,000 megawatts.

\section{Geysers and Hot Springs}

Yellowstone hosts more than 10,000 thermal features, including geysers, hot springs, fumaroles, and mud pots. These features are incredibly dynamic, displaying a range of behaviors that vary over time. Some geysers, especially those that exist in comparative isolation, like Old Faithful, follow patterns that allow their activity to be forecast. However, the vast majority of Yellowstone's geysers, springs, and other thermal features have unpredictable behavior.

\section{Summary of Geyser Activity in 2019}

Noteworthy geyser activity in Yellowstone National Park during 2019 was dominated by water eruptions from Steamboat Geyser, the tallest active geyser in the world. The year also saw continued efforts to document thermal features in Yellowstone National Park, focusing on the Upper Geyser Basin, and also to establish patterns in hydrothermal activity over time using tree ring data.

\section{Steamboat Geyser}

Steamboat Geyser is a prominent feature of Norris Geyser Basin. The geyser typically experiences frequent minor eruptions that include water splashing as high as a few meters above the vent and infrequent major eruptions (that have water columns more than 100 meters [300 feet] in height) separated in some cases by several years. The geyser has a history, however, of entering phases of more frequent major eruptions, as in the 1960s and 1980s, when dozens of eruptions occurred, separated by only days to weeks.

In 2018, Steamboat Geyser entered a new phase of increased activity, with 32 major water eruptions - a new record for a single calendar year (see the 2018 YVO annual report). That trend continued in 2019 with 48 major eruptions (table 1), shattering the record set during the previous year. Each eruption of Steamboat Geyser followed the same general pattern: gradually increasing minor activity over hours to days, culminating in a major water eruption that lasts tens of minutes. A steam phase (fig. 17), lasting for about a day, follows the water eruption, and the minor activity ceases for several days until the buildup to the next eruption begins and the cycle repeats. Also, as is common with Steamboat Geyser eruptions, Cistern Spring, located about 100 meters (300 feet) downslope, drains within a day of each eruption and then gradually refills over the following days (fig. 18).

Times between eruptions in 2019 varied widely, from a little more than 3 days (a new record for the shortest time between major eruptions) to more than 17 days. YVO used three indicators to detect eruptions of Steamboat Geyser: (1) increased seismic noise recorded at a seismometer located in Norris Museum, about 300 meters $(\sim 1,000$ feet) from the geyser, (2) a spike in temperature recorded on the temperature probe in the geyser's outflow channel, and (3) a spike in discharge recorded at the Tantalus Stream gage, through which all water from Norris Geyser Basin hydrothermal features passes. All these data are freely 
Table 1. Water eruptions of Steamboat Geyser in 2019.

\section{Eruption date and time \\ January 4, 2019, 4:19 p.m. \\ January 16, 2019, 7:12 a.m. \\ January 25, 2019, 12:32 p.m. \\ February 1, 2019, 3:21 p.m. \\ February 8, 2019, 8:46 p.m. \\ February 16, 2019, 1:06 a.m. \\ February 25, 2019, 11:42 a.m.}

March 4, 2019, 11:39 p.m.

March 11, 2019, 1:54 a.m.

March 17, 2019, 2:54 p.m.

March 25, 2019, 5:37 p.m.

April 8, 2019, 8:44 p.m.

April 25, 2019, 10:25 p.m.

May 3, 2019, 2:20 a.m.

May 8, 2019, 8:01 a.m.

May 13, 2019, 7:56 p.m.

May 20, 2019, 3:23 p.m.

May 27, 2019, 5:30 p.m.

June 1, 2019, 8:47 p.m.

June 7, 2019, 1:13 a.m.

June 12, 2019, 12:52 p.m.

June 15, 2019, 4:40 p.m.

June 19, 2019, 2:20 a.m.

June 23, 2019, 12:46 p.m.

June 28, 2019, 11:44 p.m.

July 4, 2019, 1:16 a.m.

July 10, 2019, 7:09 p.m.

July 18, 2019, 6:12 a.m.

July 24, 2019, 1:57 a.m.

July 30, 2019, 7:21 a.m.

August 12, 2019, 10:23 p.m.

August 20, 2019, 12:51 p.m.

August 27, 2019, 10:47 a.m.

September 3, 2019, 2:34 a.m.

September 11, 2019, 9:40 p.m.

September 17, 2019, 11:42 p.m.

September 25, 2019, 6:22 a.m.

October 1, 2019, 12:53 p.m.

October 7, 2019, 8:45 p.m.

October 16, 2019, 3:51 a.m.

October 22, 2019, 1:16 p.m.

October 30, 2019, 3:54 p.m.

November 8, 2019, 3:59 a.m.

November 17, 2019, 12:29 p.m.

November 27, 2019, 12:47 a.m.

December 8, 2019, 4:53 p.m.

December 18, 2019, 3:42 p.m.

December 26, 2019, 9:34 p.m.

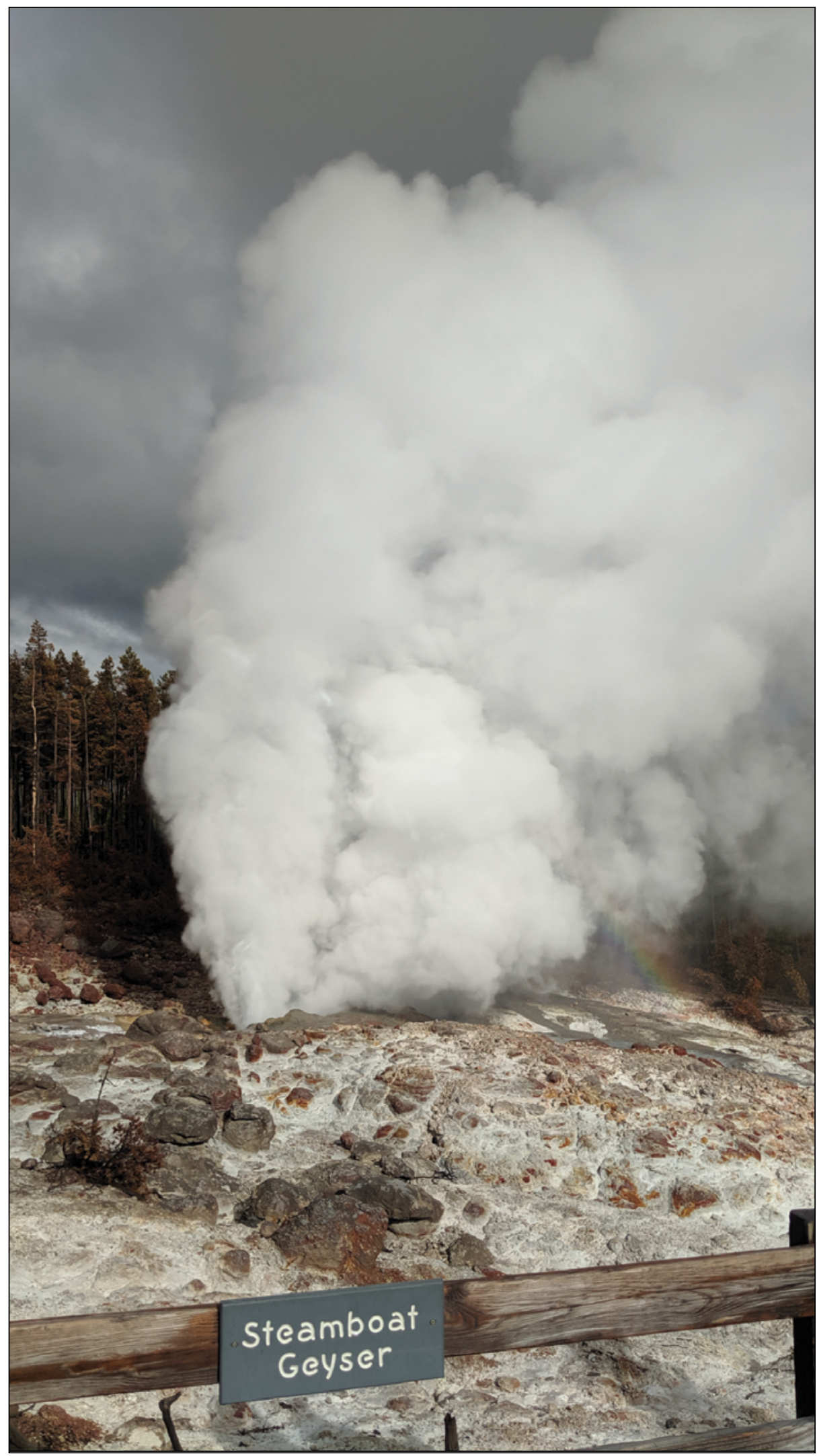

Figure 17. Photograph of the steam phase of a Steamboat Geyser eruption. Image was taken at 6:01 p.m. Mountain Daylight Time on May 20, 2019, about 3 hours after the water phase of the eruption on that day. U.S. Geological Survey photograph by Mike Poland. 


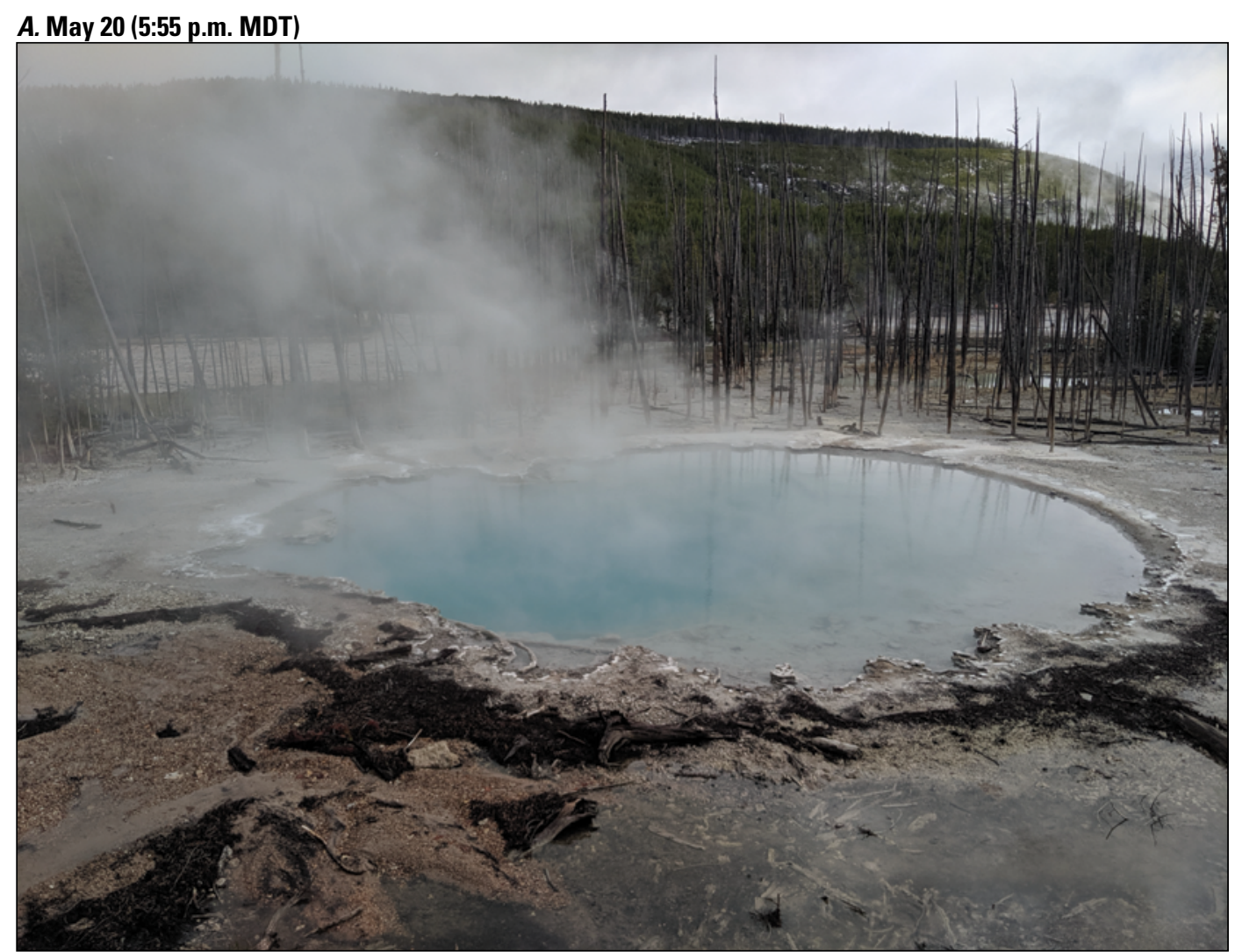

B. May 21 (10:47 a.m. MDT)

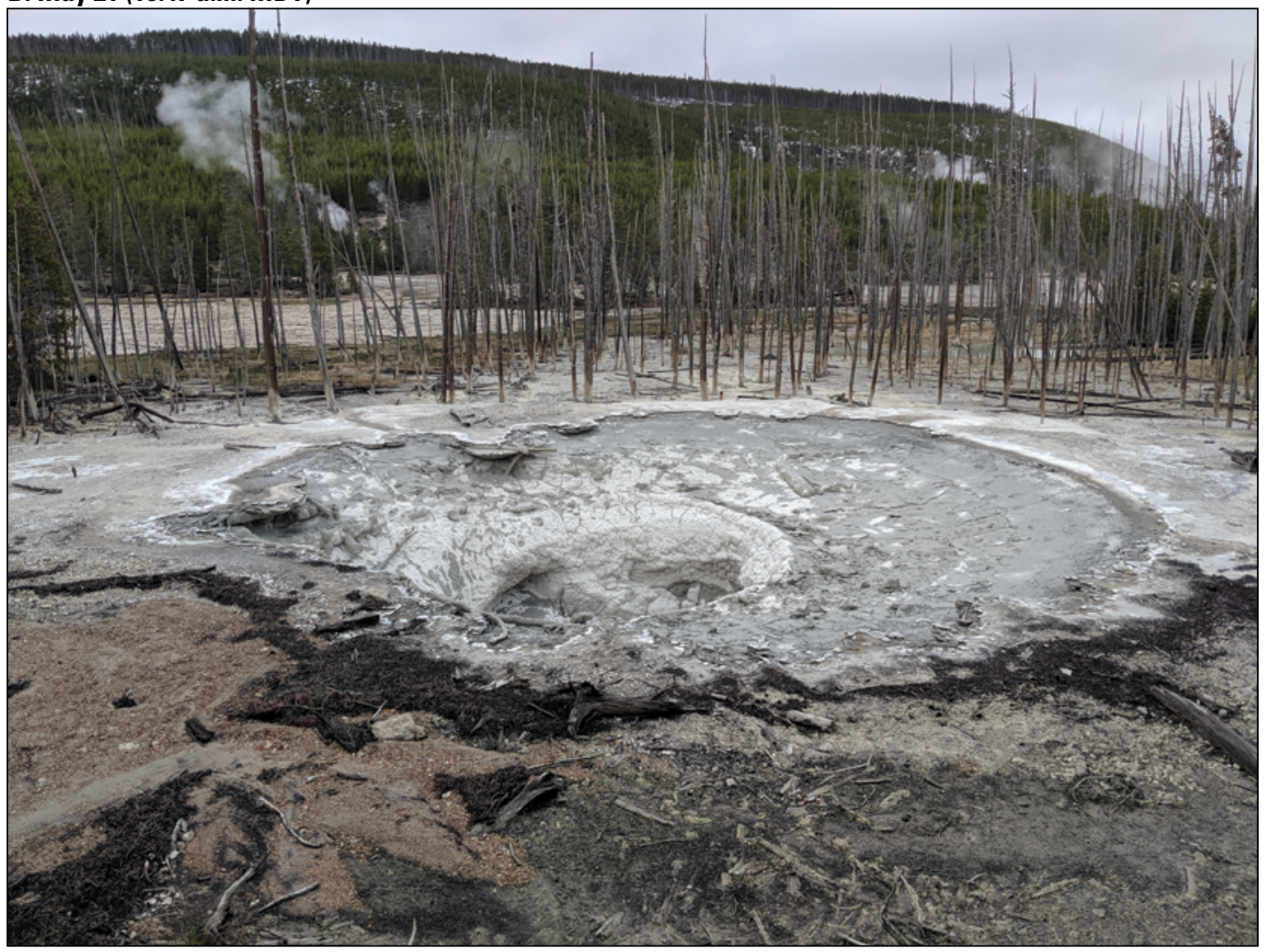

Figure 18. Photographs of Cistern Spring showing the draining behavior that occurs after major water eruptions of Steamboat Geyser. $A$, About 2.5 hours after the onset of a major eruption. $B$, About 19.5 hours after that eruption. U.S. Geological Survey photographs by Mike Poland. 
available on the YVO website, accessible at https://volcanoes.usgs. gov/volcanoes/yellowstone/monitoring_map.html.

\section{Upper Geyser Basin Dendrochronology}

In April 2019, USGS scientists collaborated with dendrochronologist (tree ring expert) John King to sample tree cores from around the Upper Geyser Basin. The goal of the work is to establish variations in the hydrothermal system over time by examining tree growth patterns. Tree rings from samples located within hydrothermal areas will be compared to rings from trees outside regions of hydrothermal activity to establish how tree growth patterns varied in response to changes in thermal activity. When completed, this work may provide insights into temporal variations in hydrothermal activity — a parameter that is poorly known prior to historical records owing to the difficulty of dating hydrothermal deposits.

\section{Hydrothermal Feature Survey}

In 2019, the Yellowstone National Park Geology Program continued its multi-year effort to visit and document every hydrothermal feature in the park, building on a previous survey completed during 1998-2007. In 2018, the hydrothermal feature inventory project documented 916 features identified in Norris Geyser Basin south of the Gibbon River as compared to 493 in the previous inventory. This does not reflect an increase in the number of thermal features, but rather a change in inventory protocol - specifically, the types of features that were included in the inventory. Smaller features that were included or grouped with other features during the first survey have been classified as independent features in the recent survey.

During the 2019 field season, the Geology Program team inventoried another 206 hydrothermal features in Norris Geyser Basin, increasing the number of features inventoried south of the Gibbon River to 1,100. The team then focused efforts on the Upper Geyser Basin and inventoried 1,336 hydrothermal features in the geothermal area where 668 features were documented during the previous inventory project.

The new inventory will support the National Park Service's mission to preserve and protect natural resources for the enjoyment and education of present and future generations and provide a more detailed baseline against which future changes can be compared. In 2020, the Geology Program team will focus its efforts north of the Gibbon River in Norris Geyser Basin area and in the eastern part of the Upper Geyser Basin before moving into the Midway Geyser Basin.

\section{Communications and Outreach}

In 2019, YVO introduced a new outreach product - a video version of the monthly update. Coincident with the release of the regular activity update at the beginning of each month, YVO recorded a video version that discusses seismicity, deformation, geyser eruptions, and other interesting geological activity in Yellowstone that occurred during the preceding month. In addition to being publicized on@USGSVolcanoes Twitter and Facebook accounts, the videos are posted to the USGS YouTube channel at the beginning of each month, available at https://www.youtube. com/user/usgs.

Public events featuring YVO scientists were held in several places during the year. In May, YVO Scientist-in-Charge Mike Poland and USGS Geophysicist Dan Dzurisin spoke to about 75 people in Gardiner, Mont., and Mike and YVO Chief Seismologist Jamie Farrell gave a presentation to nearly 100 people in West Yellowstone, Mont. (fig. 19). In both locations, recent research results and current Yellowstone activity were discussed. In addition, Mike and Idaho Geological Survey Geologist Zach Lifton gave presentations about Yellowstone activity and regional geologic hazards to a regional meeting of Idaho emergency managers in Rexburg, Idaho. University of Utah Seismologist Bob Smith, one of the original founding members of YVO, gave several presentations across the country and throughout the year, including lectures at the University of California at Santa Barbara, Idaho

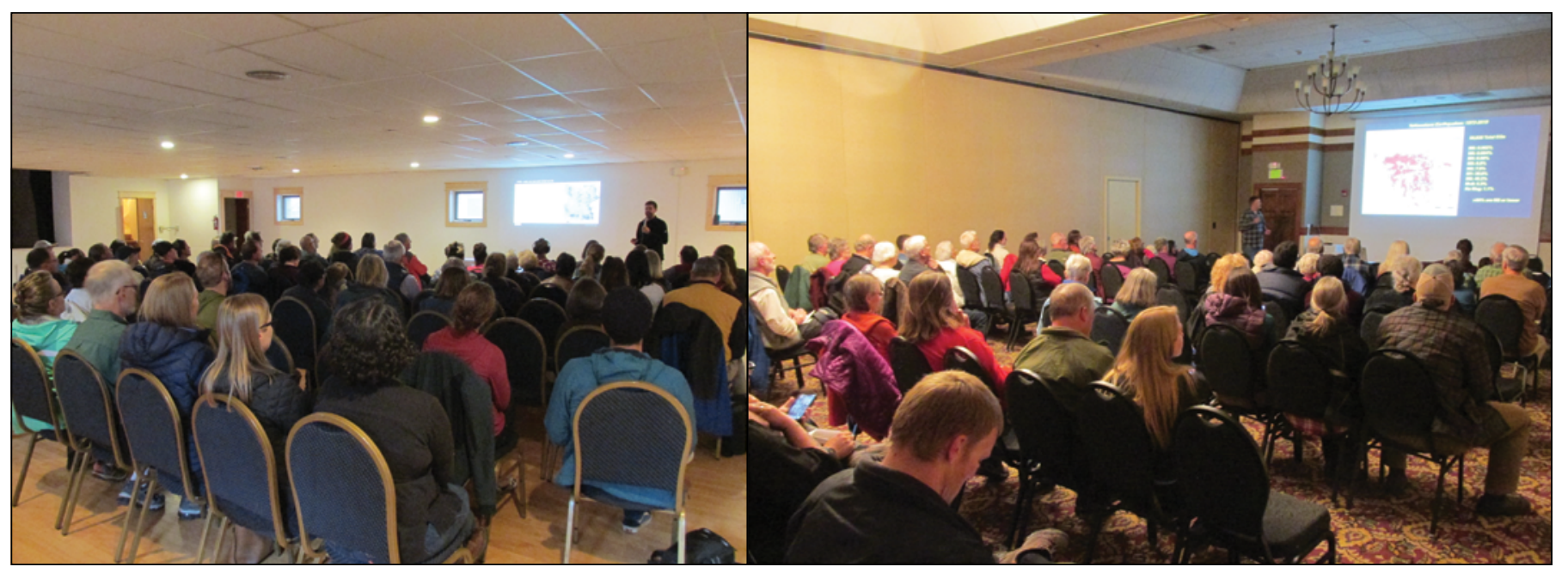

Figure 19. Public talks were given by Yellowstone Volcano Observatory scientists in Gardiner, Montana, on May 16, 2019 (/eft), and in West Yellowstone, Mont., on May 22, 2019 (right). National Park Service photographs by Annie Carlson. 
National Laboratory, Buffalo Bill Center of the West in Cody, Wyo., and to the Geologists of Jackson Hole in Jackson Hole, Wyo.

Finally, the HD-YLAKE project (see Geology section) is preparing an exhibition for the Buffalo Bill Center of the West in Cody, Wyo., that will be on display from April 2021 to April 2022. The exhibit, entitled "What Lies Beneath: Exploring Yellowstone Lake's Mysterious Vents" will include two videos, 25 framed 48- by 36-inch photographs by Chris Linder of Woods Hole Oceanographic Institute, and four large interpretive panels.

\section{Summary}

As in 2018, the most noteworthy activity in 2019 was the continued sequence of major water eruptions at Steamboat Geyser, which, for the second year in a row, set a record for the greatest number of eruptions in a calendar year. Geyser activity is not indicative of changes in the underlying magmatic system, and although the Steamboat Geyser eruptions do not have any implications for volcanic behavior, they have provided an unparalleled opportunity to study the geyser and better understand its shallow plumbing system. Seven eruptions were monitored by a dense array of seismometers in June and July. When fully analyzed, these data will help to reveal the characteristics of the geyser's subsurface structure, and perhaps why it is experiencing a cycle of frequent eruptions. Other monitoring instruments indicated background levels of activity. The number of located earthquakes decreased for the second consecutive year-1,218 in 2019, down from 3,427 in 2017 and 2,007 in 2018 - and by the end of 2019, subsidence was being recorded at GPS stations in the caldera and near Norris Geyser Basin. Yellowstone is dynamic, however, and these trends in seismic and deformation activity are not expected to last long. At some point, earthquake activity will increase and uplift will occur, following the pattern of fluctuating activity that has been established over decades.

Research efforts in 2019 focused on hydrothermal and geological characteristics of Yellowstone. The park hosts one of the world's most extensive and diverse hydrothermal system - a national and world treasure deserving of study and preservation. Geologic investigations into the timing of large lava-flow eruptions that occur during long periods between calderaforming eruptions indicate that multiple flows erupt during closely spaced episodes, rather than spaced more evenly through time. YVO scientists also were able to visit the newest known thermal area in the park - an area of dead trees, altered ground, and steaming cracks that emerged from the forest near Tern Lake over the past 20 years - and continued to sample and analyze thermal waters and gases across the Yellowstone region. Studies based on these data, as well as deployments of geophysical equipment and other monitoring instruments, will continue to form the basis for scientific investigations. New results will also be highlighted in future editions of YVO's weekly series of online articles, Yellowstone Caldera Chronicles, which can be accessed at https://www.usgs.gov/volcanoes/yellowstone/ caldera-chronicles, as well as in annual reports, monthly updates and videos, and public presentations.

\section{Publications}

Bergfeld, D., Lowenstern, J.B., Hunt, A.G., Hurwitz, S., McCleskey, B.R., and Peek, S.E., 2019, Chemical and isotopic data on gases and waters for thermal and non-thermal features across Yellowstone National Park (ver. 2.0, March 2019): U.S. Geological Survey data release, https://doi.org/10.5066/F7H13105.

Bouligand, C., Hurwitz, S., Vandemeulebrouck, J., Byrdina, S., Kass, M.A., and Lewicki, J.L., 2019, Heat and mass transport in a vapor-dominated hydrothermal area in Yellowstone National Park, USA - Inferences from magnetic, electrical, electromagnetic, subsurface temperature, and diffuse $\mathrm{CO}_{2}$ flux measurements: Journal of Geophysical Research, v. 124, no. 1, p. 291-309, https://doi. org/10.1029/2018JB016202.

Brown, S.R., Fritz, S.C., Morgan, L.A., and Shanks, W.C., III, 2019, Fossilized diatoms of siliceous hydrothermal deposits in Yellowstone National Park, USA: Diatom Research, v. 34, p. 193-204, https://doi.org/10.1080/0269249X.2019.1698466.

Dzurisin, D., Lu, Z., Poland, M.P., and Wicks, C.W., 2019, Space-based imaging radar studies of U.S. volcanoes: Frontiers in Earth Science, v. 6, no. 249, https://doi.org/10.3389/ feart.2018.00249.

Farrell, J., Burlacu, R., Roberson, P.M., Hale, J.M., Parapuzha, A., Forbes, N., Koper, K.D., Smith, R.B., Pechmann, J.C., and Pankow, K.L., 2020, Earthquake activity in the Yellowstone region preliminary epicenters October 1-December 31, 2019: University of Utah Seismograph Stations quarterly report, 19 p., available at https://quake.utah.edu/wp-content/uploads/2019Q4-Yell.pdf.

Farrell, J., Burlacu, R., Roberson, P.M., Hale, J.M., Parapuzha, A., Forbes, N., Koper, K.D., Smith, R.B., Pechmann, J.C., and Pankow, K.L., 2019, Earthquake activity in the Yellowstone region preliminary epicenters July 1-September 30, 2019: University of Utah Seismograph Stations quarterly report, 18 p., available at https://quake.utah.edu/wp-content/uploads/2019Q3-Yell.pdf.

Farrell, J., Burlacu, R., Roberson, P.M., Hale, J.M., Parapuzha, A., Forbes, N., Koper, K.D., Smith, R.B., Pechmann, J.C., and Pankow, K.L., 2019, Earthquake activity in the Yellowstone region preliminary epicenters April 1-June 30, 2019: University of Utah Seismograph Stations quarterly report, 15 p., available at https:// quake.utah.edu/wp-content/uploads/2019Q2-Yell.pdf.

Farrell, J., Burlacu, R., Roberson, P.M., Hale, J.M., Parapuzha, A., Forbes, N., Koper, K.D., Smith, R.B., Pechmann, J.C., and Pankow, K. L., 2019, Earthquake activity in the Yellowstone region preliminary epicenters January 1-March 31, 2019: University of Utah Seismograph Stations quarterly report, 17 p., available at https://quake.utah.edu/wp-content/uploads/2019Q1-Yell.pdf.

Fowler, A.P.G., Liu, Q.-L., Huang, Y., Tan, C., Volk, M.W.R., Shanks, W.C.P., III, and Seyfried W., Jr., 2019, Pyrite $\delta^{34}$ S and $\Delta^{33} \mathrm{~S}$ constraints on sulfur cycling at sublacustrine hydrothermal vents in Yellowstone Lake, Wyoming, USA: Geochimica et Cosmochimica Acta, v. 265, p. 148-162, https://doi. org/10.1016/j.gca.2019.09.004. 
Fowler, A.P.G., Tan, C., Cino, C., Scheuermann, P., Volk, M.W.R., Shanks, W.C.P., III, and Seyfried, W.E., Jr., 2019, Vapor-driven sublacustrine vents in Yellowstone Lake, Wyoming, USA: Geology Today, v. 47, p. 223-226, https:// doi.org/10.1130/G45577.1.

Fowler, A.P.G., Tan, C., Luttrell, K., Tudor, A., Scheuermann, P., Shanks, W.C.P., and Seyfried, W.E., 2019, Geochemical heterogeneity of sublacustrine hydrothermal vents in Yellowstone Lake, Wyoming: Journal of Volcanology and Geothermal Research, v. 386, no. 106677, https://doi. org/10.1016/j.jvolgeores.2019.106677.

McCleskey, R.B., Roth, D.A., Hurwitz, S., Bergfeld, D., Peek, S.E., Susong, D.D., White, E.B., Hungerford, J., Hunt, A.G., Paces, J.B., and Olson, L., 2019, Water chemistry data for selected hot springs and rivers in Southwest Yellowstone National Park, Wyoming: U.S. Geological Survey data release, https://doi.org/10.5066/P9MJ0HYM.

McCleskey, R.B., Roth, D.A., Mahony, D., Nordstrom, D.K., Kinsey, S., 2019, Sources, fate, and flux of geothermal solutes in the Yellowstone and Gardner Rivers, Yellowstone National Park, WY: Applied Geochemistry, v. 111, no. 104458, https://doi.org/10.1016/j.apgeochem.2019.104458.

McCleskey, R.B., and Stevens, E.B., 2019, Specific conductance data for selected rivers and creeks in Yellowstone National Park, beginning in 2010: U.S. Geological Survey data release, https://doi.org/10.5066/ F7BP011G.

Pang, G., Koper, K.D., Hale, J.M., Burlacu, R., Farrell, J., and Smith, R.B., 2019, The 2017-2018 Maple Creek earthquake sequence in Yellowstone National Park, USA: Geophysical Research Letters, v. 46, no. 9, p. 4,653-4,663, https://doi. org/10.1029/2019GL082376.

Poland, M.P., and de Zeeuw-van Dalfsen, E., 2019, Assessing seasonal changes in microgravity at Yellowstone caldera: Journal of Geophysical Research Solid Earth, v. 124, no. 4, p. 4,174-4,188, https://doi.org/10.1029/2018JB017061.

Shelly, D.R., and Hardebeck, J.L., 2019, Illuminating faulting complexity of the 2017 Yellowstone Maple Creek earthquake swarm: Geophysical Research Letters, v. 46, no. 5, p. 2,544-2,552, https://doi.org/10.1029/2018GL081607.

Till, C.B., Vazquez, J.A., Stelten, M.E., Shamloo, H.I., and Shaffer, J.S., 2019, Co-existing discrete bodies of rhyolite and punctuated volcanism characterize Yellowstone's post-Lava Creek Tuff caldera evolution: Geochemistry, Geophysics, Geosystems, v. 20, no. 8, p. 3,861-3,881, https://doi.org/10.1029/2019GC008321.

Wu, S-M., Lin, F-C., Farrell, J., and Allam, A., 2019, Imaging the deep subsurface plumbing of Old Faithful geyser from low-frequency hydrothermal tremor migration: Geophysical Research Letters, v. 46, no. 13, p. 7,315-7,322, https://doi. org/10.1029/2018GL081771.

\section{References Cited}

Bergfeld, D., Lowenstern, J.B., Hunt, A.G., Hurwitz, S., McCleskey, B.R., and Peek, S.E., 2019, Chemical and isotopic data on gases and waters for thermal and non-thermal features across Yellowstone National Park (ver. 2.0, March 2019): U.S. Geological Survey data release, https://doi.org/10.5066/ F7H13105.

Dzurisin, D., Wicks, C.W, and Poland, M.P., 2012, History of surface displacements at the Yellowstone Caldera, Wyoming, from leveling surveys and InSAR observations, 1923-2008: U.S. Geological Survey Professional Paper 1788, 68 p., https:// doi.org/10.3133/pp1788.

Lewicki, J.L., Kelly, P.J., Bergfeld, D., Vaughan, R.G. and Lowenstern, J.B., 2017, Monitoring gas and heat emissions at Norris Geyser Basin, Yellowstone National Park, USA based on a combined eddy covariance and MultiGAS approach: Journal of Volcanology and Geothermal Research, v. 347, p. 312-326, https://doi.org/10.1016/j. jvolgeores.2017.10.001.

Lowenstern, J.B., Christiansen, R.L., Smith, R.B., Morgan, L.A., and Heasler, H., 2005, Steam explosions, earthquakes, and volcanic eruptions - What's in Yellowstone's future?: U.S. Geological Survey Fact Sheet 2005-3024, 6 p., https://doi. org/10.3133/fs20053024.

McCleskey, R.B., Roth, D.A., Hurwitz, S., Bergfeld, D., Peek, S.E., Susong, D.D., White, E.B., Hungerford, J., Hunt, A.G., Paces, J.B., and Olson, L., 2019, Water chemistry data for selected hot springs and rivers in southwest Yellowstone National Park, Wyoming: U.S. Geological Survey data release, https://doi.org/10.5066/P9MJ0HYM.

Morgan, L.A., Shanks, W.C, Lee, G.K., and Webring, M.W., 2007, Bathymetry and geology of the floor of Yellowstone Lake, Yellowstone National Park, Wyoming, Idaho, and Montana: U.S. Geological Survey Scientific Investigations Map 2973, 2 sheets, https://doi.org/10.3133/sim2973.

Smith, R.B, and Siegel, L.J., 2000, Windows into the Earth, The Geologic Story of Yellowstone and Grand Teton National Park: New York, Oxford University Press, Inc., 242 p.

Yellowstone Volcano Observatory [YVO], 2006, Volcano and Earthquake Monitoring Plan for the Yellowstone Volcano Observatory, 2006-2015: U.S. Geological Survey Scientific Investigations Report 2006-5276, 13 p., https://doi. org/10.3133/sir20065276.

Yellowstone Volcano Observatory [YVO], 2019, Yellowstone Volcano Observatory 2017 annual report: U.S. Geological Survey Circular 1456, 37 p, https://doi.org/10.3133/cir1456.

Yellowstone Volcano Observatory [YVO], 2021, Yellowstone Volcano Observatory 2018 annual report: U.S. Geological Survey Circular 1474, 38 p, https://doi.org/10.3133/cir1474. 


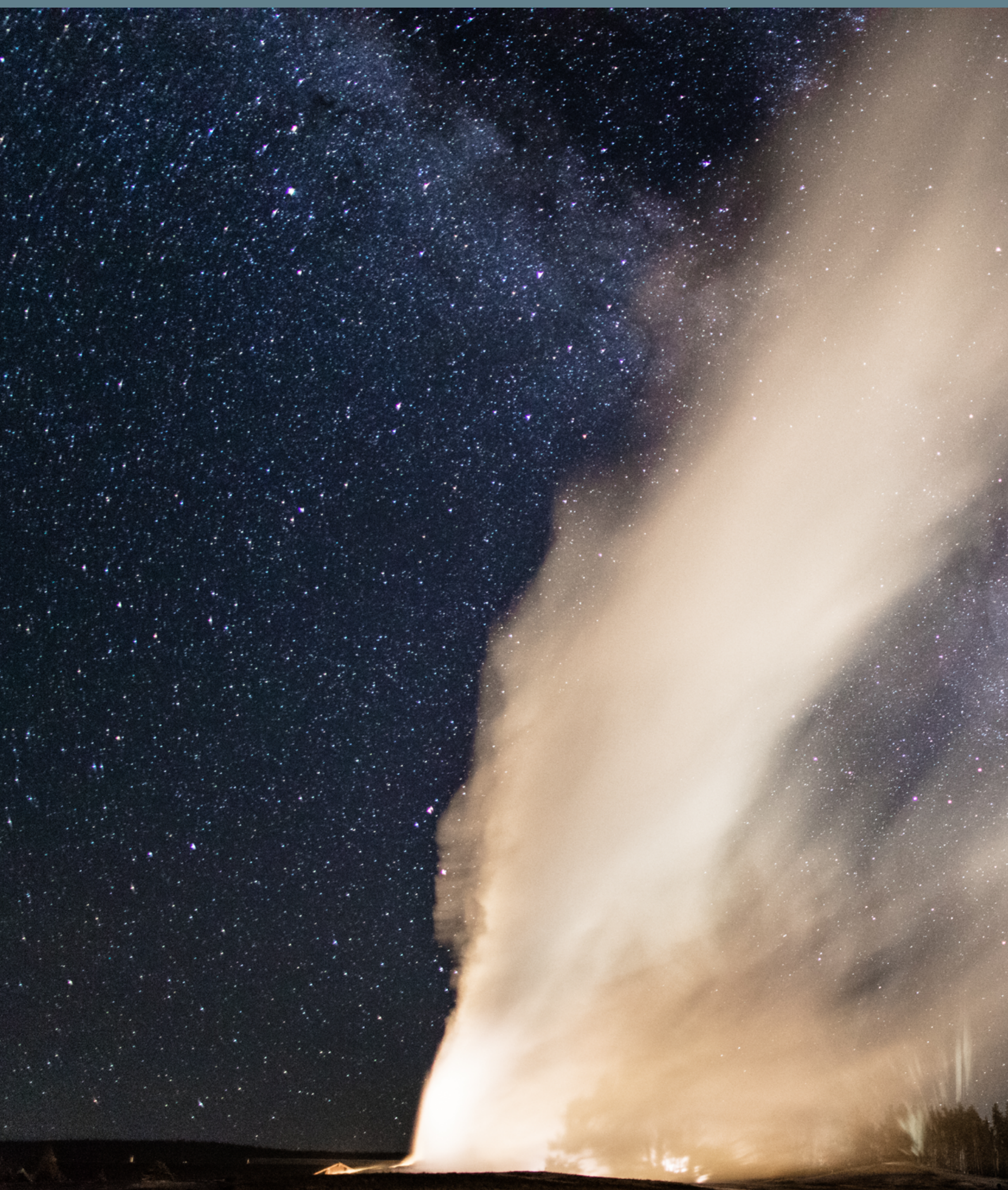



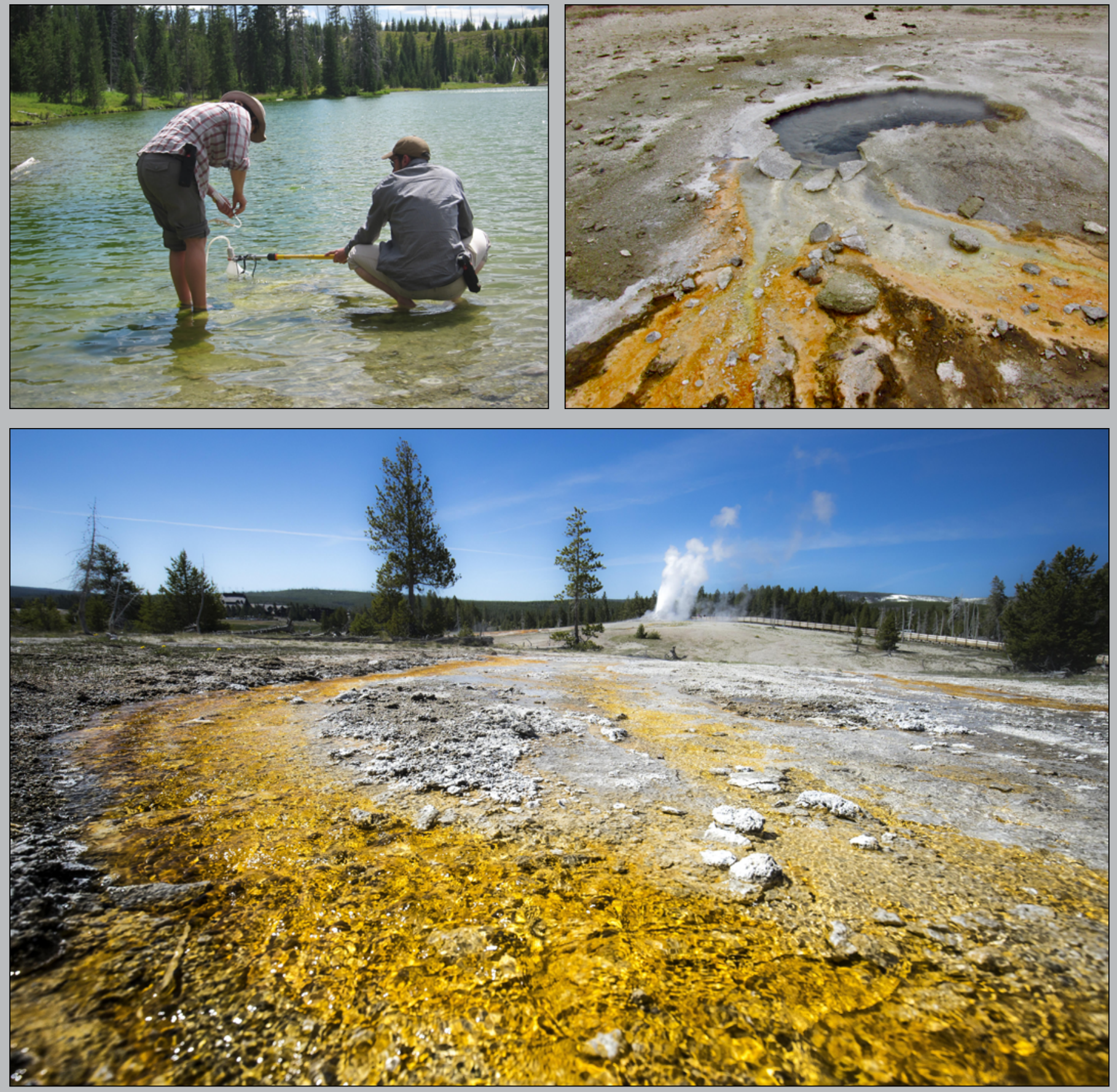